\title{
Paradigmatic structure in the tonal inflection of Amuzgo
}

\author{
Enrique L. Palancar, SeDyL-CNRS, enrique.palancar@cnrs.fr \\ Morphology (2021) 31(1):45-82 https://doi.org/10.1007/s11525-021-09373-x
}

\begin{abstract}
The tonal inflection of verbs of the Amuzgo language of San Pedro Amuzgos (Oto-Manguean, Mexico) displays a great degree of allomorphy. When faced with allomorphy of this sort, the inflectional class model often reveals an internal logic in a system, but in the case of Amuzgo organizing the inflection into tonal classes results instead in a system which is seemingly chaotic, and somewhat impractical for descriptive purposes. In order to make sense of the apparent chaos, in this paper I pursue an alternative view of the data based on characterizing verbs firstly according to their paradigmatic structure with regard to tonal inflection and then characterizing tonal exponents by way of default and implicative rules of exponence which allow us to comprehend the core of this inflectional system. Having identified this core, I then show how verbs relate to each other on a continuum of morphological complexity.
\end{abstract}

\section{Table of contents}

1. Introduction

1.1. The problem

1.2. Proposal and structure of the paper

2. An introduction to SP-Amuzgo

2.1. The language and the data

2.2. Basics of SP-Amuzgo verbal inflection

3. Tonal inflection and tonal allomorphy in SP-Amuzgo

4. Tonal classes

5. Paradigmatic classes

5.1. Establishing lexical tone

5.2. Selecting inflectional tone

5.3. Inflectional tone through the lens of paradigmatic classes

6. A rule-based approach to tonal exponence in SP-Amuzgo

6.1. Tones for 1SG: defaults, deviations and morphological complexity

6.2. Tones for $2 \mathrm{SG}$

6.3. Tones for 1PL.INCL

7. Calculating the core of tonal inflection in SP-Amuzgo

8. Conclusion

\section{Introduction}

In this paper, I study the tonal inflection of a sample of almost 560 verbs from the Amuzgo language spoken in the village of San Pedro Amuzgos in the State of Oaxaca in Mexico. The Amuzgo from San Pedro Amuzgos (SP-Amuzgo) is a Mesoamerican language that belongs to the Amuzgan branch of the Oto-Manguean stock. Given the great degree of structural similarity between SP-Amuzgo and Xochistlahuaca Amuzgo (Buck 2018, DoBui 2018), it is very likely that the analysis I propose here for the tonal inflection of SP-Amuzgo could be extended to Xochistlahuaca Amuzgo (as well as to other Amuzgo varieties).

The purpose of the paper is to provide a description of the tonal inflection of verbs in SPAmuzgo that serves as a reference point to help us discern which patterns can be treated as regular and which as irregular, and to what degree. I show that a model based on tonal classes - the obvious approach to linguists faced with systems like that of SP-Amuzgo - does not get us very far because the system is so intricate as to obscure any internal logic that it might possess. As an alternative, I propose a different approach, which involves two steps. One concerns the categorization of verbs into different classes according to the paradigmatic structure of their tonal inflection. This means that verbs can be divided into different types of paradigms attending to the number and type of cells for which they require inflectional tone. The other proposes to deal with the remaining tonal allomorphy by way of a non-technical rule-based model that uses concepts such as default and implicative rules of exponence. 


\subsection{The problem}

In the verbal inflection of SP-Amuzgo, tone alterations on the last syllable of a verbal stem express person/number of the subject. But the type of inflectional system that these tonal alterations engender is very intricate. Two situations are responsible for the intricacy. The first is that there is a great degree of tonal allomorphy for the encoding of person/number values. The other is that there are no dedicated tones that may serve as clear exponents for those values. To illustrate this, consider the final-syllable tones in the $1 \mathrm{SG}$ and $2 \mathrm{sG}$ imperfect forms of the verbs in Table 1 (data from Feist et al. 2015). ${ }^{1}$ For convenience, the relevant tones are given in the last two columns. ${ }^{2}$

\begin{tabular}{|c|c|c|c|c|}
\hline 1SG & 2SG & & 1SG & 2SG \\
\hline a. to $^{3}-\mathrm{nd} \varepsilon^{1}$ & to $^{3}-n d \varepsilon P^{53}$ & 'chew' & 1 & 53 \\
\hline b. to ${ }^{3}-m i{ }^{1}{ }^{k i}{ }^{1}$ ty $\tilde{\varepsilon}^{1}$ & to $^{3}-\mathrm{mi}^{1}{ }^{1} \mathrm{ki}^{1} \mathrm{tye}{ }^{1}$ & 'sit down' & 1 & 1 \\
\hline c. to $^{3}$-ndi ${ }^{5}$ Phndo ${ }^{3}$ & to $^{3}$-ndi ${ }^{5}$ Phndu ${ }^{3}$ & 'be corpulent' & 3 & 3 \\
\hline d. to $^{3}-\mathrm{tzi}^{5} \mathrm{Pma}^{12}$ & to $^{3}-\mathrm{tzi}^{5} \mathrm{Pma}^{1}{ }^{1}$ & 'show' & 12 & 1 \\
\hline e. to $^{3}-\operatorname{tiu}^{51} \mathrm{u}^{3}$ & to ${ }^{3}$-tiu? ${ }^{1}$ & 'whistle' & 51 & 1 \\
\hline f. to $^{3}-\mathrm{tzia}^{51} \mathrm{a}^{3}$ & to $^{3}-$ tzia $^{51}$ & 'build' & 51 & 51 \\
\hline g. to $^{3}-b \mathrm{P}^{1}{ }^{1} \mathrm{ba}^{53}$ & to $^{3}-b^{3}{ }^{b a} ?^{1}$ & 'go up' & 53 & 1 \\
\hline h. to $^{3}-\mathrm{ba} ?^{1} \mathrm{no}^{53}$ & to $^{3}-\mathrm{ba}^{3} \mathrm{no}^{12}$ & 'walk a bit further' & 53 & 12 \\
\hline i. to $^{3}-\mathrm{ma}^{53}$ & to $^{3}-m a 2^{53}$ & ‘wash' & 53 & 53 \\
\hline
\end{tabular}

Table 1. Tonal allomorphy for $1 \mathrm{SG}$ and $2 \mathrm{SG}$ in some SP-Amuzgo verbs

The tones in Table 1 can be observed in two different ways: vertically and horizontally. Seen vertically, we can focus on the type of tonal exponents for a given value. If we look at column ' $1 \mathrm{SG}$ ' this way, we can see that there are five different tone allomorphs for $1 \mathrm{SG}$, namely: T1, T3, T12, T51 and T53. This already points to a complex system, but the situation becomes more challenging when we see in column ' $2 \mathrm{SG}$ ' that the same five tones are also used to encode $2 \mathrm{SG}$. A horizontal view allow us to see what set of exponents are selected by each individual verb (e.g., the verb 'chew' in (a) has T1 for 1SG and T53 for 2sG, etc.). The verbs in Table 1 reveal different situations. One situation is to have the same tone for both 1SG and 2SG (i.e., tonal syncretism), like in (b) T1-T1; (c) T3-T3; (f) T51-T51; or (i) T53-T53. As shown in Figure 1, when the inflection of more verbs is considered, this tonal syncretism is attested for all the possible tones we find for $1 \mathrm{SG}$ and $2 \mathrm{sG}$.

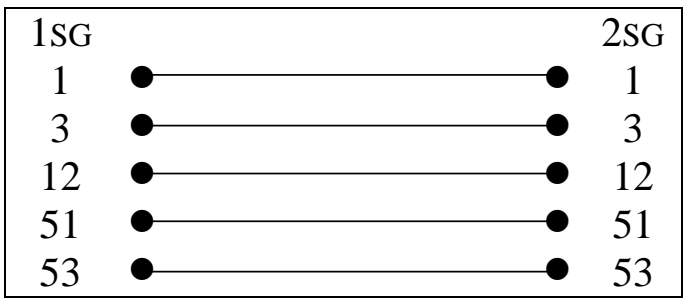

Figure 1. Attested tone syncretisms for $1 \mathrm{SG}$ and $2 \mathrm{SG}$

Another situation in Table 1 concerns inverse patterns. For example, the verb 'chew' in (a) has T1-T53, while the verb 'go up' in (g) has T53-T1. This situation commonly involves T53 as an exponent for either 1SG or 2SG and all combinations with T53 are attested, as can be seen in Figure 2. In contrast, Figure 3 shows that the picture is much less complete when the combinations involve other tones (like T12-T1 in (d); T51- T1 in (e), etc.).

\footnotetext{
${ }^{1}$ The 1 SG forms of the verbs in (e) and (f) end in an echo vowel with T3 (see Section 2.2).

${ }^{2}$ SP-Amuzgo tones are written with numbers following Smith-Stark \& Tapia García (2002); the lower the number, the lower the tone (i.e. 1 represents the lowest level tone). When I refer to tones in the text, I will represent them as T1, T3, T5, etc. Two numbers on a single syllable indicate a contour tone (e.g. T53 represents a HIGH-MID descending tone).
} 


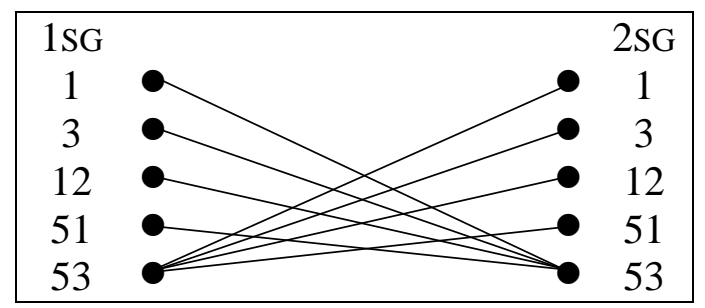

Figure 2. Attested tone combinations involving T53 for either $1 \mathrm{SG}$ or $2 \mathrm{SG}$

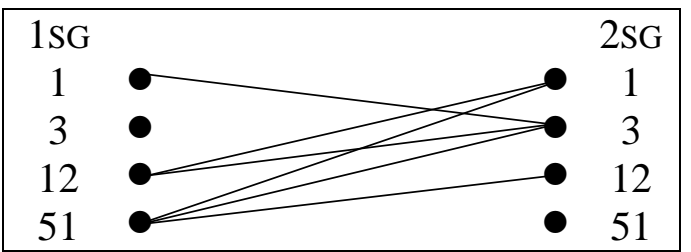

Figure 3. Attested tone combinations not involving T53

A system like this raises important questions: what is the extent of tonal allomorphy? If there are no specific tones for specific values, how are tones distributed across paradigms? If the different combinations of tones as exponents in Figures 2 and 3 were to be taken to represent tonal classes, how many tonal classes would we end up having? Are the instances of tonal syncretisms in Figure 1 true morphological patterns or are they just phonological accidents? While I attempt to provide some answers to such questions and others, the picture we obtain of the tonal inflection of SP-Amuzgo becomes more intricate as we add more person/number values and more verbs to it, to the point that, taken at face value, the system of exponence might be more readily characterized as chaotic. In other words, the assignment of tonal exponence could be taken as random, resulting in a situation where most verbs are seen as having idiosyncratic inflection. If this were to be our conclusion, the tonal values of most forms in the paradigms of verbs in SP-Amuzgo would have to be stored in speakers' minds as independent stems. Whether or not that is an appealing hypothesis that would defy the limits of the concept of inflection as we know it, we would only have to seriously consider it if we have given up finding possible structure. In this connection, the situation we observe in SPAmuzgo makes its description challenging for theoretical purposes, because as linguists finding morphological structure is paramount. Finding morphological structure in such a system is the first goal of the paper. But after finding it, we should also be able to evaluate how verbs relate to each other regarding their inflection and be able to rank the verbs in the sample attending to their degree of morphological complexity. This is the second goal of the paper.

\subsection{Proposal and structure of the paper}

To achieve these two goals, after briefly introducing the basics of the verbal inflection of SPAmuzgo in Section 2 and of its tonal allomorphy in Section 3, I argue in Section 4 that the notion of tone class (i.e. an inflectional class realized by tone distinctions) is not at all useful in finding logic in this system. Instead, I propose that to comprehend verbal inflection in Amuzgo it is convenient to focus first on a verb's paradigmatic signature (in the sense of 'feature signature' in Corbett 2015). In this sense, verbs will be seen as having different paradigms according to the number of cells for which they require inflectional tone, which will configure their paradigm type regarding tonal inflection. For this, I first build on previous research by Kim (2016) to distinguish lexical from inflectional tone in the paradigm of an Amuzgo verb. I do this in Section 5, where I propose that verbs can be divided into eight different classes with respect to their paradigmatic signature. In Section 6, to deal with tonal allomorphy in these paradigmatic classes, I propose a non-technical rule-based analysis of the tonal exponence of SP-Amuzgo inspired by the tenets of implicative approaches to morphology like Ackerman et al. (2009), Bonami (2014), among others, and by default-based 
approaches like Brown \& Hippisley (2012). I advocate that taking this morphological approach has clear descriptive advantages over the tone class model, because it establishes a reference point which can be used to delineate the regular core of the tonal inflection of SPAmuzgo. This is what I do in Section 7, where I propose that we can account for the tonal inflection of no less than $85 \%$ of the verbs in the sample (473/558) as being regular to a certain extent. The paradigms of the remaining verbs (85/558) are seen as deviations from this core, but with a gradience of irregularity. Section 8 concludes.

\section{An introduction to SP-Amuzgo}

\subsection{The language and the data}

SP-Amuzgo is a Mesoamerican language from Mexico spoken by about 4,600 people in the village of San Pedro Amuzgos in the state of Oaxaca (INEGI 2010). The language belongs to the small Amuzgan branch of the Oto-Manguean stock. The branch comprises at least two other Amuzgo languages: Santa María Ipapala Amuzgo and Xochistlahuaca Amuzgo, but there might be others, because the degree of dialectal divergence of other Amuzgo varieties from the villages of Tlacoachixtlahuaca and Ometepec is not yet known. Santa María Ipapala Amuzgo remains undescribed. There have been linguistic studies on SP-Amuzgo, namely in Tapia García (1999), Buck (2000), and Smith-Stark \& Tapia García (2002), and more recently Palancar and Feist (2015), Kim (2016, 2019), and Hernández Hernández (2019). Studies on Xochistlathuaca Amuzgo include the works by Apostol Polanco (2014), Herrera Zendejas (2014), and more recently Buck (2018) and DoBui (2018). To these, one must also add the recent study of the phonological system of the variety of Cochoapan by De Jesús García (2019). Despite the previous literature on Amuzgo, none of these works except for Kim (2016) have concentrated on tonal inflection, although most of them touch upon the phenomenon in some way or another.

While no Amuzgo language has been properly documented when it comes to natural discourse, the documentation efforts on the lexicon and on the verbal inflection of SPAmuzgo by native linguist Fermín Tapia García have been invaluable. These efforts have recently come to fruition, with the data having been made available in an online database by Feist et al. (2015), partially revised by linguist Yuni Kim (University of Essex). The database has served as the basis for recent studies such as Palancar and Feist (2015) and Kim (2016, 2019). This paper is also based on the data in Feist et al. (2015), more specifically on the analysis of the patterns found in a sample of 558 (active) verbs. ${ }^{3}$

\subsection{Basics of SP-Amuzgo verbal inflection}

Verbal inflection in Amuzgo is intricate, although it is not productive. ${ }^{4}$ Verbs can be divided into two main classes (inactive and active) according to how they behave morphologically with respect to agreement of person/number of subject. ${ }^{5}$ Inactive verbs do not inflect for person/number; indexing person/number of subject is attained by pronominal enclitics. An example of the imperfect (IMPF) subparadigm of an inactive verb is given in Table 2 with the verb 'use force'. First and second person enclitics are obligatory, and third person enclitics are only used when there is no overt NP subject in the clause. ${ }^{6}$ In contrast, active verbs do inflect for person/number, and the morphological means of conveying the relevant distinctions is

\footnotetext{
3 My sample comprises only verbal lexemes with (different and distinct) monosyllabic stems. All the verbs in the sample have semantics that allow them to be inflected in all persons (i.e. they can all have a human subject).

${ }^{4} \mathrm{New}$ verbs are introduced into the language by means of a light verb construction involving the verb $-t s$ ' $a a$ 'do/make'.

${ }^{5}$ For convenience, I subsume clusivity of 1PL under the umbrella of person/number.

${ }^{6}$ The enclitics I use for third person in Table 2 indicate a human subject, e.g. $=\tilde{e}^{5}\{3$ SG.HUM $\}$. For the singular, we also have: $=\tilde{e}^{3}$ as an honorific for humans and deities; $=o P^{5} /=\tilde{a} P^{5}$ for an animal; and $=\tilde{a} P^{l}$ for an inanimate subject. These semantic distinctions are neutralized in the plural where there are only two plural enclitics: $=\tilde{e}^{3}$ and $=\tilde{a}^{34}\{3 \mathrm{PL}\}$; the first is used in a neutral register, the second is honorific.
} 
complex, because it involves various components. An example of an active verb is 'come' in Table 2. ${ }^{7}$

\begin{tabular}{|c|c|c|}
\hline IMPF & $\begin{array}{l}\text { inactive } \\
\text { 'use force' }\end{array}$ & $\begin{array}{l}\text { active } \\
\text { 'come' }\end{array}$ \\
\hline $1 \mathrm{SG}$ & to $^{3}$-tyio $\tilde{P}^{35}=$ ha $^{3}$ & to $^{3}-n d y<>^{53}$ \\
\hline $2 \mathrm{SG}$ & to $^{3}$-tyiõ $P^{35}=[?] \mathrm{u}^{3}$ & to $^{3}-$ ndyo $^{3}-?$ \\
\hline 3SG(.HUM) & to ${ }^{3}$-tyiõ $P^{35}\left(=\mathrm{e}^{\tilde{e}^{5}}\right)$ & to $^{3}-$ ndyo $^{1}\left(=\mathrm{hu}^{5}\right)$ \\
\hline 1PL.INCL & to $^{3}-$ tyiõ ${ }^{35}=h a^{5}\langle a\rangle^{5}$ & to $^{3}-\mathrm{nki}\langle 0\rangle^{34}\langle 0\rangle^{5}$ \\
\hline & to $^{3}$-tyio $P^{35}=$ ha $^{51}$ & to $\left.^{3}-n k i<0\right\rangle^{51}$ \\
\hline 2PL & to $^{3}$-tyiõ P $^{35}=0 ?^{3}$ & to $^{3}-$ nkio $^{3}=\mathrm{o}^{3}$ \\
\hline 3PL(.HUM) & to $^{3}$-tyiỗ ${ }^{35}\left(=\tilde{e}^{3}\right)$ & to $^{3}-$ nkio $^{3}\left(=\right.$ ho $\left.^{5}\right)$ \\
\hline
\end{tabular}

Table 2. The imperfect forms of an inactive and an active verb in SP-Amuzgo

Active verbs exhibit internal changes, some of which are segmental. They involve a glottal stop suffix for $2 \mathrm{SG}$, vowel lowering for stems ending in /e/ and /o/ for first person forms, and an echo vowel for 1PL.INCL (including $1 \mathrm{SG}$ for some verbs). ${ }^{8}$ For the rest of the forms, namely 3SG, 3PL and 2PL, ${ }^{9}$ active verbs make use of pronominal enclitics. ${ }^{10}$ Furthermore, many active verbs in SP-Amuzgo also have a paradigmatic split between forms with a singular subject and those with a plural subject (Palancar \& Feist 2015), where the forms for the singular cells are based on one stem and the forms for the plural on another. For the verb 'come' in Table 2, the singular stem is -ndyo, while the plural stem is -nkio. In Section 5, I argue that this SG/PL split is very relevant for the architecture of tonal inflection.

But most crucial for our purposes is the fact that, besides segmental contrasts, active verbs further exhibit tonal changes in the inflection of person/number. For example, the tonal paradigm of a verb like 'come' in Table 2 has T53 for 1SG, T3 for 2sG, T1 for 3SG, T34 for 1PL.INCL, T51 for 1PL.EXCL, and T3 for both 2PL and 3PL. Inactive verbs lack tonal changes. ${ }^{11}$

\footnotetext{
7 Abbreviations: EXCL: exclusive; HUM: human; IMPF: imperfect; INCL: inclusive; NC: number class; PC: paradigmatic class; PL: plural; SG: singular; TA: tonal arrangement; TC: tonal class; TMC: tonal macro-class.

${ }^{8}$ An echo vowel is a mora with a specific, invariable, tone that is realized by a copy of the last vowel of the base with which the mora is associated; in verbs, the base for this mora is the stem. I have used angle brackets to represent both echo vowels and lowered vowels, because neither of them are clearly segmentable.

${ }^{9}$ For the singular, apart from $=h u^{5}$ for a human, we have: $=h o^{n 53}$ as an honorific for humans and deities; $=o P^{5}$ for an animal; and $=a^{n} ?^{l}$ for an inanimate subject. Again, the semantic distinctions of the singular are neutralized in the plural where there are only two plural enclitics: $=h o^{5}$ and $=a^{n 34}\{3 \mathrm{PL}\}$; the first is used in a neutral register, the second is honorific.

${ }^{10}$ While making a clear distinction between affixes and clitics has no bearing on my proposal here, it is worth stating the basic arguments on which this distinction is based. Pronominal clitics of third person alternate (never co-occur) with overt subject NPs. As for 2PL, I have treated $=O P^{3}$ as a verbal enclitic, and not an affix, because of its syntactic behaviour in verbal serializations involving two inflected verbs. To illustrate this, consider how the associated motion meaning "go and come back" is expressed in Table $i$, which consists of the verb 'go' (exhibiting stem suppletion) plus its complement verb 'return', which occurs in the irrealis marked by $n^{5}$-. Both verbs are inflected for person/number by internal changes, but note that $=o P^{3}$ is absent from the stem of the matrix verb 'go', occurring only after the verb 'return'. I take the fact that $=o P^{3}$ occurs after the second verb as an indication that it is an enclitic that takes the verbal complex created in the serialization as its syntactic host.
}

\begin{tabular}{|c|c|c|}
\hline \multirow[t]{2}{*}{ IMPF } & \multicolumn{2}{|c|}{ "go and come back" } \\
\hline & 'go' & 'return’ \\
\hline $1 \mathrm{SG}$ & to $^{3}-\mathrm{ka}^{1}$ & $\mathrm{n}^{5}-\mathrm{tkw}\left\langle\langle\varepsilon\rangle^{3}\right.$ \\
\hline $2 \mathrm{SG}$ & $\mathrm{to}^{3}-\mathrm{ka}^{53}-?$ & $\mathrm{n}^{5}-\mathrm{tkwe}[?]^{3}-?$ \\
\hline $3 \mathrm{SG}$ & to $^{3}-\mathrm{ka}^{5}$ & $\mathrm{n}^{5}-\mathrm{tkwe}^{3}$ \\
\hline 1PL.INCL & $t 0^{3}-2\langle 0\rangle^{5}\langle 0\rangle^{5}$ & $\mathrm{n}^{5}-\mathrm{tkw}\langle\varepsilon \varepsilon\rangle^{34}$ \\
\hline 1PL.EXCL & to $^{3}-$ tza $^{51}$ & $\mathrm{n}^{5}-\mathrm{tkw}\left\langle\langle\varepsilon\rangle{ }^{51}\right.$ \\
\hline 2PL & to $^{3}-\mathrm{Po}^{5}$ & $\mathrm{n}^{5}-\mathrm{tkwe}^{3}=\mathbf{o} ?^{3}$ \\
\hline 3PL & $t^{3}-1 o^{5}$ & $n^{5}-$ tkwe $^{3}$ \\
\hline
\end{tabular}

Table $i$. The marking of 2PL in verb serialization

${ }^{11}$ I interpret this lack of tonal changes as a consequence of the fact that inactive verbs are not subject to person/number inflection. 
This means that because active verbs are the only verbs in SP-Amuzgo that can display tonal changes, it is only active verbs that I study here. But as we have seen, these verbs display a great amount of tonal allomorphy, and so, in the next section, I introduce the tonal allomorphy we observe in the paradigms of 558 active verbs in the sample.

\section{Tonal inflection and tonal allomorphy in SP-Amuzgo}

SP-Amuzgo is a tonal language. Most sources on SP-Amuzgo, ${ }^{12}$ starting from Tapia García (1999) and including Buck (2000), Smith-Stark \& Tapia García (2002) and Kim (2016), agree that the language has eight different phonological tones (i.e. T1, T3, T5, T12, T51, T34, T35 and T53). ${ }^{13}$ As we will see, all these tones are involved in some way or another in verbal inflection. When we compare the tonal paradigms of active verbs, the first thing that strikes us is that there are many alternations. As an illustration, consider the four verbs in Table 3. In order to see the relevant tones more clearly, I have denuded the stems of components such as TAM markers, stem formatives, the glottal affix, the echo vowels, and any person/number enclitics. I have also repeated the tones in separate columns for convenience.

\begin{tabular}{|c|c|c|c|c|c|c|c|c|}
\hline IMPF & \multicolumn{2}{|c|}{ 'grasp' } & \multicolumn{2}{|c|}{ 'put' } & \multicolumn{2}{|c|}{ 'sell' } & \multicolumn{2}{|c|}{$\begin{array}{l}\text { 'walk along, } \\
\text { (side of a hill), }\end{array}$} \\
\hline $1 \mathrm{SG}$ & $-\operatorname{tyi}^{12}$ & 12 & - tyio $^{53}$ & 53 & $-\mathrm{hnd} \varepsilon^{53}$ & 53 & $-k i^{5} \tilde{n} o^{5}$ & 51 \\
\hline $2 \mathrm{SG}$ & $-t^{12} i^{12}$ & 12 & -tyio ${ }^{53}$ & 53 & $-h n d \varepsilon^{53}$ & 53 & $-k i^{3} \tilde{n} o^{1}$ & 1 \\
\hline $3 \mathrm{SG}$ & - tyi $^{12}$ & 12 & - tyio $^{3}$ & 3 & $-h n d \varepsilon^{35}$ & 35 & $-k i^{3} \tilde{n} o^{1}$ & 1 \\
\hline 1PL.INCL & $-t^{12} i^{12}$ & 12 & -tyis ${ }^{34}$ & 34 & $-h n d \varepsilon^{35}$ & 35 & $-k i^{3} \tilde{n} \rho^{1}$ & 12 \\
\hline 1PL.EXCL & $-t y i^{51}$ & 51 & -tyio ${ }^{51}$ & 51 & $-h n d \varepsilon^{51}$ & 51 & $-k i^{3} \tilde{n} 5^{5}$ & 51 \\
\hline $2 \mathrm{PL}$ & $-\operatorname{tyi}^{12}$ & 12 & - tyio $^{3}$ & 3 & $-h n d \varepsilon^{35}$ & 35 & $-k i^{3} \tilde{n} o^{1}$ & 1 \\
\hline 3PL & $-\operatorname{tyi}^{12}$ & 12 & - tyio $^{3}$ & 3 & -hnd $\varepsilon^{35}$ & 35 & $-k i^{3} \tilde{n} o^{1}$ & 1 \\
\hline
\end{tabular}

Table 3. Comparison of the tonal inflection of four active verbs in SP-Amuzgo

The verb 'grasp' displays the lowest number of tonal alternations: it has tone T12 in all forms, ${ }^{14}$ except for 1PL.EXCL that has T51. When the forms in Table 3 are viewed horizontally by person/number value, we observe that there is some degree of tonal allomorphy for the realization of person/number values (e.g. for 1SG we find T12 in 'grasp', T53 in 'put over' and 'sell', and T51 in 'walk along'). This is true for all person/number values except for 1PL.EXCL, where all verbs invariably select T51. But we can also observe that T51 is not exclusively used for 1PL.EXCL, because it is also used for 1SG in 'walk along'. Finally, there is tone syncretism in the realization of some values. For example, each verb uses the same tone

\footnotetext{
${ }^{12}$ Based on the data from four native speakers (the oldest of whom was 60 years of age in 2019 and the youngest 25), Hernández Hernández (2019) gives a very different picture of the tonal system of SP-Amuzgo. She argues that there are only seven tones instead of eight. She further postulates that there are five level tones (super high, extra high, high, mid, and low) and only two contour tones (mid-high and mid-low). This system is puzzlingly different from the one that has been consistently reported by Tapia García for years, on whose data this analysis is based. Given that Fermín Tapia García is more than 20 years older than Hernández Hernández's oldest speaker, the disparity may well reflect intergenerational changes. Hernández Hernández's analysis does not attempt to account for tonal correlations between the two systems, so it is not apparent to what extent the differences in categorization reflect diachronic changes nor to what extent such changes may have affected the state of the verbal inflection as I am describing it here. But meaningful correlations need to exist, because if speakers from different generations were not able to perceive them, it would make it impossible for them to understand each other. As far as I have been able to establish from Hernández Hernández's data, her extra high tone corresponds to Tapia García's T53, while her super high is rendered as T51 by Tapia García. In view of Hernández Hernández's (2019) data and in want of more correlations of this type, for the time being the label SP-Amuzgo should be taken to represent the variety of SP-Amuzgo spoken by Fermín Tapia García and his generation.

${ }^{13}$ Kim (2016) proposes that Tapia García’s (1999) T51 could be better treated as a case of T51. I adopt Kim's representation of this tone here.

${ }^{14}$ We might refer to this as tonal syncretism, but we could alternatively talk about this verb having invariant tone for all cells except 1PL.EXCL; this is what I argue for in Section 5.
} 
in the forms for 3SG, 2PL and 3PL, but while some verbs like 'put over' and 'sell' have T53 for both $1 \mathrm{SG}$ and $2 \mathrm{SG}$, in some other verbs these two values are contrastively marked ("walk along' has T51 for 1SG, but T1 for 2SG). This is as much as we can observe in four verbs. Let us now turn to how each tone value is involved in the forms encoding the different person/number values in the sample of 558 verbs. This is shown in Table 4 .

\begin{tabular}{|c|c|c|c|c|c|c|c|c|c|c|c|c|c|c|}
\hline \multirow[b]{2}{*}{ T1 } & \multicolumn{2}{|c|}{$1 \mathrm{SG}$} & \multicolumn{2}{|c|}{$2 \mathrm{SG}$} & \multicolumn{2}{|c|}{$3 \mathrm{SG}$} & \multicolumn{2}{|c|}{ 1PL.INCL } & \multicolumn{2}{|c|}{ 1PL.EXCL } & \multicolumn{2}{|c|}{$2 \mathrm{PL}$} & \multicolumn{2}{|c|}{ 3PL } \\
\hline & 21 & $4 \%$ & 69 & $13 \%$ & 91 & $16 \%$ & 1 & $0 \%$ & 0 & $0 \%$ & 108 & $19 \%$ & 108 & $19 \%$ \\
\hline T3 & 84 & $15 \%$ & 125 & $22 \%$ & 121 & $22 \%$ & 2 & $0 \%$ & 0 & $0 \%$ & 135 & $24 \%$ & 135 & $24 \%$ \\
\hline T5 & 0 & $0 \%$ & 0 & $0 \%$ & 107 & $19 \%$ & 95 & $17 \%$ & 0 & $0 \%$ & 90 & $16 \%$ & 90 & $16 \%$ \\
\hline T12 & 90 & $16 \%$ & 19 & $3 \%$ & 48 & $9 \%$ & 183 & $33 \%$ & 0 & $0 \%$ & 88 & $16 \%$ & 88 & $16 \%$ \\
\hline T51 & 27 & $5 \%$ & 5 & $1 \%$ & 8 & $1 \%$ & 3 & $1 \%$ & 558 & $100 \%$ & 3 & $1 \%$ & 3 & $1 \%$ \\
\hline T34 & 0 & $0 \%$ & 0 & $0 \%$ & 65 & $12 \%$ & 190 & $34 \%$ & 0 & $0 \%$ & 52 & $9 \%$ & 52 & $9 \%$ \\
\hline T35 & 0 & $0 \%$ & 0 & $0 \%$ & 86 & $15 \%$ & 59 & $11 \%$ & 0 & $0 \%$ & 57 & $10 \%$ & 57 & $10 \%$ \\
\hline T53 & 336 & $60 \%$ & 340 & $61 \%$ & 32 & $6 \%$ & 25 & $4 \%$ & 0 & $0 \%$ & 25 & $4 \%$ & 25 & $4 \%$ \\
\hline Total & 558 & $100 \%$ & 558 & $100 \%$ & 558 & $100 \%$ & 558 & $100 \%$ & 558 & $100 \%$ & 558 & $100 \%$ & 558 & $100 \%$ \\
\hline
\end{tabular}

Table 4. Distribution of tonal values as possible exponents for each person/number in 558 verbs

On the basis of this distribution of tone values (Table 4), a number of observations can be made about the system with regard to exponents of person/number:

- The distribution of tones in 2PL and 3PL in Table 4 is exactly the same. Far from being a coincidence, the figures actually reflect the fact that the forms for 2PL and 3PL have tonal syncretism without exception. When tonal neutralization is complete, we could think of this phenomenon as revealing the existence of a 'paradigmatic cell' in the sense in Boyé and Schalchi (2017). This means that the forms for 2PL and 3PL are treated (both tonally and segmentally) as based on the form of one paradigmatic cell that I refer to as 'PL'.

- The four verbs in Table 3 above had tonal syncretism between 3SG and PL (2PL and 3PL). But Table 4 reveals that the distribution of tones across these two cells is different. In other words, the syncretism is not systematic to the same degree as it is for 2PL and 3PL (i.e. some verbs have it, some verbs do not).

- T51 is the only exponent for 1PL.EXCL. For all other person/number values, we are faced with tonal allomorphy.

Table 5 presents the same data as Table 4, transposed in order to show the distribution of the functional load of each tone across the different morphosyntactic values.

\begin{tabular}{|c|c|c|c|c|c|c|c|c|c|c|c|c|c|c|c|c|}
\hline \multirow[b]{2}{*}{$1 \mathrm{SG}$} & \multicolumn{2}{|c|}{$\mathrm{T} 1$} & \multicolumn{2}{|c|}{ T3 } & \multicolumn{2}{|c|}{ T5 } & \multicolumn{2}{|c|}{ T12 } & \multicolumn{2}{|c|}{ T51 } & \multicolumn{2}{|c|}{ T34 } & \multicolumn{2}{|c|}{ T35 } & \multicolumn{2}{|c|}{ T53 } \\
\hline & 21 & $8 \%$ & 84 & $18 \%$ & 0 & $0 \%$ & 90 & $21 \%$ & 27 & $4 \%$ & 0 & $0 \%$ & 0 & $0 \%$ & 336 & $44 \%$ \\
\hline $2 \mathrm{SG}$ & 69 & $24 \%$ & 125 & $27 \%$ & 0 & $0 \%$ & 19 & $4 \%$ & 5 & $1 \%$ & 0 & $0 \%$ & 0 & $0 \%$ & 340 & $45 \%$ \\
\hline $3 \mathrm{SG}$ & 91 & $31 \%$ & 121 & $26 \%$ & 107 & $37 \%$ & 48 & $11 \%$ & 8 & $1 \%$ & 65 & $21 \%$ & 86 & $43 \%$ & 32 & $4 \%$ \\
\hline 1PL.INCL & 1 & $0 \%$ & 2 & $0 \%$ & 95 & $32 \%$ & 183 & $43 \%$ & 3 & $1 \%$ & 190 & 629 & 59 & $29 \%$ & 25 & $3 \%$ \\
\hline 1PL.EXCL & 0 & $0 \%$ & 0 & $0 \%$ & 0 & $0 \%$ & 0 & $0 \%$ & 558 & $92 \%$ & 0 & $0 \%$ & 0 & $0 \%$ & 0 & $0 \%$ \\
\hline PL & 108 & $37 \%$ & 135 & $29 \%$ & 90 & $31 \%$ & 88 & $21 \%$ & 3 & $0 \%$ & 52 & $17 \%$ & 57 & $28 \%$ & 25 & $3 \%$ \\
\hline Total & 290 & $100 \%$ & 467 & $100 \%$ & 292 & $100 \%$ & 428 & $100 \%$ & 604 & $100 \%$ & 307 & $100 \%$ & 202 & $100 \%$ & 758 & $100 \%$ \\
\hline
\end{tabular}

Table 5. Ways that each person/number feature is realized by tonal exponents in 558 verbs

On the basis of this distribution, a number of observations can also be made:

- We have seen that all active verbs without exception realize 1PL.EXCL by means of T51. Following Palancar's (2016) typology of inflectional tone, T51 could be treated 
as a 'morphosyntactic' inflectional tone, because there is an apparent one-to-one mapping between morphosyntactic value (1PL.EXCL) and realization by a tone value (T51). However, the correlation is not perfect from the form side of the mapping, as T51 also serves as exponent for other values (e.g. it is selected for 1SG by at least 27 verbs).

- Leaving aside the realization of 1PL.EXCL, we could further conclude that T1 and T3 are not exponents of 1PL.INCL (except for three verbs) and the same goes for T5, T34 and T35, which are NOT exponents of 1 SG or 2 SG. In contrast, T53 could be said to be almost exclusively dedicated to the realization of $1 \mathrm{SG}$ and/or $2 \mathrm{SG}$. This leaves us with T12, which, as far as functional load goes, is the least informative of all tone values.

Despite these useful generalizations, there remains a great amount of tonal allomorphy that speakers of SP-Amuzgo still need to contend with when dealing with the tonal inflection of verbs. Seen in this way, we still have five (or at least five) different tones involved in the realization of $1 \mathrm{SG}, 2 \mathrm{SG}$ and $1 \mathrm{PL}$.INCL, let alone all the different tones that appear to realize $3 \mathrm{SG}$ and PL. How do we deal with the structure of such an inflectional system? The first possible model that comes to mind is to approach the system by way of tonal classes. This is what I do in the next section.

\section{Tonal classes}

Following Aronoff's (1994:64) definition of an inflectional class as "a set of lexemes whose members each select the same set of inflectional realizations", the four verbs in Table 3 above would represent four different inflectional classes realized by tone alternations. I call such classes 'tonal classes'. We can group the 558 verbs into tonal classes according to the set of tones they select for the forms of the cells relevant for our purposes, namely $1 \mathrm{SG}, 2 \mathrm{SG}, 3 \mathrm{SG}$, 1PL.INCL and PL (1PL.EXCL is excluded here, because all verbs select T51). In this exercise, we can further identify the areas in the paradigms of verbs where we find the same tones, which can be treated as instances of 'tonal syncretisms'. As we will see further below, I will argue that such cases can be exploited further to shed more light on the architecture of the system.

The outcome of both exercises is presented in Table 6, where tonal syncretisms are shaded. The end result is a staggering 92 tonal classes! (NB. For reasons that will become apparent in Section 5, 3SG and PL have been placed next to each other; the designation 1PL.INCL has been reduced to 1PL). The final column gives the number of verbs from my sample that belong to each tonal class (the abbreviation TC stands for 'tonal class'). 


\begin{tabular}{|c|c|c|c|c|c|c|c|c|c|c|c|c|c|}
\hline TC & $1 \mathrm{SG}$ & $2 \mathrm{SG}$ & $3 \mathrm{SG}$ & PL & 1PL & \# & TC & $1 \mathrm{SG}$ & $2 \mathrm{SG}$ & $3 \mathrm{SG}$ & PL & $1 \mathrm{PL}$ & \# \\
\hline 1 & 51 & 1 & 3 & 12 & 5 & 1 & 48 & 1 & 53 & 5 & 5 & 5 & 2 \\
\hline 2 & 51 & 12 & 53 & 3 & 34 & 1 & 49 & 3 & 53 & 34 & 34 & 34 & 12 \\
\hline 3 & 51 & 53 & 1 & 3 & 34 & 1 & 50 & 1 & 3 & 3 & 3 & 34 & 3 \\
\hline 4 & 51 & 53 & 5 & 1 & 12 & 1 & 51 & 51 & 1 & 1 & 1 & 12 & 3 \\
\hline 5 & 53 & 3 & 35 & 12 & 5 & 2 & 52 & 53 & 3 & 3 & 3 & 34 & 14 \\
\hline 6 & 1 & 1 & 5 & 3 & 34 & 1 & 53 & 53 & 3 & 3 & 3 & 35 & 2 \\
\hline 7 & 53 & 53 & 1 & 3 & 34 & 7 & 54 & 3 & 53 & 3 & 3 & 34 & 18 \\
\hline 8 & 53 & 53 & 3 & 1 & 12 & 3 & 55 & 1 & 1 & 5 & 1 & 12 & 1 \\
\hline 9 & 53 & 53 & 5 & 1 & 12 & 2 & 56 & 1 & 1 & 35 & 1 & 34 & 1 \\
\hline 10 & 53 & 53 & 51 & 3 & 34 & 2 & 57 & 3 & 3 & 5 & 3 & 34 & 2 \\
\hline 11 & 53 & 53 & 34 & 1 & 12 & 1 & 58 & 3 & 3 & 3 & 3 & 34 & 43 \\
\hline 12 & 53 & 53 & 35 & 1 & 12 & 15 & 59 & 53 & 3 & 3 & 3 & 3 & 1 \\
\hline 13 & 53 & 53 & 35 & 12 & 34 & 1 & 60 & 3 & 53 & 3 & 3 & 3 & 1 \\
\hline 14 & 53 & 53 & 35 & 1 & 5 & 1 & 61 & 12 & 3 & 12 & 12 & 12 & 6 \\
\hline 15 & 3 & 53 & 34 & 34 & 35 & 2 & 62 & 12 & 53 & 12 & 12 & 12 & 17 \\
\hline 16 & 3 & 53 & 35 & 35 & 5 & 1 & 63 & 51 & 53 & 51 & 51 & 51 & 1 \\
\hline 17 & 53 & 3 & 1 & 1 & 12 & 1 & 64 & 53 & 53 & 34 & 3 & 34 & 1 \\
\hline 18 & 53 & 12 & 3 & 3 & 35 & 1 & 65 & 53 & 53 & 34 & 12 & 34 & 1 \\
\hline 19 & 53 & 51 & 3 & 3 & 34 & 1 & 66 & 1 & 1 & 35 & 35 & 5 & 1 \\
\hline 20 & 1 & 53 & 5 & 12 & 12 & 1 & 67 & 53 & 53 & 3 & 3 & 34 & 2 \\
\hline 21 & 1 & 53 & 35 & 12 & 12 & 1 & 68 & 53 & 53 & 5 & 5 & 12 & 2 \\
\hline 22 & 51 & 1 & 3 & 12 & 12 & 2 & 69 & 53 & 53 & 35 & 35 & 5 & 1 \\
\hline 23 & 51 & 1 & 1 & 3 & 34 & 12 & 70 & 53 & 53 & 3 & 12 & 12 & 3 \\
\hline 24 & 53 & 1 & 1 & 3 & 34 & 4 & 71 & 53 & 53 & 5 & 12 & 12 & 3 \\
\hline 25 & 53 & 3 & 3 & 1 & 12 & 9 & 72 & 53 & 53 & 34 & 12 & 12 & 10 \\
\hline 26 & 53 & 3 & 3 & 1 & 34 & 1 & 73 & 53 & 53 & 35 & 12 & 12 & 4 \\
\hline 27 & 1 & 3 & 5 & 3 & 34 & 1 & 74 & 53 & 53 & 5 & 35 & 35 & 1 \\
\hline 28 & 1 & 3 & 35 & 3 & 34 & 1 & 75 & 53 & 53 & 51 & 5 & 5 & 1 \\
\hline 29 & 12 & 3 & 1 & 3 & 34 & 1 & 76 & 3 & 3 & 5 & 5 & 5 & 1 \\
\hline 30 & 1 & 3 & 35 & 1 & 12 & 1 & 77 & 53 & 53 & 5 & 5 & 5 & 85 \\
\hline 31 & 1 & 53 & 5 & 1 & 12 & 3 & 78 & 53 & 53 & 12 & 12 & 12 & 9 \\
\hline 32 & 1 & 53 & 5 & 1 & 34 & 1 & 79 & 53 & 53 & 34 & 34 & 34 & 38 \\
\hline 33 & 1 & 53 & 35 & 1 & 12 & 1 & 80 & 53 & 53 & 35 & 35 & 35 & 52 \\
\hline 34 & 1 & 53 & 35 & 1 & 34 & 2 & 81 & 12 & 3 & 1 & 1 & 12 & 12 \\
\hline 35 & 12 & 3 & 35 & 12 & 34 & 1 & 82 & 53 & 3 & 3 & 12 & 12 & 6 \\
\hline 36 & 51 & 3 & 1 & 3 & 34 & 1 & 83 & 53 & 3 & 3 & 35 & 35 & 1 \\
\hline 37 & 53 & 1 & 3 & 1 & 12 & 2 & 84 & 12 & 1 & 1 & 12 & 12 & 1 \\
\hline 38 & 53 & 1 & 3 & 1 & 34 & 1 & 85 & 12 & 1 & 1 & 1 & 12 & 37 \\
\hline 39 & 53 & 1 & 5 & 1 & 12 & 1 & 86 & 53 & 1 & 53 & 1 & 12 & 1 \\
\hline 40 & 53 & 3 & 1 & 3 & 34 & 11 & 87 & 3 & 3 & 3 & 1 & 1 & 1 \\
\hline 41 & 53 & 12 & 3 & 1 & 12 & 2 & 88 & 3 & 3 & 3 & 12 & 12 & 1 \\
\hline 42 & 3 & 3 & 3 & 1 & 12 & 1 & 89 & 53 & 53 & 53 & 12 & 12 & 2 \\
\hline 43 & 3 & 3 & 3 & 1 & 34 & 1 & 90 & 12 & 12 & 12 & 12 & 12 & 15 \\
\hline 44 & 51 & 51 & 51 & 3 & 34 & 1 & 91 & 51 & 51 & 51 & 51 & 51 & 2 \\
\hline 45 & 51 & 51 & 51 & 1 & 12 & 1 & 92 & 53 & 53 & 53 & 53 & 53 & 25 \\
\hline 46 & 53 & 53 & 53 & 1 & 12 & 1 & & & & & & & \\
\hline 47 & 53 & 53 & 53 & 3 & 34 & 2 & & & & & & & \\
\hline
\end{tabular}

Table 6. The 92 tonal classes of the sample of 558 SP-Amuzgo verbs

The number of tonal classes is outstanding and the system has the appearance of a stochastic system (i.e. chaotic, without structure). However, one could argue that there are hints at structure in the asymmetric distribution of class membership. This can be seen in the fact that there are a few classes (only 6) with a significant number of verbs and a myriad of classes (47) with only one member. In this respect, if the system were genuinely chaotic, one would not expect this asymmetry, but rather we would anticipate a situation where class membership was more evenly distributed (see Wichmann 2019 for a discussion on a similar system in Me?pá, an Oto-Manguean language from the Tlapanecan branch). The six classes with the greatest number of members $(\geq 20)$ are given in Table 7 . 


\begin{tabular}{|l|ccccc|r|}
\hline TC & 1SG & 2SG & 3SG & PL & 1PL & \# \\
\hline 58 & 3 & 3 & 3 & 3 & 34 & 43 \\
77 & 53 & 53 & 5 & 5 & 5 & 85 \\
79 & 53 & 53 & 34 & 34 & 34 & 38 \\
80 & 53 & 53 & 35 & 35 & 35 & 52 \\
85 & 12 & 1 & 1 & 1 & 12 & 37 \\
92 & 53 & 53 & 53 & 53 & 53 & 25 \\
\hline Total & & & & & & 280 \\
\hline
\end{tabular}

Table 7. The most populated tonal classes in the 558-verb sample

We could further contend that membership to the largest tonal classes is partially motivated, because $92 \%$ of their members $(259 / 280)$ have a special morphological profile, being verbs with composite stems, which mostly include causative verbs $(223 / 259),{ }^{15}$ but also other types (36/259). It is worth exploring the distribution of these verbs. Let us start with causative verbs first.

Causative verbs in SP-Amuzgo bear a specific stem formative (indicated by the plus sign + ) which marks number of subject. There are two subclasses of causative verbs (now lexicalized), which are only distinctive in the singular. The two subclasses are illustrated in Table 8 by two verbs of tonal class 77 .

\begin{tabular}{|c|c|c|}
\hline IMPF & $\begin{array}{l}\text { tz+ subclass } \\
\text { 'feed a pig' } \\
\text { (TC77) }\end{array}$ & $\begin{array}{c}\text { tzi }^{5}+\text { subclass } \\
\text { 'harden' } \\
\text { (TC77) }\end{array}$ \\
\hline $1 \mathrm{SG}$ & $\mathrm{to}^{3}-\mathrm{tz}+\mathrm{ki} \mathrm{i}^{53}$ & $\mathrm{to}^{3}-\mathrm{tzi}^{5}+\mathrm{ki} \mathrm{i}^{53}$ \\
\hline $2 \mathrm{SG}$ & $\mathrm{to}^{3}-\mathrm{tz}+\mathrm{ki} \mathrm{P}^{53}$ & to $^{3}-\mathrm{tzi}^{5}+\mathrm{ki} \mathrm{P}^{53}$ \\
\hline $3 \mathrm{SG}$ & to $^{3}-\mathrm{tz}+\mathrm{ki}^{5}$ & $\mathrm{to}^{3}-\mathrm{tzi}^{5}+\mathrm{ki} \mathrm{i}^{5}$ \\
\hline 1PL.INCL & to ${ }^{3}-n a P^{1}+k i^{5} i^{5}$ & to $^{3}-\mathrm{na}{ }^{1}+\mathrm{nk} \varepsilon^{5} \varepsilon^{5}$ \\
\hline 1PL.EXCL & to $^{3}-\mathrm{na}^{1}+\mathrm{ki}^{51}$ & $\mathrm{to}^{3}-\mathrm{na} \mathrm{P}^{1}+\mathrm{nk} \varepsilon^{51}$ \\
\hline $2 \mathrm{PL}$ & to $^{3}-n a P^{1}+k i^{5}=o ?^{3}$ & to $^{3}-\mathrm{na}^{1}+\mathrm{nke}^{5}=\mathrm{o} ?^{3}$ \\
\hline $3 \mathrm{PL}$ & to $^{3}-n a P^{1}+\mathrm{ki}^{5}$ & to $^{3}-\mathrm{na}^{1}+\mathrm{nke}^{5}$ \\
\hline
\end{tabular}

Table 8. Two causative verbs in SP-Amuzgo

In my sample of 558 verbs, there are 290 causative verbs (60 of the tz+ subclass and 230 of the tzi ${ }^{5}+$ subclass). Now note in Table 9 how causative verbs in the sample are distributed across the tonal classes.

\footnotetext{
15 In SP-Amuzgo the morphological derivation of a causative verb from an intransitive verb is no longer productive. There are also transitive verbs in this group which lack a semantically transparent lexical correlate in an intransitive verb.
} 


\begin{tabular}{|c|c|c|c|c|c|c|c|c|c|c|c|}
\hline \multicolumn{2}{|c|}{$\begin{array}{c}\text { Total of } \\
\text { verbs in TC }\end{array}$} & $\begin{array}{c}\text { Total of } \\
\text { CAUS verbs }\end{array}$ & $\begin{array}{c}\% \text { of } \\
\text { CAUS/TC }\end{array}$ & $\mathrm{TC}$ & $1 \mathrm{SG}$ & $2 \mathrm{SG}$ & $3 \mathrm{SG}$ & PL & $1 \mathrm{PL}$ & tz+ & $\mathrm{tzi}^{5}+$ \\
\hline \multirow[t]{6}{*}{$\geq 20$} & 85 & 67 & $79 \%$ & 77 & 53 & 53 & 5 & 5 & 5 & 19 & 48 \\
\hline & 52 & 31 & $60 \%$ & 80 & 53 & 53 & 35 & 35 & 35 & 6 & 25 \\
\hline & 43 & 37 & $86 \%$ & 58 & 3 & 3 & 3 & 3 & 34 & 6 & 31 \\
\hline & 38 & 29 & $76 \%$ & 79 & 53 & 53 & 34 & 34 & 34 & 5 & 24 \\
\hline & 37 & 34 & $92 \%$ & 85 & 12 & 1 & 1 & 1 & 12 & 2 & 32 \\
\hline & 25 & 25 & $100 \%$ & 92 & 53 & 53 & 53 & 53 & 53 & 4 & 21 \\
\hline \multirow[t]{7}{*}{$<20$} & 18 & 13 & $72 \%$ & 54 & 3 & 53 & 3 & 3 & 34 & 4 & 9 \\
\hline & 17 & 9 & $53 \%$ & 62 & 12 & 53 & 12 & 12 & 12 & 2 & 7 \\
\hline & 15 & 1 & $7 \%$ & 11 & 53 & 53 & 35 & 1 & 12 & & 1 \\
\hline & 14 & 1 & $7 \%$ & 52 & 53 & 3 & 3 & 3 & 34 & & 1 \\
\hline & 14 & 9 & $64 \%$ & 90 & 12 & 12 & 12 & 12 & 12 & 4 & 5 \\
\hline & 12 & 3 & $25 \%$ & 49 & 3 & 53 & 34 & 34 & 34 & 1 & 2 \\
\hline & 12 & 11 & $92 \%$ & 81 & 12 & 3 & 1 & 1 & 12 & & 11 \\
\hline \multirow[t]{5}{*}{$<10$} & 9 & 4 & $44 \%$ & 78 & 53 & 53 & 12 & 12 & 12 & 1 & 3 \\
\hline & 3 & 1 & $33 \%$ & 71 & 53 & 53 & 5 & 12 & 12 & & 1 \\
\hline & 2 & 2 & $100 \%$ & 47 & 53 & 53 & 53 & 3 & 34 & 2 & \\
\hline & 2 & 1 & $50 \%$ & 57 & 3 & 3 & 5 & 3 & 34 & & 1 \\
\hline & 2 & 2 & $100 \%$ & 91 & 51 & 51 & 51 & 51 & 51 & & 2 \\
\hline \multirow[t]{10}{*}{$=1$} & 1 & 1 & $100 \%$ & 14 & 53 & 53 & 35 & 1 & 5 & 1 & \\
\hline & 1 & 1 & $100 \%$ & 19 & 53 & 51 & 3 & 3 & 34 & & 1 \\
\hline & 1 & 1 & $100 \%$ & 29 & 12 & 3 & 1 & 3 & 34 & 1 & \\
\hline & 1 & 1 & $100 \%$ & 45 & 51 & 51 & 51 & 1 & 12 & & 1 \\
\hline & 1 & 1 & $100 \%$ & 60 & 3 & 53 & 3 & 3 & 3 & 1 & \\
\hline & 1 & 1 & $100 \%$ & 63 & 51 & 53 & 51 & 51 & 51 & & 1 \\
\hline & 1 & 1 & $100 \%$ & 64 & 53 & 53 & 34 & 3 & 34 & & 1 \\
\hline & 1 & 1 & $100 \%$ & 74 & 53 & 53 & 5 & 35 & 35 & 1 & \\
\hline & 1 & 1 & $100 \%$ & 75 & 53 & 53 & 51 & 5 & 5 & & 1 \\
\hline & 1 & 1 & $100 \%$ & 84 & 12 & 1 & 1 & 12 & 12 & & 1 \\
\hline
\end{tabular}

Table 9. Causative verbs by tonal class

Table 9 shows that causative verbs are distributed across 28 tonal classes in the sample. The strongest correlation is shown by tonal class 92 , which is a class with causative verbs only, but apart from this correlation, Table 9 shows that class membership to the tonal classes cannot be thought of as semantically or morphologically motivated, because speakers still need to store the class membership of causative verbs. Despite the fact that the largest tonal classes contain most causative verbs, those classes also contain other types of verbs (except for tonal class 92), and the same can be said of the smaller classes.

Apart from causative verbs, the most populated tonal classes also have verbs with complex stems that exhibit stem formatives. As illustrated in Table 10, there are four classes of such verbs, which I treat as the $b a^{3}+$ class, the $b a^{5}+$ class, the $b a r^{2}+$ class and the $n d i^{5}+$ class. $^{16}$ Except for the $n d i^{5}+$ class, which has an invariant formative, the stems of the other three classes involve more than one stem formative, all having a special one for the plural. All these verbs represent lexicalized combinations, but the semantics of most verbs of the $b a ?^{l}+$ class have a certain motion component, and many of the $n d i^{5}+$ class have inchoative or stative semantics. The T53 for 2SG of the verbs 'know' and 'be lucky' in Table 10 is underlined to indicate Kim's (2016) rule that in these forms T53 is a phonological tone that surfaces as T51. ${ }^{17}$

\footnotetext{
${ }^{16}$ The formatives of the $b a^{5}+$ class and the $b a ?^{l}+$ class also exhibit tonal changes in the singular forms.

${ }^{17} \mathrm{Kim}$ (2016) argues convincingly that T51 and T1 are the surface outcomes of a morphophonological tone lowering rule that involves a change from T53 to T51 and from T3 to T1 when the glottal suffix for 2SG is attached to a stem that already ends in a glottal.
} 


\begin{tabular}{|c|c|c|c|c|}
\hline IMPF & $\begin{array}{c}\mathrm{ba}^{3}+\text { class } \\
\text { 'lie upside down' } \\
\text { (TC58) }\end{array}$ & $\begin{array}{c}\mathrm{ba}^{5}+\text { class } \\
\text { 'know' } \\
\text { (TC77) }\end{array}$ & $\begin{array}{c}\mathrm{ba}^{1}+\text { class } \\
\text { 'lean on' } \\
\text { (TC80) }\end{array}$ & $\begin{array}{c}\text { ndi }^{5}+\text { class } \\
\text { 'be lucky' } \\
\text { (TC80) }\end{array}$ \\
\hline $\begin{array}{l}\text { 1SG } \\
\text { 2SG } \\
\text { 3SG } \\
\text { 1PL.INCL } \\
\text { 1PL.EXCL } \\
\text { 2PL } \\
\text { 3PL }\end{array}$ & 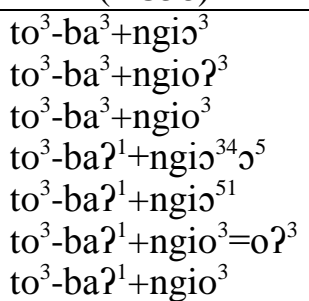 & $\begin{array}{l}\text { to }{ }^{3}-\mathrm{ba}^{5}+\mathrm{hn} \mathrm{Pa}^{53} \\
\text { to }^{3}-\mathrm{ba}^{5}+\mathrm{hna}[\mathrm{P}] \mathrm{P}^{53} \\
\text { to }^{3}-\mathrm{ba}^{3}+\mathrm{hna} ?^{5} \\
\text { to }^{3}-\mathrm{ta}^{1}+\mathrm{hnPa}^{5} \tilde{a}^{5} \\
\text { to }^{3}-\mathrm{ta}^{1}+\mathrm{hnPa}^{51} \\
\text { to }^{3}-\mathrm{ta}^{1}+\mathrm{hnPa}^{5}=o ?^{3} \\
\text { to }^{3}-\mathrm{ta}^{1}+\mathrm{hnPa}^{5}\end{array}$ & 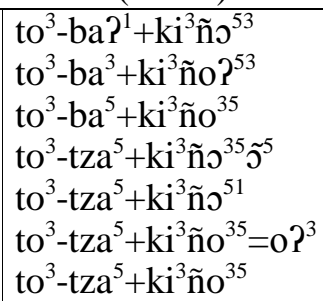 & $\begin{array}{l}\text { to }{ }^{3}-\mathrm{ndi}^{5}+\mathrm{hno}^{53} \\
\text { to }^{3}-\mathrm{ndi}^{5}+\mathrm{hno}[\mathrm{T}] \mathrm{P}^{53} \\
\text { to }^{3}-\mathrm{ndi}^{5}+\mathrm{hno}^{35} \\
\text { to }^{3}-\mathrm{ndi}^{5}+\mathrm{hno}^{35} \tilde{\mathrm{o}}^{5} \\
\text { to }^{3}-\mathrm{ndi}^{5}+\mathrm{hno}^{51} \\
\text { to }^{3}-\mathrm{ndi}^{5}+\mathrm{hno}^{35}=\mathrm{o} ?^{3} \\
\text { to }^{3}-\mathrm{ndi}^{5}+\mathrm{hno}^{35}\end{array}$ \\
\hline
\end{tabular}

Table 10. Verbs with other types of complex stems

But verbs of all these classes are found across many other tonal classes: five verbs of the $b a^{3}+$ class in three tonal classes; 13 of the $b a^{5}+$ class in eight tonal classes; 28 of the $b a ?^{l}+$ class in no less than 25 tonal classes(!); and finally 60 of the $n d i^{5}+$ class in 24 tonal classes. The fact that verbs like the ones in Table 10 are found in other classes is further evidence that membership to the most populated classes is not motivated.

We have seen that a characterization of the tonal inflection of SP-Amuzgo verbs in terms of tonal classes as it is presented in Table 6 renders a system with little structure. In such a characterization, tonal inflection is conceived of as consisting of nearly one hundred different sets of combinations of tonal exponents, making it appear that their selection is random for each individual value and lexeme. But this would go against a view of inflectional class systems as networks of cells bearing implicative relations to each other, as suggested by Carstairs (1983), and exploited in implicative approaches such as Müller (2007), Ackerman \& Malouf (2013), Bonami (2014) or Stump \& Finkel (2015), among many others. In other words, if the hundred-odd tonal classes in Amuzgo verbs really revealed a truly chaotic system, ${ }^{18}$ this would imply that Amuzgo verbal inflection is not composed of a functional network of rules of exponence at work, but instead that tone values are assigned by the lexicon to forms in a lexeme's paradigm on a cell-by-cell basis; in other words, it would mean there is nothing regular in this system, but all is irregular. ${ }^{19}$ In the following sections, I propose, building on the proposals by Kim (2016), that we can indeed find some structure in the system by making a primary distinction between those tones in a verb's forms which are inflectional and those which are lexical. A good place to start is tonal syncretisms.

Patterns of tonal syncretisms (shaded in the tables) can reveal a degree of structure in the system. For example, tonal classes 90-92, repeated here in Table 11, show instances of total tonal syncretism. Alternatively, these verbs could be taken to be tonally invariant verbs.

\begin{tabular}{|l|ccccc|r|}
\hline TC & 1SG & 2SG & 3SG & PL & 1PL & \# \\
\hline 90 & 12 & 12 & 12 & 12 & 12 & 15 \\
91 & 51 & 51 & 51 & 51 & 51 & 2 \\
92 & 53 & 53 & 53 & 53 & 53 & 25 \\
\hline
\end{tabular}

Table 11. Tonal classes with complete tonal syncretism

If we see the verbs in Table 11 as having defective tonal inflection, they would constitute a class on their own that we could call the 'invariant class', where the different tones we observe in Table 11 are not tonal exponents, but rather the tonal phonological component of the stem, that is, lexical tones. Such a class with 42 members would represent $7.5 \%$ of the

\footnotetext{
${ }^{18}$ I have used the online software at <https://www.cs.uky.edu/ raphael/linguistics/analyze.html> created by Raphael Finkel and Gregory Stump at the University of Kentucky as a computational tool to produce quantitative views of the internal structure of inflectional classes including entropy measures across cells. As far as my knowledge goes, the results output by this tool are not indicative of any sort of order in the system. Readers wishing to carry out the exercise themselves are advised to input the data in Table 6, replacing the numbers for each tone value with a specific letter (e.g. T53 > 'a', T51 > 'b', etc.).

${ }^{19}$ Such a system would raise important questions about learnability which I cannot address here, but which would doubtless constitute a most relevant topic for language acquisition research.
} 
verbs in the sample. This has consequences for the way we treat the tonal syncretisms in Table 6, because it may be the case that some of those syncretisms represent lexical tones and not tonal exponents. This possibility opens a different approach to analysing the inflection of verbs in SP-Amuzgo. In the next section, I explore this possibility to its ultimate consequences, and I show that it has substantial advantages over the model of tonal classes when it comes to understanding the architecture of tonal inflection in SP-Amuzgo.

\section{Paradigmatic classes}

\subsection{Establishing lexical tone}

We have seen that invariant verbs open an alternative entry point into the tonal inflection of SP-Amuzgo verbs. Invariant verbs constitute a special type of inflectional class that is not characterized by exponents, but by the structure of the paradigm of the verb, a notion that Corbett (2015) calls the 'feature signature' of a lexeme, which I propose to rename as 'paradigmatic signature'. In this way, instead of having tonal classes based on tone values in cells, classes are defined by their paradigmatic requirements regarding tonal inflection, such that the paradigm signature of invariant verbs consists of a single cell that requires inflectional tone $\left(\mathrm{T}_{\mathrm{INFL}}\right)$, the one for 1PL.EXCL (which is always realized by T51). As a consequence of their paradigmatic structure, all remaining forms of these verbs exhibit a tonally invariant stem that bears a lexical tone $\left(\mathrm{T}_{\mathrm{LEX}}\right)$. The paradigms of two tonally invariant verbs in the imperfect are given in Table 12. ${ }^{20}$

\begin{tabular}{|c|c|c|c|c|c|c|}
\hline IMPF & \multicolumn{2}{|l|}{ 'confound' } & (TC92) & 'suck' & \multicolumn{2}{|c|}{ (TC90) } \\
\hline $1 \mathrm{SG}$ & to $^{3}-\mathrm{tz}+\mathrm{k} \mathrm{Pua}^{53}$ & $\mathrm{~T}_{\text {LEX }}$ & 53 & $\mathrm{to}^{3}-\mathrm{ti}^{12}$ & $\mathrm{~T}_{\mathrm{LEX}}$ & 12 \\
\hline $2 \mathrm{SG}$ & $\mathrm{to}^{3}-\mathrm{tz}+\mathrm{k}$ ?ua? ${ }^{53}$ & $\mathrm{~T}_{\text {LEX }}$ & 53 & to $^{3}-\mathrm{ti}^{12}$ & $\mathrm{~T}_{\mathrm{LEX}}$ & 12 \\
\hline $3 \mathrm{SG}$ & $\mathrm{to}^{3}-\mathrm{tz}+\mathrm{k} \mathrm{Pua}^{53}$ & $\mathrm{~T}_{\mathrm{LEX}}$ & 53 & $\mathrm{to}^{3}-\mathrm{ti}^{12}$ & $\mathrm{~T}_{\mathrm{LEX}}$ & 12 \\
\hline 1PL.INCL & to $^{3}-n a P^{1}+k$ Pua $^{53} a^{5}$ & $\mathrm{~T}_{\text {LEX }}$ & 53 & to $^{3}-\mathrm{ti}^{12} \mathrm{i}^{5}$ & $\mathrm{~T}_{\text {LEX }}$ & 12 \\
\hline 1PL.EXCL & to $^{3}-\mathrm{na}^{1}+\mathrm{k} \mathrm{Pua}^{51}$ & $\mathrm{~T}_{\mathrm{INFL}}$ & 51 & $\mathrm{to}^{3}-\mathrm{ti}^{51}$ & $\mathrm{~T}_{\mathrm{INFL}}$ & 51 \\
\hline $\begin{array}{l}2 \mathrm{PL} \\
3 \mathrm{PL}\end{array}$ & $\begin{array}{l}\text { to }^{3}-\text { na }^{1}+\mathrm{k} \mathrm{uua}^{53}=o P^{3} \\
\text { to }^{3}-\mathrm{na}^{1}+\mathrm{k}^{1} \mathrm{Pu}^{53}\end{array}$ & $\mathrm{~T}_{\mathrm{LEX}}$ & 53 & $\begin{array}{l}\mathrm{to}^{3}-\mathrm{ti}^{12}=\mathrm{o} ?^{3} \\
\text { to }^{3}-\mathrm{ti}^{12}\end{array}$ & $\mathrm{~T}_{\mathrm{LEX}}$ & 12 \\
\hline
\end{tabular}

Table 12. Two tonally invariant verbs in SP-Amuzgo

In my sample of 558 verbs, there are 42 tonally invariant verbs (36 of them are causative verbs like 'confound', while the rest are non-causative verbs like 'suck'). To the situation in Table 11 of tonal classes 90-92, we can add the four verbs of tonal classes 87-89 in Table 13.

\begin{tabular}{|l|ccccc|r|}
\hline TC & 1 SG & 2SG & 3SG & PL & 1 PL & \# \\
\hline 87 & 3 & 3 & 3 & 1 & 1 & 1 \\
88 & 3 & 3 & 3 & 12 & 12 & 1 \\
89 & 53 & 53 & 53 & 12 & 12 & 2 \\
\hline
\end{tabular}

Table 13. Some more invariant verbs

The verbs in Table 13 can also be taken to be tonally invariant verbs, but of a different type. These verbs exhibit the stem split that is conditioned by the number of the subject that we observe in many active verbs, and which results in the verb having two stems: a singular stem and a plural stem. The SG/PL split can be realized in three different ways: (i) by tones alone, like the verb 'have an accident' in Table 14 which has only one segmental stem (LEX) but two lexical tones ( $\mathrm{T}_{\mathrm{LEX} 1}$ and $\left.\mathrm{T}_{\mathrm{LEX} 2}\right)$; (ii) by both tones and segments, like the verb 'demand' with two segmental stems (LEX1 and LEX2), each one with a different lexical tone ( $\mathrm{T}_{\mathrm{LEX} 1}$ and

\footnotetext{
${ }^{20}$ As a causative verb, the verb $-t z+k P u a^{53}$ 'confound' in Table 12 has a complex stem by means of two stem formatives. As we have seen in Tables 8 and 10 above, stem formatives in complex stems carry tone when syllabic, but such tones are fixed by their formative class. Inflectional tone appears on the lexical stem. In the verb $-t z+k$ ? $u a^{53}$ 'confound', the tones we are concerned with are T53 and T51.
} 
$\mathrm{T}_{\mathrm{LEX} 2}$ ); or (iii) just by segments, like the verb 'confound' in Table 10, which as a causative verb has two segmental stems (LEX1 and LEX2), but an invariant lexical tone.

\begin{tabular}{|c|c|c|c|c|c|c|c|}
\hline IMPF & $\begin{array}{l}\text { 'have an ac } \\
\text { ("pass acci }\end{array}$ & $\begin{array}{l}\text { ident' } \\
\text { lent") }\end{array}$ & & (TC88 & 'demand' & & $\overline{(\mathrm{TC} 89)}$ \\
\hline $1 \mathrm{SG}$ & to ${ }^{3}-\mathrm{tj} \tilde{o}^{3}$ & $n a^{3} t \varepsilon ?^{3}$ & LEX $\mathrm{T}_{\text {LEX } 1}$ & 3 & \multirow{6}{*}{$\begin{array}{l}\text { to }^{3}-j u^{53} \\
\text { to }^{3}-j u P^{53} \\
\text { to }^{3}-j u^{53} \\
\text { to }^{3}-\mathrm{tjw}^{12} \varepsilon^{12} \varepsilon^{5} \\
\text { to }^{3}-\mathrm{tjw}^{51} \\
\text { to }^{3}-\mathrm{tjwe}^{12}=o \mathrm{P}^{3} \\
\text { to }^{3}-\mathrm{tiwe}^{12}\end{array}$} & $\mathrm{LEX}_{1} \mathrm{~T}_{\mathrm{LEX} 1}$ & 53 \\
\hline $2 \mathrm{SG}$ & to ${ }^{3}-\mathrm{tj} \tilde{0} \mathrm{O}^{3}$ & $n a^{3} t \varepsilon ?^{3}$ & LEX $T_{\text {LEX1 }}$ & 3 & & LEX $_{1} \mathrm{~T}_{\mathrm{LEX} 1}$ & 53 \\
\hline $3 \mathrm{SG}$ & to ${ }^{3}-t j \tilde{o}^{3}$ & $n a^{3} t \varepsilon ?^{3}$ & LEX $T_{\text {LEX } 1}$ & 3 & & $\mathrm{LEX}_{1} \mathrm{~T}_{\mathrm{LEX}}$ & 53 \\
\hline 1PL.INCL & to ${ }^{3}-\mathrm{t} j \tilde{\jmath}^{12}$ & $\mathrm{na}^{3} \mathrm{t} \varepsilon ?^{3}$ & LEX $\mathrm{T}_{\text {LEX } 2}$ & 12 & & $\mathrm{LEX}_{2} \mathrm{~T}_{\mathrm{LEX} 2}$ & 12 \\
\hline 1PL.EXCL & to ${ }^{3}-\mathrm{tj} \tilde{s}^{51}$ & $n a^{3} t \varepsilon ?^{3}$ & LEX $\mathrm{T}_{\mathrm{INFL}}$ & 51 & & $\begin{array}{ll}\text { LEX }_{2} & \mathrm{~T}_{\mathrm{INFL}}\end{array}$ & 51 \\
\hline $\begin{array}{l}\text { 2PL } \\
3 \mathrm{PL}\end{array}$ & $\begin{array}{l}\text { to }^{3}-\mathrm{tjj}^{12}=\mathrm{o} \mathrm{P}^{3} \\
\text { to }^{3}-\mathrm{tj}^{12}\end{array}$ & $\begin{array}{l}n a^{3} t \varepsilon ?^{3} \\
n a^{3} t \varepsilon ?^{3}\end{array}$ & LEX $\mathrm{T}_{\text {LEX } 2}$ & 12 & & LEX $_{2} \mathrm{~T}_{\text {LEX2 }}$ & 12 \\
\hline
\end{tabular}

Table 14. Two verbs exhibiting the SG/PL split at tonal level

The logical possibilities concerning the SG/PL split are summarized in (1) and, as indicated in Table 15, all of them are attested. Table 15 further shows that $94 \%$ of active verbs in the sample manifest the split in some way or another.

(1) a. No SG/PL split: consistent stem segmentally (LEX) + consistent stem tonally ( $\left.\mathrm{T}_{\text {LEX }}\right)$ : (e.g. 'suck', Table 12).

b. SG/PL split: consistent stem segmentally $(\mathrm{LEX})+$ split stem tonally $\left(\mathrm{T}_{\mathrm{LEX} 1} / \mathrm{T}_{\mathrm{LEX} 2}\right)$ : (e.g. 'have an accident', Table 14).

c. SG/PL split: split stem segmentally $\left(\mathrm{LEX}_{1} / \mathrm{LEX}_{2}\right)+$ consistent stem tonally $\left(\mathrm{T}_{\mathrm{LEX}}\right)$ : (e.g. 'confound', Table 12). ${ }^{21}$

d. SG/PL split: split stem segmentally $\left(\operatorname{LEX}_{1} / \mathrm{LEX}_{2}\right)+$ split stem tonally $\left(\mathrm{T}_{\mathrm{LEX} 1} / \mathrm{T}_{\mathrm{LEX} 2}\right)$ : (e.g. 'demand', Table 14).

\begin{tabular}{|c|c|c|c|c|c|}
\hline \multirow[t]{2}{*}{$\begin{array}{l}\text { No SG/PL split } \\
\text { SG/PL split }\end{array}$} & $\begin{array}{r}33 \\
525\end{array}$ & $\begin{array}{r}6 \% \\
94 \%\end{array}$ & $\begin{array}{l}\mathrm{LEX}+\mathrm{T}_{\mathrm{LEX}} \\
\mathrm{LEX}+\mathrm{T}_{\mathrm{LEX} 1} / \mathrm{T}_{\mathrm{LEX} 2} \\
\mathrm{LEX}_{1} / \mathrm{LEX}_{2}+\mathrm{T}_{\mathrm{LEX}} \\
\mathrm{LEX}_{1} / \mathrm{LEX}_{2}+\mathrm{T}_{\mathrm{LEX} 1} / \mathrm{T}_{\mathrm{LEX} 2}\end{array}$ & $\begin{array}{r}39 \\
378 \\
108 \\
\end{array}$ & $\begin{array}{r}7 \% \\
72 \% \\
21 \% \\
\end{array}$ \\
\hline & & & & 525 & $100 \%$ \\
\hline
\end{tabular}

Table 15. Distribution of the SG/PL split in the sample

In the paradigms of verbs, in the same way that Kim (2016) does, I take the stem of the cell for $3 \mathrm{SG}$ as being the lexical stem that carries the lexical tone of the verb for SG. In a similar fashion, the stem of the cell for PL (2PL and 3PL) will be the lexical stem that carries the lexical tone of the verb for PL. ${ }^{22}$ Concerning tone, the SG/PL split creates a division of active verbs into two classes, which for lack of a better term I call the 'number classes': the class with a consistent lexical tone (Consistent $\mathrm{T}_{\mathrm{LEX}}$ ) in $\mathrm{SG}$ and $\mathrm{PL}$, and the one with a split lexical tone (Split $\mathrm{T}_{\mathrm{LEX}}$ ). The existence of a tonal syncretism between the cells for SG and PL in the tone classes in Table 6, or the absence of such syncretisms, indicates membership of verbs in these classes. This is represented in Table 16 (the abbreviation NC stands for 'number class').

\footnotetext{
${ }^{21}$ Following Palancar \& Feist (2015), I take causative verbs to be verbs that display the SG/PL split because the elements on which the stems are built $\left(t z+/ t z i^{5}+\right.$ for SG; $n a ?^{l}+$ for PL) are not affixes but stem formatives. Causativization is no longer a transparent or productive morphological mechanism in SP-Amuzgo. Some causative verbs like 'harden' in Table 8 manifest the split both at stem formative level and at root level.

${ }^{22}$ Recall that Tables 4 and 5 show that we find all tone values in the forms of the 3SG and PL cells; this could be taken as independent evidence that the stems in these forms exhibit lexical tone.
} 


\begin{tabular}{|c|c|c|c|c|}
\hline $\mathrm{NC}$ & SG & PL & \# & Tonal classes \\
\hline \multirow{2}{*}{$\begin{array}{l}\text { Consistent } \mathrm{T}_{\text {LEX }} \\
\text { Split }_{\mathrm{T}_{\text {LEX }}}\end{array}$} & $\mathrm{T}_{\mathrm{LEX}}$ & $\mathrm{T}_{\mathrm{LEX}}$ & 411 & $15-19,48-54,58-63,66-69,76-81,85,90-92$ \\
\hline & $\mathrm{T}_{\mathrm{LEX} 1}$ & $\overline{\mathrm{T}_{\text {LEX2 }}}$ & 147 & $1-14,20-47,55-57,64-65,70-75,82-84,86-89$ \\
\hline Total & & & 558 & \\
\hline
\end{tabular}

Table 16. Distribution of the two number classes involving the SG/PL tonal split

As for lexical tone, the SG stem in the SG/PL split behaves as the basic stem in verbs with no split. This is illustrated in Table 17, which shows that when both types of lexical tones $\mathrm{T}_{\mathrm{LEX}}$ and $\mathrm{T}_{\mathrm{LEX} 1}$ are compared, their distribution is not significantly different, although the absence of T12 in $\mathrm{T}_{\mathrm{LEX} 1}$ is informative about the absence of the SG/PL split, suggesting that if a verb has T12 in its SG stem, it does not have the split; it is a member of the Consistent $\mathrm{T}_{\mathrm{LEX}}$ class. In contrast, $\mathrm{T}_{\mathrm{LEX} 2}$ has phonological restrictions, as it involves only five tones, three of which (T1, $\mathrm{T} 3$ and T12) are equally frequent. In Table 17, I have also correlated the tone values in $\mathrm{T}_{\mathrm{LEx} 1}$ with those in $\mathrm{T}_{\mathrm{LEX} 2}$. The result renders it difficult to establish a clear derivation of $\mathrm{T}_{\mathrm{LEX} 2}$ from $\mathrm{T}_{\mathrm{LEX} 1}$, although one could conclude that when $\mathrm{T}_{\mathrm{LEX} 1}$ has $\mathrm{T} 1, \mathrm{~T}_{\mathrm{LEX} 2}$ will have $\mathrm{T} 3$ (with only one exception).

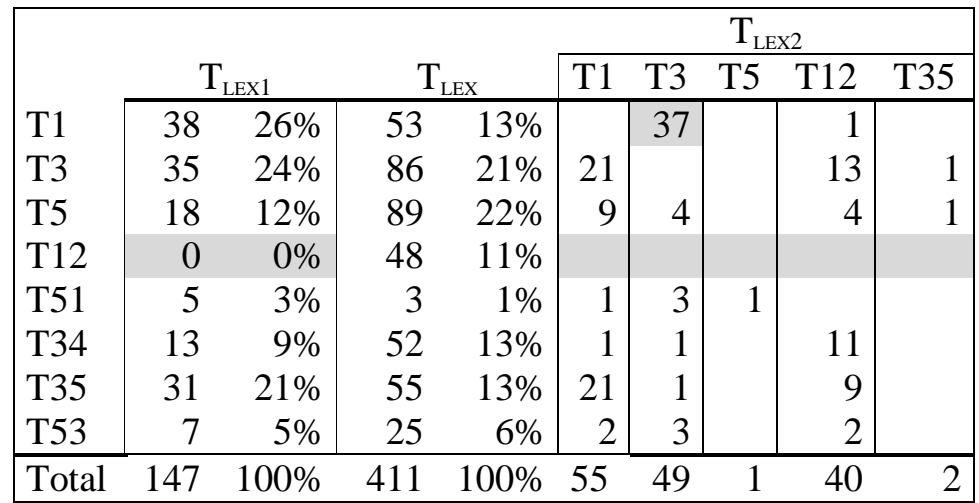

Table 17. Correlations between lexical tones in SG and PL

\subsection{Selecting inflectional tone}

Having established that the stems of the cells for 3SG and PL carry lexical tone, we can now turn to the forms that exhibit inflectional tone. To deal with them, one possible way is to follow Kim's (2016) tone class analysis, which considers tones in the forms for 1SG and 2SG as being exponents of $1 \mathrm{SG}$ and $2 \mathrm{SG}$, respectively. In her approach, Kim takes the singular and the plural forms of a verb in SP-Amuzgo as generated independently from two suppletive stems. Kim's analysis is based on the shape of the tonal paradigm of a verb in SP-Amuzgo being conceived of as in Table 18 .

\begin{tabular}{|c|c|c||c|c|c|}
\hline 1 SG & \multicolumn{1}{c}{2 SG } & \multicolumn{1}{c}{ SG } & \multicolumn{1}{c|}{ PL } & \multicolumn{1}{c|}{ 1PL.INCL } & 1PL.EXCL \\
\hline $\mathrm{T}_{\text {INFL }}$ & $\mathrm{T}_{\text {INFL }}$ & $\mathrm{T}_{\text {LEX1 }}$ & $\mathrm{T}_{\text {LEX2 }}$ & $\mathrm{T}_{\text {INFL }}$ & $\mathrm{T}_{\text {INFL }}$ \\
\hline
\end{tabular}

Table 18. A possible view of the tonal paradigm of a verb in SP-Amuzgo

From this viewpoint, Kim (2016) advances an analysis of the tone classes of 125 verbs by focusing on the singular forms only. The key to her analysis is to take the tone of 3SG out of the equation in the calculation of tone classes, because she takes that tone to be lexical (i.e. non-inflectional). Following this approach, from Kim's 125-verb sample we end up with 11 different tonal classes, illustrated in Table 19 (Kim's class labels using double letters have no bearing on my analysis). ${ }^{23}$

\footnotetext{
${ }^{23}$ A label such as 'A/I' reflects, for example, a reduction of two tone classes 'A' and 'I', which had been proposed earlier on as two independent classes. Kim's (2016) specific goal is to propose that for most instances of T51 in 2SG forms, one is dealing with a disguised T53, so her purpose is to reduce the inflectional complexity of the verbal system by equating many instances of T51 and T53 as representing the same inflectional exponent.
} 


\begin{tabular}{|l|cc|rr|}
\hline $\mathrm{TC}$ & $1 \mathrm{SG}$ & \multicolumn{1}{c}{ 2SG } & $\#$ & $\%$ \\
\hline $\mathrm{A} / \mathrm{I}$ & 53 & 53 & 65 & $52 \%$ \\
$\mathrm{~B} / \mathrm{J}$ & 53 & 3 & 27 & $22 \%$ \\
$\mathrm{C}$ & 53 & 12 & 1 & $1 \%$ \\
$\mathrm{D}$ & 51 & 1 & 8 & $6 \%$ \\
$\mathrm{E}$ & 3 & 3 & 2 & $2 \%$ \\
$\mathrm{~F} / \mathrm{L}$ & 12 & 12 & 4 & $3 \%$ \\
$\mathrm{G}$ & 1 & 53 & 4 & $3 \%$ \\
$\mathrm{H} / \mathrm{O}$ & 1 & 3 & 3 & $2 \%$ \\
$\mathrm{~K}$ & 3 & 51 & 6 & $5 \%$ \\
$\mathrm{M}$ & 51 & 51 & 1 & $1 \%$ \\
$\mathrm{~N}$ & 3 & 1 & 4 & $3 \%$ \\
\hline Total & & & 125 & $100 \%$ \\
\hline
\end{tabular}

Table 19. Kim's (2016) tonal classes based on 1SG and 2SG

I have applied Kim's approach to my sample of 588 verbs in Table 20 . Here we can see that because the size of the sample is substantially larger, one obtains ten additional classes. But it is noteworthy that Kim's 125 verb sample is rather representative, because it already accounts for almost $80 \%$ of the verbs in my larger sample (432/558), although I have no instances of tone classes $\mathrm{K}$ and $\mathrm{N}$ in my sample. ${ }^{24}$ Nevertheless, to account for the tonal inflection of the whole paradigm of verbs in Table 6 , we also need to include tonal information for 1PL.INCL (i.e. we already know that 1PL.EXCL selects T51). I have done this in Table 20 too, with the resulting eight tone classes. In this exercise, the tone of PL, being lexical, is also not taken into consideration.

\begin{tabular}{|c|c|c|c|c|c|c|c|c|}
\hline TC-sg & $1 \mathrm{SG}$ & $2 \mathrm{SG}$ & \# & & TC-pl & 1PL & \# & \\
\hline $\mathrm{A} / \mathrm{I}$ & 53 & 53 & 275 & $49 \%$ & $\mathrm{a}$ & 1 & 2 & $0 \%$ \\
\hline $\mathrm{B} / \mathrm{J}$ & 53 & 3 & 49 & $9 \%$ & b & 3 & 2 & $0 \%$ \\
\hline $\mathrm{C}$ & 53 & 12 & 3 & $1 \%$ & $\mathrm{c}$ & 5 & 94 & $17 \%$ \\
\hline D & 51 & 1 & 18 & $3 \%$ & d & 12 & 181 & $32 \%$ \\
\hline E & 3 & 3 & 50 & $9 \%$ & $\mathrm{e}$ & 51 & 5 & $1 \%$ \\
\hline $\mathrm{F} / \mathrm{L}$ & 12 & 12 & 15 & $3 \%$ & $\mathrm{f}$ & 34 & 190 & $34 \%$ \\
\hline G & 1 & 53 & 11 & $2 \%$ & g & 35 & 59 & $11 \%$ \\
\hline $\mathrm{H} / \mathrm{O}$ & 1 & 3 & 6 & $1 \%$ & $\mathrm{~h}$ & 53 & 25 & $4 \%$ \\
\hline $\mathrm{K}$ & 3 & 51 & 0 & $0 \%$ & & & & \\
\hline M & 51 & 51 & 4 & $1 \%$ & & & & \\
\hline $\mathrm{N}$ & 3 & 1 & 0 & $0 \%$ & & & & \\
\hline $\mathrm{P}$ & 1 & 1 & 4 & $1 \%$ & & & & \\
\hline Q & 12 & 1 & 38 & $7 \%$ & & & & \\
\hline $\mathrm{R}$ & 53 & 1 & 8 & $1 \%$ & & & & \\
\hline$S$ & 12 & 3 & 20 & $4 \%$ & & & & \\
\hline $\mathrm{T}$ & 51 & 3 & 1 & $0 \%$ & & & & \\
\hline $\mathrm{U}$ & 51 & 12 & 1 & $0 \%$ & & & & \\
\hline V & 53 & 51 & 1 & $0 \%$ & & & & \\
\hline W & 3 & 53 & 34 & $6 \%$ & & & & \\
\hline$X$ & 12 & 53 & 17 & $3 \%$ & & & & \\
\hline Y & 51 & 53 & 3 & $1 \%$ & & & & \\
\hline \multicolumn{3}{|l|}{ Total } & 558 & $100 \%$ & & & 558 & $100 \%$ \\
\hline
\end{tabular}

Table 20. Kim's (2016) tone class model applied to the 558 verb sample

Kim's approach, which is still based on the tone class model, has the advantage of reducing the number of tonal classes from Table 6: instead of almost a hundred classes, we now have 20 classes for the singular and eight for the plural. But to provide a comprehensive

\footnotetext{
${ }^{24}$ The absence of such classes in my sample may be due to the fact that I am using different verbs, and it should bear no relevance for the current exercise.
} 
account of the tonal paradigm of a verb as a whole, for the lexical entry of each active verb we need to specify each verb's membership of each of these two classes. This means that verbs would need to be grouped into tonal macro-classes, according to what type of double membership they exhibit. The exercise gives us almost 50 macro-classes, shown in Table 21 (the abbreviation TMC stands for 'tonal macro-class').

\begin{tabular}{|l|cl|rl|ll|lll|lr|r|}
\hline TMC & TC-sg & TC-pl & \# & TMC & TC-sg & TC-pl & \# & \multicolumn{1}{l|}{ TMC } & \multicolumn{2}{l|}{ TC-sg } & TC-pl & \# \\
\hline$i$ & $\mathrm{~A} / \mathrm{I}$ & $\mathrm{c}$ & 88 & xvii & $\mathrm{E}$ & $\mathrm{c}$ & 1 & $x x x i i i$ & $\mathrm{R}$ & $\mathrm{d}$ & 4 \\
$i i$ & $\mathrm{~A} / \mathrm{I}$ & $\mathrm{d}$ & 55 & $x v i i i$ & $\mathrm{E}$ & $\mathrm{d}$ & 2 & $x x x i v$ & $\mathrm{R}$ & $\mathrm{f}$ & 4 \\
$i i i$ & $\mathrm{~A} / \mathrm{I}$ & $\mathrm{f}$ & 54 & $x i x$ & $\mathrm{E}$ & $\mathrm{f}$ & 46 & $x x x v$ & $\mathrm{~S}$ & $\mathrm{~d}$ & 18 \\
$i v$ & $\mathrm{~A} / \mathrm{I}$ & $\mathrm{g}$ & 53 & $x x$ & $\mathrm{~F} / \mathrm{L}$ & $\mathrm{d}$ & 15 & $x x x v i$ & $\mathrm{~S}$ & $\mathrm{f}$ & 2 \\
$v$ & $\mathrm{~A} / \mathrm{I}$ & $\mathrm{h}$ & 25 & $x x i$ & $\mathrm{G}$ & $\mathrm{c}$ & 1 & $x x x v i i$ & $\mathrm{~T}$ & $\mathrm{f}$ & 1 \\
$v i$ & $\mathrm{~B} / \mathrm{J}$ & $\mathrm{b}$ & 1 & $x x i i$ & $\mathrm{G}$ & $\mathrm{d}$ & 7 & $x x x v i i i$ & $\mathrm{U}$ & $\mathrm{f}$ & 1 \\
$v i i$ & $\mathrm{~B} / \mathrm{J}$ & $\mathrm{c}$ & 2 & $x x i i i$ & $\mathrm{G}$ & $\mathrm{f}$ & 3 & $x x x i x$ & $\mathrm{~V}$ & $\mathrm{f}$ & 1 \\
$v i i i$ & $\mathrm{~B} / \mathrm{J}$ & $\mathrm{d}$ & 16 & $x x i v$ & $\mathrm{H} / \mathrm{O}$ & $\mathrm{d}$ & 1 & $x l$ & $\mathrm{~W}$ & $\mathrm{~b}$ & 1 \\
$i x$ & $\mathrm{~B} / \mathrm{J}$ & $\mathrm{f}$ & 27 & $x x v$ & $\mathrm{H} / \mathrm{O}$ & $\mathrm{f}$ & 5 & $x l i$ & $\mathrm{~W}$ & $\mathrm{c}$ & 1 \\
$x$ & $\mathrm{~B} / \mathrm{J}$ & $\mathrm{g}$ & 3 & $x x v i$ & $\mathrm{M}$ & $\mathrm{d}$ & 1 & $x l i i$ & $\mathrm{~W}$ & $\mathrm{f}$ & 30 \\
$x i$ & $\mathrm{C}$ & $\mathrm{d}$ & 2 & $x x v i i$ & $\mathrm{M}$ & $\mathrm{e}$ & 2 & $x l i i i$ & $\mathrm{~W}$ & $\mathrm{~g}$ & 2 \\
$x i i$ & $\mathrm{C}$ & $\mathrm{g}$ & 1 & $x x v i i i$ & $\mathrm{M}$ & $\mathrm{f}$ & 1 & $x l i v$ & $\mathrm{X}$ & $\mathrm{d}$ & 17 \\
$x i i i$ & $\mathrm{D}$ & $\mathrm{c}$ & 1 & $x x i x$ & $\mathrm{P}$ & $\mathrm{c}$ & 1 & $x l v$ & $\mathrm{Y}$ & $\mathrm{d}$ & 1 \\
$x i v$ & $\mathrm{D}$ & $\mathrm{d}$ & 5 & $x x x$ & $\mathrm{P}$ & $\mathrm{d}$ & 1 & $x l v i$ & $\mathrm{Y}$ & $\mathrm{e}$ & 1 \\
$x v$ & $\mathrm{D}$ & $\mathrm{f}$ & 12 & $x x x i$ & $\mathrm{P}$ & $\mathrm{f}$ & 2 & $x l v i i$ & $\mathrm{Y}$ & $\mathrm{f}$ & 1 \\
$x v i$ & $\mathrm{E}$ & $\mathrm{a}$ & 1 & $x x x i i$ & $\mathrm{Q}$ & $\mathrm{d}$ & 38 & & & & \\
\hline
\end{tabular}

Table 21. Tonal macro-classes

It is difficult to establish meaningful correlations within the macro-classes in Table 21, except for $x x, x x x i i, x x x v$ and $x l i v$, which predict that if we have T12 in 1 sG we will also have T12 in 1PL.INCL (except for the two verbs of macro-class xxxvi which have T12 for 1sG but T34 for 1PL.INCL). This suggests that the two systems are not completely orthogonal. The descriptive exercise in Table 21 is reductionist, but it adds a layer of complexity as it operates on the basis that a speaker would have to remember double class membership of each entry as well as the possible interactions of the two subsystems. Of course, one could easily do away with this added layer, while obtaining exactly the same result, if we stated that the new tonal classes were defined by the alignment of the tonal exponents for 1SG, 2SG and 1PL.INCL together.

We have seen that the upside of this approach is to reduce the number of tonal classes by taking lexical tone out of the equation. But it is precisely in reaching that reduction, that the approach meets its downside, because by doing so we lose sight of lexical tone completely making it impossible to visualize the existence of tonal syncretisms between lexical tone and inflectional tone. Similarly, by excluding lexical tone, we lose track of the tonally invariant verbs that we identified in Tables 11 and Tables 13 above, and by missing tonal syncretism we are not able to see that PL class $e$ with T51 is only found with SG class M that also exhibits T51 for both $1 \mathrm{SG}$ and $2 \mathrm{SG}$, and that this happens precisely in the two invariant verbs of tone class 91.

In the alternative view I propose here, I consider both lexical tone and tonal syncretisms as crucial elements in understanding the architecture of tonal inflection of verbs in SP-Amuzgo. On this basis, in the next section I advance a different concept of what does and does not count as inflectional tone in the paradigms of SP-Amuzgo active verbs. I do so by establishing that verbs differ in paradigm shape (i.e. not all verbs have the tonal paradigm of Table 18). I explore the tonal classes in Table 6 through the lens of the different paradigmatic shapes that we find. Unlike a tonal class approach that takes all possible tone values occurring in the cells for 1SG, 2SG and 1PL.INCL as inflectional exponents, I propose that the only true inflectional tones occurring in these three cells are those that deviate from the lexical tones of their corresponding stem. 


\subsection{Inflectional tone through the lens of paradigmatic classes}

Building on Kim's (2016) approach, which is motivated by the analytical convenience of distinguishing between lexical and inflectional tone, I advance here an alternative to the tonal inflection of SP-Amuzgo by proposing that verbs in SP-Amuzgo fall into different classes according to the shape of their tonal paradigm. I refer to these as 'paradigmatic classes'. There are eight such classes, a number that follows from the eight different logical combinations of lexical and inflectional tone shown in Table 22.

All paradigmatic classes have two properties in common: (i) they have one or two lexical tones; and (ii) they all require inflectional tone for 1PL.EXCL. More specifically, Class I encompasses invariant verbs with no tonal inflection for the remaining cells. Besides 1PL.EXCL, Classes II-IV require inflectional tone in just one other cell: in the case of Class II the 1PL.INCL, as a result of which both 1PL cells receive inflectional tone; for Class III the $1 \mathrm{SG}$; and for Class IV the 2SG. Classes V-VII combine two requirements: Class V requires inflectional tone for 1SG and 1PL.INCL; in Class VI the 2SG and 1PL.INCL receive inflectional tone; and in Class VII it is the 1SG and 2SG. Finally, Class VIII requires inflectional tone in 1SG, $2 \mathrm{SG}$ and 1PL.INCL cells.

The eight paradigmatic classes in Table 22 are further divided in two subclasses depending on whether the verbs in question are members of the Consistent $\mathrm{T}_{\mathrm{LEX}}$ class or the Split $\mathrm{T}_{\mathrm{LEX}}$ class (PC 'paradigmatic class; NC 'number class').

\begin{tabular}{|c|c|c|c|c|c|c|c|c|c|}
\hline PC & $\mathrm{NC}$ & $1 \mathrm{SG}$ & $2 \mathrm{SG}$ & SG & PL & 1PL.INCL & 1PL.EXCL & \# & \# \\
\hline \multirow[t]{2}{*}{ I } & \multirow{2}{*}{$\begin{array}{l}\text { a. Consistent } \mathrm{T}_{\mathrm{LEX}} \\
\text { b. Split } \mathrm{T}_{\mathrm{LEX}}\end{array}$} & $\mathrm{T}_{\mathrm{EEX}}$ & $T_{L E X}$ & $T_{\mathrm{LEX}}$ & $T_{\mathrm{LEX}}$ & $\mathrm{T}_{\mathrm{LEX}}$ & $\mathrm{T}_{\mathrm{INE}}$ & \multirow{2}{*}{$\begin{array}{r}42 \\
4\end{array}$} & \multirow[t]{2}{*}{46} \\
\hline & & $\mathrm{T}_{\mathrm{LEX} 1}$ & $\mathrm{~T}_{\text {LEX } 1}$ & $\mathrm{~T}_{\mathrm{LEX} 1}$ & $\mathrm{~T}_{\mathrm{LEX} 2}$ & $\mathrm{~T}_{\mathrm{LEX} 2}$ & $\mathrm{~T}_{\mathrm{INFL}}$ & & \\
\hline \multirow[t]{2}{*}{ II } & \multirow{2}{*}{$\begin{array}{l}\text { a. Consistent } \mathrm{T}_{\mathrm{LEX}} \\
\text { b. Split } \mathrm{T}_{\mathrm{LEX}}\end{array}$} & $\mathrm{T}_{\mathrm{LEX}}$ & $\mathrm{T}_{\mathrm{LEX}}$ & $\mathrm{T}_{\mathrm{LEX}}$ & $\mathrm{T}_{\mathrm{LEX}}$ & $\mathrm{T}_{\mathrm{INFL}}$ & $\mathrm{T}_{\mathrm{INFL}}$ & \multirow{2}{*}{$\begin{array}{r}43 \\
7\end{array}$} & \multirow{2}{*}{50} \\
\hline & & $\mathrm{T}_{\text {LEX1 }}$ & $\mathrm{T}_{\mathrm{LEX} 1}$ & $\mathrm{~T}_{\mathrm{LEX} 1}$ & $\mathrm{~T}_{\mathrm{LEX} 2}$ & $\mathrm{~T}_{\mathrm{INFL}}$ & $\mathrm{T}_{\mathrm{INFL}}$ & & \\
\hline \multirow[t]{2}{*}{ III } & \multirow{2}{*}{$\begin{array}{l}\text { a. Consistent } \mathrm{T}_{\mathrm{LEX}} \\
\text { b. Split } \mathrm{T}_{\mathrm{LEX}}\end{array}$} & $\mathrm{T}_{\mathrm{INFL}}$ & $\mathrm{T}_{\mathrm{LEX}}$ & $\mathrm{T}_{\mathrm{LEX}}$ & $\mathrm{T}_{\text {LEX }}$ & $\mathrm{T}_{\mathrm{LEX}}$ & $\mathrm{T}_{\mathrm{INFL}}$ & \multirow{2}{*}{$\begin{array}{l}1 \\
8\end{array}$} & 9 \\
\hline & & $\mathrm{T}_{\mathrm{INFL}}$ & $\mathrm{T}_{\mathrm{LEX} 1}$ & $\mathrm{~T}_{\mathrm{LEX} 1}$ & $\mathrm{~T}_{\mathrm{LEX} 2}$ & $\mathrm{~T}_{\text {LEX2 }}$ & $\mathrm{T}_{\mathrm{INFL}}$ & & \\
\hline \multirow[t]{2}{*}{ IV } & \multirow{2}{*}{$\begin{array}{l}\text { a. Consistent } \mathrm{T}_{\mathrm{LEX}} \\
\text { b. Split } \mathrm{T}_{\mathrm{LEX}}\end{array}$} & $\mathrm{T}_{\text {LEX }}$ & $\mathrm{T}_{\mathrm{INFL}}$ & $T_{\text {LEX }}$ & $\mathrm{T}_{\mathrm{LEX}}$ & $T_{\text {LEX }}$ & $\mathrm{T}_{\mathrm{INFL}}$ & \multirow{2}{*}{$\begin{array}{r}25 \\
0\end{array}$} & \multirow[t]{2}{*}{25} \\
\hline & & $\mathrm{T}_{\mathrm{LEX} 1}$ & $\mathrm{~T}_{\mathrm{INFL}}$ & $\mathrm{T}_{\mathrm{LEX} 1}$ & $\mathrm{~T}_{\text {LEX2 }}$ & $\mathrm{T}_{\mathrm{LEX} 2}$ & $\mathrm{~T}_{\mathrm{INFL}}$ & & \\
\hline \multirow[t]{2}{*}{ V } & \multirow{2}{*}{$\begin{array}{l}\text { a. Consistent } \mathrm{T}_{\mathrm{LEX}} \\
\text { b. }\end{array}$} & $\mathrm{T}_{\mathrm{INFL}}$ & $\mathrm{T}_{\mathrm{LEX}}$ & $\mathrm{T}_{\mathrm{LEX}}$ & $\mathrm{T}_{\mathrm{LEX}}$ & $\mathrm{T}_{\mathrm{INFL}}$ & $\mathrm{T}_{\mathrm{INFL}}$ & \multirow{2}{*}{$\begin{array}{l}59 \\
26\end{array}$} & \multirow[t]{2}{*}{85} \\
\hline & & $\mathrm{T}_{\mathrm{INFL}}$ & $\mathrm{T}_{\text {LEX1 } 1}$ & $\mathrm{~T}_{\mathrm{LEX1} 1}$ & $\mathrm{~T}_{\mathrm{LEX} 2}$ & $\mathrm{~T}_{\mathrm{INFL}}$ & $\mathrm{T}_{\mathrm{INFL}}$ & & \\
\hline \multirow[t]{2}{*}{ VI } & \multirow{2}{*}{$\begin{array}{l}\text { a. Consistent } \mathrm{T}_{\mathrm{LEX}} \\
\text { b. Split } \mathrm{T}_{\mathrm{LEX}}\end{array}$} & $\mathrm{T}_{\mathrm{LEX}}$ & $\mathrm{T}_{\mathrm{INFL}}$ & $\mathrm{T}_{\mathrm{LEX}}$ & $T_{\text {LEX }}$ & $\mathrm{T}_{\mathrm{INFL}}$ & $\mathrm{T}_{\mathrm{INFL}}$ & \multirow{2}{*}{$\begin{array}{r}18 \\
1\end{array}$} & \multirow[t]{2}{*}{19} \\
\hline & & $\mathrm{T}_{\text {LEX1 }}$ & $\mathrm{T}_{\mathrm{INFL}}$ & $\mathrm{T}_{\mathrm{LEX} 1}$ & $\mathrm{~T}_{\mathrm{LEX} 2}$ & $\mathrm{~T}_{\mathrm{INFL}}$ & $\mathrm{T}_{\mathrm{INFL}}$ & & \\
\hline \multirow[t]{2}{*}{ VII } & \multirow{2}{*}{$\begin{array}{l}\text { a. Consistent } \mathrm{T}_{\mathrm{LEX}} \\
\text { b. }\end{array}$} & $\mathrm{T}_{\mathrm{INFL}}$ & $\mathrm{T}_{\mathrm{INFL}}$ & $\mathrm{T}_{\mathrm{LEX}}$ & $\mathrm{T}_{\mathrm{LEX}}$ & $\mathrm{T}_{\mathrm{LEX}}$ & $\mathrm{T}_{\mathrm{INFL}}$ & \multirow{2}{*}{$\begin{array}{r}199 \\
26\end{array}$} & \multirow[t]{2}{*}{225} \\
\hline & & $\mathrm{T}_{\mathrm{INFL}}$ & $\mathrm{T}_{\mathrm{INFL}}$ & $\mathrm{T}_{\mathrm{LEX} 1}$ & $\mathrm{~T}_{\mathrm{LEX} 2}$ & $\mathrm{~T}_{\mathrm{LEX} 2}$ & $\mathrm{~T}_{\mathrm{INFL}}$ & & \\
\hline \multirow[t]{2}{*}{ VIII } & \multirow{2}{*}{$\begin{array}{l}\text { a. Consistent } \mathrm{T}_{\mathrm{LEX}} \\
\text { b. }\end{array}$} & $\mathrm{T}_{\mathrm{INFL}}$ & $\mathrm{T}_{\mathrm{INFL}}$ & $\mathrm{T}_{\mathrm{LEX}}$ & $\mathrm{T}_{\mathrm{LEX}}$ & $\mathrm{T}_{\mathrm{INFL}}$ & $\mathrm{T}_{\mathrm{INFL}}$ & \multirow{2}{*}{$\begin{array}{l}25 \\
74\end{array}$} & \multirow[t]{2}{*}{99} \\
\hline & & $\mathrm{T}_{\mathrm{INFL}}$ & $\mathrm{T}_{\mathrm{INFL}}$ & $\mathrm{T}_{\mathrm{LEX1} 1}$ & $\mathrm{~T}_{\mathrm{LEX} 2}$ & $\mathrm{~T}_{\mathrm{INFL}}$ & $\mathrm{T}_{\mathrm{INFL}}$ & & \\
\hline Tota & & & & & & & & 558 & 558 \\
\hline
\end{tabular}

Table 22. Paradigmatic tonal classes in SP-Amuzgo

All paradigmatic classes, except for IV.b, are attested in the sample. Three of the classes (III, IV, and VI) are considerably less populated than the rest. This may be due to the fact that the groups of cells involved that require inflectional tone do not form natural classes. For example, while Class II or Class V verbs are consistent in requiring inflectional tone in either 1PL cells or in all cells for the first person, Class III misses out 1PL.INCL. Similarly, while Class VII requires inflectional tone for the cells of the prototypical set of speech act participants (1SG and 2SG) and Class VIII for all values which permit it, Classes IV and VI 
group 2SG with either 1PL.EXCL or with 1PL cells, missing out 1SG. Example verbs from each of the eight paradigmatic classes are presented in Appendix A, with representatives from both the Consistent $\mathrm{T}_{\mathrm{LEX}}$ and Split $\mathrm{T}_{\mathrm{LEX}}$ subclasses.

The eight paradigmatic classes with their two subclasses that follow the SG/PL split allow for a rearrangement of the way we conceive of the verbs from the different tonal classes. This rearrangement is presented in Table 23. In the table, shading indicates lexical tone (when there is a split, light shading is $\mathrm{T}_{\mathrm{LEX} 1}$, and dark shading $\mathrm{T}_{\mathrm{LEX} 2}$ ). The cells targeted by inflectional tone have also been highlighted (PC 'paradigmatic class'; NC 'number class'; TC 'tone class').

(See Table 23 on the next page)

Table 23 makes it easier to appreciate that Class VIII is the one with the most tonal distinctions at cell level. Actually, as a consequence of the SG/PL split, verbs of Class VIII.b are the ones that allow for the maximum number of such distinctions in their paradigm, amounting to six if one were to consider 1PL.EXCL. An example of such a verb is the verb 'look at' of tonal class 5, presented in Table 24.

\begin{tabular}{|c|c|c|c|c|}
\hline IMPF & 'look at' & & & (TC5) \\
\hline $1 \mathrm{SG}$ & to $^{3}-$ ndy $^{2} \mathrm{ia}^{53}$ & $\mathrm{LEX}_{1}$ & $\mathrm{~T}_{\mathrm{INFL}}$ & 53 \\
\hline $2 \mathrm{SG}$ & to $^{3}$-ndyia? ${ }^{3}$ & $\mathrm{LEX}_{1}$ & $\mathrm{~T}_{\mathrm{INFL}}$ & $\underline{3}$ \\
\hline $3 \mathrm{SG}$ & to $^{3}$-ndyia? $P^{35}$ & $\mathrm{LEX}_{1}$ & $\mathrm{~T}_{\mathrm{LEX} 1}$ & 35 \\
\hline 1PL.INCL & to ${ }^{3}-$ hndy ia $^{5} \mathrm{a}^{5}$ & $\mathrm{LEX}_{2}$ & $\mathrm{~T}_{\mathrm{INFL}}$ & 5 \\
\hline 1PL.EXCL & to $^{3}$-hndyPia ${ }^{51}$ & $\mathrm{LEX}_{2}$ & $\mathrm{~T}_{\mathrm{INFL}}$ & 51 \\
\hline $\begin{array}{l}2 \mathrm{PL} \\
3 \mathrm{PL}\end{array}$ & $\begin{array}{l}\text { to }^{3} \text {-hndy } \text { ia }^{12}=o ?^{3} \\
\text { to }^{3} \text {-hndy } \text { hia }^{12}\end{array}$ & $\mathrm{LEX}_{2}$ & $\mathrm{~T}_{\text {LEX2 }}$ & 12 \\
\hline
\end{tabular}

Table 24. A verb with the maximal number of tonal distinctions

However, the reality of tonal syncretism makes it difficult to get distinctive tones in all cells. For example, there are 75 verbs of Class VIII.b in my sample, but there are only five more verbs that behave like 'look at' in Table 24 (tonal classes 1-5); the rest show some degree of tonal syncretism. Many involve a T53 for both 1SG and 2SG. There are others which appear to be accidents of the phonology (i.e. tonal homophony rather than morphological or paradigmatic syncretism), for example when some verbs select T51 for 1sG, which is homophonous with T51 of 1PL.EXCL, or when some select the same tone value for 1SG or 2SG that happens to also occur in the PL stem.

I have proposed that the eight paradigmatic classes in Table 22 constitute the different types of tonal paradigms that a verb in SP-Amuzgo can have, based on which cells require inflectional tone and which require lexical tone. However, except for 1PL.EXCL, which is always unequivocally realized by T51, tonal allomorphy still remains a problem. For example, in Class VIII there are no fewer than five possibilities for the realization of either 1SG or 2SG (T1, T3, T12, T51 and T53), and four for 1PL.INCL (T5, T12, T34 and T35). In this way, although paradigmatic classes have the advantage of taking out of the equation many tonal distinctions by treating them as lexical tones as opposed to inflectional exponents, we still need to address the question of what tone value is selected for the cells that require inflectional tones. What is the best way to account for the selection of such tonal exponents? One possibility is to return to the model of tonal classes. For Class VIII verbs we could use the revised tonal class model that we applied in Section 5.2 in Table 21, which was based on tonal macro-classes resulting from the interaction of tonal classes for $1 \mathrm{SG}$ and $2 \mathrm{SG}$ plus the tonal classes for 1PL.INCL. The result of this analytical exercise applied to Class VIII verbs is given in Table 25, where for convenience the tonal macro-classes of Table 21 have been relabeled as 'new tonal macro-classes' (NTMC) using roman numbers in capitals. 


\begin{tabular}{|c|c|c|c|c|c|c|c|c|c|c|c|c|c|c|c|c|c|}
\hline $\mathrm{PC}$ & $\mathrm{NC}$ & TC & $1 \mathrm{SG}$ & $2 \mathrm{SG}$ & SG & PL & $1 \mathrm{PL}$ & \# & $\mathrm{PC}$ & $\mathrm{NC}$ & $\mathrm{TC}$ & $1 \mathrm{SG}$ & $2 \mathrm{SG}$ & SG & PL & $1 \mathrm{PL}$ & \# \\
\hline \multirow[t]{6}{*}{ I } & $\mathrm{a}$ & 90 & 12 & 12 & 12 & 12 & 12 & 15 & VIII & $\mathrm{a}$ & 15 & 3 & 53 & 34 & 34 & 35 & 2 \\
\hline & & 91 & 51 & 51 & 51 & 51 & 51 & 2 & & & 16 & 3 & 53 & 35 & 35 & 5 & 1 \\
\hline & & 92 & 53 & 53 & 53 & 53 & 53 & 25 & & & 17 & 53 & 3 & 1 & 1 & 12 & 1 \\
\hline & $\mathrm{b}$ & 87 & 3 & 3 & 3 & 1 & 1 & 1 & & & 18 & 53 & 12 & 3 & 3 & 35 & 1 \\
\hline & & 88 & 3 & 3 & 3 & 12 & 12 & 1 & & & 19 & 53 & 51 & 3 & 3 & 34 & 1 \\
\hline & & 89 & 53 & 53 & 53 & 12 & 12 & 2 & & & 66 & 1 & 1 & 35 & 35 & 5 & 1 \\
\hline \multirow[t]{7}{*}{ II } & a & 58 & 3 & 3 & 3 & 3 & 34 & 43 & & & 67 & 53 & 53 & 3 & 3 & 34 & 2 \\
\hline & $\mathrm{b}$ & 42 & 3 & 3 & 3 & 1 & 12 & 1 & & & 68 & 53 & 53 & 5 & 5 & 12 & 2 \\
\hline & & 43 & 3 & 3 & 3 & 1 & 34 & 1 & & & 69 & 53 & 53 & 35 & 35 & 5 & 1 \\
\hline & & 44 & 51 & 51 & 51 & 3 & 34 & 1 & & & 81 & 12 & 3 & 1. & 1. & 12 & 12 \\
\hline & & 45 & 51 & 51 & 51 & 1 & 12 & 1 & & b & 1 & 51 & 1 & 3 & 12 & 5 & 1 \\
\hline & & 46 & 53 & 53 & 53 & 1 & 12 & 1 & & & 2 & 51 & 12 & 53 & 3 & 34 & 1 \\
\hline & & 47 & 53 & 53 & 53 & 3 & 34 & 2 & & & 3 & 51 & 53 & 1 & 3 & 34 & 1 \\
\hline \multirow[t]{4}{*}{ III } & a & 59 & 53 & 3 & 3 & 3 & 3 & 1 & & & 4 & 51 & 53 & 5 & 1 & 12 & 1 \\
\hline & b & 82 & 53 & 3 & 3 & 12 & 12 & 6 & & & 5 & 53 & 3 & 35 & 12 & 5 & 2 \\
\hline & & 83 & 53 & 3 & 3 & 35 & 35 & 1 & & & 6 & 1 & 1 & 5 & 3 & 34 & 1 \\
\hline & & 84 & 12 & 1 & 1 & 12 & 12 & 1 & & & 7 & 53 & 53 & 1 & 3 & 34 & 7 \\
\hline \multirow[t]{4}{*}{ IV } & $\mathrm{a}$ & 60 & 3 & 53 & 3 & 3 & 3 & 1 & & & 8 & 53 & 53 & 3 & 1 & 12 & 3 \\
\hline & & 61 & 12 & 3 & 12 & 12 & 12 & 6 & & & 9 & 53 & 53 & 5 & 1 & 12 & 2 \\
\hline & & 62 & 12 & 53 & 12 & 12 & 12 & 17 & & & 10 & 53 & 53 & 51 & 3 & 34 & 2 \\
\hline & & 63 & 51 & 53 & 51 & 51 & 51 & 1 & & & 11 & 53 & 53 & 34 & 1 & 12 & 1 \\
\hline \multirow[t]{9}{*}{ V } & $\mathrm{a}$ & 50 & 1 & 3 & 3 & 3 & 34 & 3 & & & 12 & 53 & 53 & 35 & 1 & 12 & 15 \\
\hline & & 51 & 51 & 1 & 1 & 1 & 12 & 3 & & & 13 & 53 & 53 & 35 & 12 & 34 & 1 \\
\hline & & 52 & 53 & 3 & 3 & 3 & 34 & 14 & & & 14 & 53 & 53 & 35 & 1 & 5 & 1 \\
\hline & & 53 & 53 & 3 & 3 & 3 & 35 & 2 & & & 27 & 1 & 3 & 5 & 3 & 34 & 1 \\
\hline & & 85 & 12 & 1. & 1 & 1 & 12 & 37 & & & 28 & 1 & 3 & 35 & 3 & 34 & 1 \\
\hline & $\mathrm{b}$ & 23 & 51 & 1 & 1 & 3 & 34 & 12 & & & 29 & 12 & 3 & 1 & 3 & 34 & 1 \\
\hline & & 24 & 53 & 1 & 1 & 3 & 34 & 4 & & & 30 & 1 & 3 & 35 & 1 & 12 & 1 \\
\hline & & 25 & 53 & 3 & 3 & 1 & 12 & 9 & & & 31 & 1 & 53 & 5 & 1 & 12 & 3 \\
\hline & & 26 & 53 & 3 & 3 & 1 & 34 & 1 & & & 32 & 1 & 53 & 5 & 1 & 34 & 1 \\
\hline \multirow[t]{2}{*}{ VI } & $\mathrm{a}$ & 54 & 3 & 53 & 3 & 3 & 34 & 18 & & & 33 & 1 & 53 & 35 & 1 & 12 & 1 \\
\hline & $\mathrm{b}$ & 86 & 53 & 1 & 53 & 1 & 12 & 1 & & & 34 & 1 & 53 & 35 & 1 & 34 & 2 \\
\hline \multirow[t]{16}{*}{ VII } & $\mathrm{a}$ & 48 & 1 & 53 & 5 & 5 & 5 & 2 & & & 35 & 12 & 3 & 35 & 12 & 34 & 1 \\
\hline & & 49 & 3 & 53 & 34 & 34 & 34 & 12 & & & 36 & 51 & 3 & 1 & 3 & 34 & 1 \\
\hline & & 76 & 3 & 3 & 5 & 5 & 5 & 1 & & & 37 & 53 & 1 & 3 & 1 & 12 & 2 \\
\hline & & 77 & 53 & 53 & 5 & 5 & 5 & 85 & & & 38 & 53 & 1 & 3 & 1 & 34 & 1 \\
\hline & & 78 & 53 & 53 & 12 & 12 & 12 & 9 & & & 39 & 53 & 1 & 5 & 1 & 12 & 1 \\
\hline & & 79 & 53 & 53 & 34 & 34 & 34 & 38 & & & 40 & 53 & 3 & 1 & 3 & 34 & 11 \\
\hline & & 80 & 53 & 53 & 35 & 35 & 35 & 52 & & & 41 & 53 & 12 & 3 & 1 & 12 & 2 \\
\hline & $\mathrm{b}$ & 20 & 1 & 53 & 5 & 12 & 12 & 1 & & & 55 & 1 & 1 & 5 & 1 & 12 & 1 \\
\hline & & 21 & 1 & 53 & 35 & 12 & 12 & 1 & & & 56 & 1 & 1 & 35 & 1 & 34 & 1 \\
\hline & & 22 & 51 & 1 & 3 & 12 & 12 & 2 & & & 57 & 3 & 3 & 5 & 3 & 34 & 2 \\
\hline & & 70 & 53 & 53 & 3 & 12 & 12 & 3 & & & 64 & 53 & 53 & 34 & 3 & 34 & 1 \\
\hline & & 71 & 53 & 53 & 5 & 12 & 12 & 3 & & & 65 & 53 & 53 & 34 & 12 & 34 & 1 \\
\hline & & 72 & 53 & 53 & 34 & 12 & 12 & 10 & & & & & & & & & \\
\hline & & 73 & 53 & 53 & 35 & 12 & 12 & 4 & & & & & & & & & \\
\hline & & 74 & 53 & 53 & 5 & 35 & 35 & 1 & & & & & & & & & \\
\hline & & 75 & 53 & 53 & 51 & 5 & 5 & 1 & & & & & & & & & \\
\hline
\end{tabular}

Table 23. The tonal paradigms of tonal classes organized into paradigmatic classes 


\begin{tabular}{|c|c|c|c|c|c|c|c|}
\hline NTMC & $\mathrm{NC}$ & TMC & TC-sg & & $\Gamma \mathrm{C}-\mathrm{p}$ & & TC \\
\hline I & $a / b$ & $i$ & $\mathrm{~A} / \mathrm{I}$ & 5353 & $\mathrm{c}$ & 5 & 14,69 \\
\hline II & & $i i$ & $\mathrm{~A} / \mathrm{I}$ & 5353 & $\mathrm{~d}$ & 12 & $8,9,11,12,68$ \\
\hline III & & iii & $\mathrm{A} / \mathrm{I}$ & $53 \quad 53$ & $\mathrm{f}$ & 34 & $7,10,13,64,65,67$ \\
\hline IV & $\mathrm{a}$ & viii & $\mathrm{B} / \mathrm{J}$ & 533 & $\mathrm{~d}$ & 12 & 17 \\
\hline V & & $x i i$ & $\mathrm{C}$ & $53 \quad 12$ & $\mathrm{~g}$ & 35 & 18 \\
\hline VI & & $x l i$ & $\mathrm{~W}$ & 353 & $\mathrm{c}$ & 5 & 16 \\
\hline VII & & xliii & W & 353 & $\mathrm{~g}$ & 35 & 15 \\
\hline VIII & & xxix & $\mathrm{P}$ & 1 & $\mathrm{c}$ & 5 & 66 \\
\hline IX & & xxxix & V & 5351 & $\mathrm{f}$ & 34 & 19 \\
\hline $\mathrm{X}$ & & $x x x y$ & S & 123 & d & 12 & 81 \\
\hline XI & b & $i x$ & $\mathrm{~B} / \mathrm{J}$ & 53 & $\mathrm{f}$ & 34 & 40 \\
\hline XII & & $v i i$ & $\mathrm{~B} / \mathrm{J}$ & 533 & $\mathrm{c}$ & 5 & 5 \\
\hline XIII & & $x i$ & $\mathrm{C}$ & $53 \quad 12$ & $\mathrm{~d}$ & 12 & 41 \\
\hline XIV & & xiii & $\mathrm{D}$ & $51 \quad 1$ & $\mathrm{c}$ & 5 & 1 \\
\hline $\mathrm{XV}$ & & $x i x$ & $\mathrm{E}$ & 3 & $\mathrm{f}$ & 34 & 57 \\
\hline XVI & & $x l v$ & $\mathrm{Y}$ & 5153 & $\mathrm{~d}$ & 12 & 4 \\
\hline XVII & & xlvii & $\mathrm{Y}$ & 5153 & $\mathrm{f}$ & 34 & 3 \\
\hline XVIII & & $x x i i$ & G & 153 & d & 12 & 31,33 \\
\hline XIX & & xxiii & G & 153 & $\mathrm{f}$ & 34 & 32,34 \\
\hline $\mathrm{XX}$ & & xxiv & $\mathrm{H} / \mathrm{O}$ & 1 & d & 12 & 30 \\
\hline XXI & & $x x v$ & $\mathrm{H} / \mathrm{O}$ & 1 & $\mathrm{f}$ & 34 & 27,28 \\
\hline XXII & & $x x x$ & $\mathrm{P}$ & 1 & d & 12 & 55 \\
\hline XXIII & & $x x x i$ & $\mathrm{P}$ & 1 & $\mathrm{f}$ & 34 & 6,56 \\
\hline XXIV & & xxxiii & $\mathrm{R}$ & 53 & d & 12 & 37,39 \\
\hline XXV & & xxxiv & $\mathrm{R}$ & 53 & $\mathrm{f}$ & 34 & 38 \\
\hline XXVI & & $x x x v i$ & S & 12 & $\mathrm{f}$ & 34 & 29,35 \\
\hline XXVII & & xxxvii & $\mathrm{T}$ & 513 & $\mathrm{f}$ & 34 & 36 \\
\hline XXVIII & & xxxviii & $\mathrm{U}$ & $\begin{array}{ll}51 \quad 12 \\
\end{array}$ & f & 34 & 2 \\
\hline
\end{tabular}

Table 25. The tonal macro-classes of Class VIII verbs

Table 25 shows how it has been possible to collapse the 47 tonal macro-classes in Table 21 into 28 new tonal macro-classes and that most of these classes turn out to be informative about membership of a verb of paradigmatic Class VIII to one of the number classes (i.e. verbs of IV-X are members of the Consistent $\mathrm{T}_{\mathrm{LEX}}$ class and those of XI-XXVIII are members of the Split $\mathrm{T}_{\mathrm{LEX}}$ class, while the verbs of I-III have T53 for both 1SG and 2SG and are members of both number classes). But despite this, it is only a modest reduction; the number of new classes that we still need to postulate to handle the tonal allomorphy involving the inflectional exponents of just Class VIII remains impractical, let alone the fact that we still need to account for the tonal classes of the remaining paradigmatic classes. There are different ways in which all this might be interpreted, but my take on it is that the model of tonal classes remains unsatisfactory. In the next section I advance an alternative analysis for the tonal allomorphy we still observe in this system. The analysis is based on a rule-based approach.

\section{A rule-based approach to tonal exponence in SP-Amuzgo}

In the previous section, making a distinction between lexical tone and inflectional tone in the paradigm of verbs in SP-Amuzgo, I have proposed that verbs fall into eight different paradigmatic classes according to the cells that are targeted by inflectional tone. However, I have also shown that there is still a great degree of tonal allomorphy in the exponence affecting the cells bearing inflectional tone. Further, I illustrated how the tonal class model still fails to reduce the complexities in a meaningful way. In this section, I propose an alternative non-technical analysis following a rule-based approach to deal with the tonal allomorphy of exponents for 1SG, 2SG and 1PL.INCL. For this, the occurrence of a given exponent in a paradigmatic cell can be seen as the outcome of a simple realization rule of exponence. 
Realization rules, however, can also show implicative contextual conditioning. In this respect, I follow the tenets of implicative morphology in Ackerman et al. (2009), Ackerman et al. (2011), Ackerman \& Malouf (2013), Bonami (2012, 2014), Bonami \& Beniamine (2015, 2016), Finkel \& Stump (2007, 2009), Stump (2016), and Stump \& Finkel (2016), among many others. Implicative morphology proposes that paradigm structure can be conceived of as a network of connections where the cells that compose the paradigm bear implicative relations with each other regarding rules of exponence. Under such an approach, a given cell may display stronger links to some cells than others. In other words, there are cells that can be used as predictors of the shape of the forms realizing other cells. In my analysis of SP-Amuzgo, I base such implicative rules on lexical tone. That is, I propose that lexical tone can, at times, be useful in delimiting the application of a certain rule of exponence for 1SG, 2SG and 1PL.INCL. Woodbury (2019) takes a similar approach for the tonal inflection of Eastern Chatino. Some implicative rules can further represent referral rules (Stump 2016), where the tone in one cell is identical to the tone in another cell. In SP-Amuzgo, this happens when the tonal syncretisms between cells do not appear to be an accident of the phonology, but points to the existence of true patterns of morphological syncretism of the type in Baerman et al. (2005), Baerman (2005) or Albright \& Fuss (2012).

As a way to deal with tonal allomorphy, I also follow the tenets of a theory of linguistic defaults. This theory allows for some rules to have a privileged status with respect to other rules. My conception of a theory of defaults is inspired by Network Morphology in Brown and Hippisley (2012), which is based on Corbett \& Fraser (1993). In this connection, Brown (2016: 273) contends that:

"An important reason why linguists should care about defaults is that they allow us to arrive at a characterization of what the standard properties of a fully inflected word are. Morphology is notorious for the exceptionality that can arise, but we need some way of understanding what the core part of the system is. We contend that it is always possible to arrive at generalizations about inflection, although this may be particularly challenging for some languages."

I find inspiration in Brown's contention, and I use the notion of a default tonal exponent in order to arrive at generalizations about the tonal inflection of SP-Amuzgo that can help us create a core for the system. This means that when we have different options for the encoding of 1SG, 2SG or 1PL.INCL, I take one of them to be less costly for information purposes and I treat it as a default. In other words, I consider a default rule to be a less-marked encoding option; a rule that would apply in the elsewhere case, if nothing else constrains its application.

Allomorphy involves competing rules, and there are rules that block (in the sense in Andrews, 1990) the application of the elsewhere rules. Such rules are seen as default overrides and their application requires further specification. We can think of the process as operating at different layers. First there is a base tone given by the lexicon. Then there are morphological rules that apply to a specific set of lexemes, and then there is the background default rule. Methodologically, given a set of rules, it is at times challenging to decide which rule serves as a default and which rules serve as overrides. In this paper, I have considered that a default rule is the one that is manifested by the largest number of verbs in my sample of SP-Amuzgo. Admittedly, this could be seen as a biased view, but it takes frequency of occurrence to represent meaningful clusters of structure which can say something about the core of the system.

In what follows, my analysis will consist of determining the rules involved in the tone assignment to the forms of $1 \mathrm{SG}, 2 \mathrm{SG}$ and 1PL.INCL in the relevant paradigmatic classes I have proposed in Section 5.

\subsection{Tones for 1SG: defaults, deviations and morphological complexity}

Tonal inflection for $1 \mathrm{SG}$ is required for paradigmatic classes III, V, VII and VIII. In my sample of 558 verbs, this involves a total of 418 verbs for which a tonal exponent is required 
for 1SG. There are five different exponents for 1SG, each one being the outcome of a rule of exponence. As a way to deal with this allomorphy, in the search for implicative relations, in Table 26 I have correlated the different tonal exponents with lexical tone. For this, I have assumed that the lexical tone to use in looking for implicative relations is the one borne by the singular stem, because when a verb has the SG/PL split at segmental level, the 1SG is always built on the singular stem, LEX $_{1}$.

\begin{tabular}{|c|c|c|c|c|c|c|c|c|c|c|c|c|c|c|c|c|c|c|}
\hline \multirow{7}{*}{$\begin{array}{l}\text { 1SG } \\
\text { T1 } \\
\text { T3 } \\
\text { T12 } \\
\text { T51 } \\
\text { T53 }\end{array}$} & \multicolumn{18}{|c|}{ SG } \\
\hline & & T1 & & T3 & & 5 & & $\Gamma 12$ & & T51 & & Г34 & & Г35 & & T53 & & otal \\
\hline & & & & $5 \%$ & 9 & $8 \%$ & 1 & $10 \%$ & & & & & 8 & $9 \%$ & & & 21 & $5 \%$ \\
\hline & & & & & 3 & $3 \%$ & & & & & 14 & $22 \%$ & 1 & $1 \%$ & & & 18 & $4 \%$ \\
\hline & 51 & $56 \%$ & & & & & & & & & & & 1 & $1 \%$ & & & 52 & $12 \%$ \\
\hline & 17 & $19 \%$ & 3 & $5 \%$ & 1 & $1 \%$ & & & & & & & & & & $100 \%$ & 22 & $5 \%$ \\
\hline & 23 & $25 \%$ & 49 & $89 \%$ & 94 & $88 \%$ & S & $90 \%$ & 3 & $100 \%$ & 51 & $78 \%$ & 76 & $88 \%$ & & & 305 & $73 \%$ \\
\hline Total & 91 & $100 \%$ & 55 & $100 \%$ & 107 & $100 \%$ & 10 & $100 \%$ & 3 & $100 \%$ & 65 & $100 \%$ & 86 & $100 \%$ & 1 & $100 \%$ & 418 & $100 \%$ \\
\hline
\end{tabular}

Table 26. Correlation of exponents for 1SG and lexical tone in the SG stem

Table 26 shows that $73 \%$ of the verbs in the sample take T53 as an exponent for 1sG. Because of this frequency of occurrence, I take T53 as the default for 1sG. In my analysis of the tonal inflection of verbs in SP-Amuzgo, I consider that default exponents like T53 for 1SG are the fundamental blocks on which the core of the system is built. This view implies that default overrides (i.e. selecting a tone other than T53 for 1SG) are seen as deviations from the pattern to which I assign a more primordial role in the construction of tonal inflection. However, such a view also imposes a problematic dichotomy of regular vs. irregular inflection, an all-or-nothing type of view of inflection without gradients that would force us to regard the remaining $27 \%$ of the verbs in the sample as a group of verbs that just deviate from the default rule.

Alternatively, we could postulate that there are intermediate cases. This is when implicative rules and rules of referral become useful, because they allow us to regard default overrides that can be accounted for in some way or another as being closer to the core than other cases for which no apparent motivation is available. In this connection, in order to create gradience in the deviation from the main core, I propose to classify tonal inflectional exponents according to the four categories in (2). ${ }^{25}$

(2) a. $\mathrm{D}_{2}$ : Indicates a default override with the greatest degree of deviation (i.e. a very irregular exponent), when the choice of the exponent over the default represents a ratio below $10 \%$.

b. $\mathrm{D}_{1}$ : Indicates a medium-level deviation, when the choice of the exponent over the default represents a ratio above $10 \%$, but not greater than the default's ratio.

c. $\mathrm{D}_{0}$ : Indicates the lowest degree of deviation from the set-up default, when the choice over the default is greater than the default's ratio.

d. Ø: Indicates that the tone under study is a default. When a verb exhibits that exponent, it is the expected outcome.

As an illustration of instances of $\mathrm{D}_{2}$, take the 55 verbs in Table 26 that have T3 in SG. Of these, $89 \%$ abide by the default, because they select T53 (Ø). However, there are six other verbs with T3 in SG that select other exponents (i.e. T1 and T51). Each of these exponents accounts for less than $10 \%$ of the verbs with T3 in SG, and I propose to analyse them as representing the greatest degree of deviation $\left(\mathrm{D}_{2}\right)$. The cut-off point below $10 \%$ is somewhat arbitrary, but it serves as a good starting point in trying to make sense of the system.

\footnotetext{
${ }^{25}$ The four categories are meant as an idealized model to measure inflectional deviations in general. The model is meant to be superimposed on Amuzgo data here, but it could be equally extended to understand deviations in other similarly complex inflectional systems.
} 
An example of $\mathrm{D}_{1}$ would be the status of the 14 verbs that select T3 as an exponent for 1sG when the verb has T34 in SG. The choice of this exponent represents a significant critical mass (i.e. $22 \%$ of the verbs which have T34 in SG) which deserves to be treated differently to other choices.

Finally, to illustrate a case like $\mathrm{D}_{0}$ take the status of the verbs that select T12 for 1 SG when the verb has T1 in SG. As indicated in Table 26, the percentage of verbs with T1 in SG that select T12 for 1SG is much greater than the percentage selecting the default T53 (56\% vs. $25 \%$ ). Actually, there is more to these verbs than meets the eye, as 50 out of the 51 verbs that select T12 for $1 \mathrm{SG}$ also have T12 for 1PL. While the opposite is not true (that is, it is not the case that every time we have T12 for 1PL we also have T12 for $1 \mathrm{SG}$ ), we could posit a morphological pattern of syncretism $\{1 \mathrm{PL}=1 \mathrm{SG}, \mathrm{T} 12\}$ for verbs that have a SG stem in T1. This would make the choice of T12 as an exponent for 1SG (partially) motivated.

The different categories in (2) in reality represent different levels of morphological complexity in the sense in Baerman et al. (2009, 2015), which is based on the amount of morphological information needed by speakers to be able to inflect lexemes. The core of an inflectional system is the part of the inflectional machinery that operates at the lowest cost, while default overrides, as deviations from the core, point to inflectional situations that increase the morphological complexity of a system, because they involve a greater amount of information. In the way I talk about the tonal inflection of verbs in SP-Amuzgo, I make a superficial correlation between levels of morphological regularity and levels of morphological complexity, in such a way that verbs which pertain to the core are talked about as being more regular than verbs which deviate, which are seen as more irregular.

In this sense, the measures in (2) are inspired by a Kolmogorov-style view of complexity based on amount of description (see Walther 2013 for an extensive discussion on complexity measures, also Sagot \& Walther 2011 and Sagot 2013), where the description of a default rule would not add complexity to the system. The measures $\mathrm{D}_{0}, \mathrm{D}_{1}$ and $\mathrm{D}_{2}$ are inspired by the proposals from implicative morphology (Bonami \& Beniamine 2016, Walther 2013, Sims \& Parker 2016, Beniamine et al. 2017, Beniamine 2018), where the predictive power of implicative relations is significant, in such a way that patterns that can be predicted from other patterns do not necessarily add complexity to the system. This is why I believe it is convenient to first distinguish between $\mathrm{D}_{0}$, on the one hand, and $\mathrm{D}_{1}$ and $\mathrm{D}_{2}$, on the other. The distinction between $D_{1}$ and $D_{2}$ is of pure descriptive convenience; it is created with the intention of allowing us to spot which verbs are really irregular with respect to the rest.

Taking this approach, we can now rank all the verbs in the sample according to the different degrees of deviation in (2) involving the marking of 1SG. The results are presented in Table $27 .{ }^{26}$

\begin{tabular}{|c|c|c|c|c|c|c|c|c|c|c|c|c|c|c|c|c|}
\hline \multirow{6}{*}{$\begin{array}{l}\text { 1SG } \\
\text { T1 } \\
\text { T3 } \\
\text { T12 } \\
\text { T51 }\end{array}$} & \multicolumn{16}{|c|}{ SG } \\
\hline & & $\mathrm{T} 1$ & & T3 & $\mathrm{T}$ & 5 & & 12 & & T51 & & T34 & & 35 & T53 & Total \\
\hline & & & & $5 \%$ & 9 & $8 \%$ & 1 & $10 \%$ & & & & & 8 & $9 \%$ & & 21 \\
\hline & & & & & 3 & $3 \%$ & & & & & 14 & $22 \%$ & 1 & $1 \%$ & & 18 \\
\hline & 51 & $56 \%$ & & & & & & & & & & & 1 & $1 \%$ & & $12 \%$ \\
\hline & 17 & $19 \%$ & 3 & $5 \%$ & 1 & $1 \%$ & & & & & & & & & $100 \%$ & $5 \%$ \\
\hline T53 & 23 & $25 \%$ & 49 & $89 \%$ & 94 & $88 \%$ & 9 & $90 \%$ & 3 & $100 \%$ & 51 & $78 \%$ & 76 & $88 \%$ & & $73 \%$ \\
\hline Total & 91 & $100 \%$ & 55 & $100 \%$ & 107 & $100 \%$ & 10 & $100 \%$ & 3 & $100 \%$ & 65 & $100 \%$ & 86 & $100 \%$ & $100 \%$ & $418 \quad 100 \%$ \\
\hline
\end{tabular}

Legend : $\square \varnothing \square \mathrm{D}_{0} \square \mathrm{D}_{1} \square \mathrm{D}_{2}$

Table 27. Degrees of deviation of the exponents for $1 \mathrm{SG}$

I show in Table 28 the tonal exponents of $1 \mathrm{SG}$, listed according to the degree of inflectional deviation (the darker the shade the further away from the core).

\footnotetext{
${ }^{26}$ When there is only one verb in a correlation that happens to not abide by the default, I take it to represent its own idiosyncratic pattern no matter what the percentage is, and I rank it as $\mathrm{D}_{2}$, accordingly.
} 


\begin{tabular}{|c|c|c|c|c|c|}
\hline Exponents of $1 \mathrm{SG}$ & Deviation & & $\mathrm{i}$ & ii & iii \\
\hline T53 & $\varnothing$ & 305 & $73 \%$ & $73 \%$ & $85 \%$ \\
\hline $\mathrm{T} 12$ if $\mathrm{T}_{\mathrm{LEX}} \mathrm{T} 1$ & $\mathrm{D}_{0}$ & 51 & $12 \%$ & $27 \%$ & \\
\hline $\mathrm{T} 51$ if $\mathrm{T}_{\mathrm{LEX}} \mathrm{T} 1$; $\mathrm{T} 3$ if $\mathrm{T}_{\mathrm{LEX}} \mathrm{T} 34$ & $\mathrm{D}_{1}$ & 31 & $7.5 \%$ & & $15 \%$ \\
\hline Any other T & $\mathrm{D}_{2}$ & 31 & $7.5 \%$ & & \\
\hline
\end{tabular}

Table 28. Overall deviation of the exponence for $1 \mathrm{SG}$

In Table 28, the columns headed ' $i$ ', 'ii' and 'iii' indicate three different ways in which the degrees of inflectional deviation can be interpreted:

(i) gives the distribution of each gradient.

(ii) indicates the distributional contrast between the verbs abiding by the default vs the verbs that display some sort of inflectional deviation, no matter what degree.

(iii) groups together cases that abide by a default and verbs whose inflectional behavior can be accounted for at least partially by some other situation. Under this perspective, we can account for $85 \%$ of the tonal exponence for $1 \mathrm{SG}$ in the sample. ${ }^{27}$

The view in (iii) offers some promising results in finding structure in the system. Having seen the inflectional behavior of verbs regarding the tonal exponence for $1 \mathrm{SG}$, we can now turn to the ways the tonal exponence for $2 \mathrm{SG}$ and 1PL.INCL behave in the sample.

\subsection{Tones for $2 \mathrm{SG}$}

There are five tonal exponents for $2 \mathrm{SG}$. None of these exponents is used exclusively for $2 \mathrm{SG}$, but all of them are also used for 1SG. The paradigmatic classes that require inflectional tone for 2 SG are IV, VI, VII and VIII. This involves a total of 368 verbs in my sample. The distribution of the different tonal exponents along with the deviation ranking is given in Table 29.

\begin{tabular}{|c|c|c|c|c|c|c|c|c|c|c|c|c|c|c|c|c|c|c|}
\hline \multirow{7}{*}{$\begin{array}{l}\text { 2SG } \\
\text { T1 } \\
\text { T3 } \\
\text { T12 } \\
\text { T51 } \\
\text { T53 }\end{array}$} & \multicolumn{18}{|c|}{ SG } \\
\hline & & $\mathrm{T} 1$ & & $\mathrm{~T} 3$ & $\mathrm{~T}$ & & & 12 & & T51 & & T34 & & 135 & & 53 & & tal \\
\hline & & & 6 & $15 \%$ & 3 & $3 \%$ & & & & & & & 2 & $2 \%$ & & $50 \%$ & 12 & $3 \%$ \\
\hline & 26 & $77 \%$ & & & 4 & $4 \%$ & 6 & $18 \%$ & & & & & 5 & $6 \%$ & & & 41 & $11 \%$ \\
\hline & & & & $8 \%$ & & & & & & & & & & & & $50 \%$ & 4 & $1 \%$ \\
\hline & & & & $2 \%$ & & & & & & & & & & & & & 1 & \\
\hline & 8 & $23 \%$ & 27 & $75 \%$ & 100 & $93 \%$ & 27 & $82 \%$ & 4 & $100 \%$ & 65 & $100 \%$ & 79 & $92 \%$ & & & 310 & $85 \%$ \\
\hline Total & 34 & $100 \%$ & 37 & $100 \%$ & 107 & $100 \%$ & 33 & $100 \%$ & 4 & $100 \%$ & 65 & $100 \%$ & 86 & $100 \%$ & 2 & $100 \%$ & 368 & $100 \%$ \\
\hline
\end{tabular}

Table 29. Degrees of deviation of the exponents for $2 \mathrm{SG}$

Table 29 shows that T53 is also a default exponent for 2sG, but when compared with what happens with $1 \mathrm{SG}$, a greater number of verbs abide by this default when it comes to marking 2SG (85\% vs. $73 \%)$. Verbs with SG in T1 again show special behavior, suggesting that speakers need to take heed of these verbs for the tonal marking of both 1sG and 2sG. The overall inflectional behavior of verbs in the sample according to the parameters I have set is given in Table 30. From the figures in column (iii), we can see that taking only the default exponent (T53) and the lowest level of deviation (T3 where $\mathrm{T}_{\mathrm{LEX}}$ is $\mathrm{T} 1$ ), we can already account for more than $90 \%$ of the inflectional exponence for $2 \mathrm{sG}$.

\footnotetext{
${ }^{27}$ An anonymous reviewer commented that the proposed implicative rules of exponence for 1sG, covering just $12 \%$ of verbs on top of the $73 \%$ that already get the default tonal inflection, could be seen as a potentially disappointing result. While I still think that increasing 'regularity' by $12 \%$ is not at all negligible for a complex system like Amuzgo's, in Section 7 I show that, when calculating the core of tonal inflection as a whole, the virtue of implicative rules adds $20 \%$ more verbs to the core.
} 


\begin{tabular}{|c|c|c|c|c|c|}
\hline Exponents of $2 \mathrm{SG}$ & Deviation & & $\mathrm{i}$ & ii & iii \\
\hline T53 & $\varnothing$ & 310 & $85 \%$ & $85 \%$ & $92 \%$ \\
\hline $\mathrm{T} 3$ if $\mathrm{T}_{\mathrm{LEX}} \mathrm{T} 1$ & $\mathrm{D}_{0}$ & 26 & $7 \%$ & $15 \%$ & \\
\hline $\mathrm{T} 1$ if $\mathrm{T}_{\mathrm{LEX}} \mathrm{T} 3 ; \mathrm{T} 3$ if $\mathrm{T}_{\mathrm{LEX}} \mathrm{T} 12$ & $\mathrm{D}_{1}$ & 12 & $3 \%$ & & $8 \%$ \\
\hline Any other T & $\mathrm{D}_{2}$ & 20 & $5 \%$ & & \\
\hline Total & Total & 368 & $100 \%$ & $100 \%$ & $100 \%$ \\
\hline
\end{tabular}

Table 30. Overall deviation of the exponence for $2 \mathrm{SG}$

\subsection{Tones for 1PL.INCL}

Tonal inflection for 1PL.INCL is required for paradigmatic classes II, V, VI and VIII, and in my sample of 558 verbs this involves a total of 253 verbs. There are four different exponents for 1PL.INCL, which I have correlated with the type of lexical tone we find in the stem used for PL, because I have assumed that if one is to establish an implicative relation between the tone for 1PL.INCL and some lexical tone, the lexical tone to look at has to be the one borne by the PL stem, as the form for 1PL.INCL is always built on the plural stem $\left(\operatorname{LEX}_{2}\right)$ when a verb has the $\mathrm{SG} / \mathrm{PL}$ split. For the verbs that do not have the SG/PL split, the stem to consider is the basic one, also used for SG. As in previous tables, Table 31 shows the distribution of the different tonal exponents for 1PL.INCL together with the complexity ranking.

\begin{tabular}{|c|c|c|c|c|c|c|c|c|c|}
\hline \multirow{3}{*}{$\begin{array}{l}\text { 1PL.INCL } \\
\text { T5 }\end{array}$} & \multicolumn{9}{|c|}{ PL } \\
\hline & & & & $\Gamma 3$ & T5 & $\mathrm{T} 12$ & T34 & T35 & Total \\
\hline & 1 & $1 \%$ & & & & $350 \%$ & & \begin{tabular}{|l|l}
3 & $100 \%$
\end{tabular} & $7 \quad 3 \%$ \\
\hline $\mathrm{T} 12$ & 99 & $93 \%$ & & & $\begin{array}{ll}2 & 100 \%\end{array}$ & & & & $40 \%$ \\
\hline T34 & 7 & $6 \%$ & 130 & $98 \%$ & & $50 \%$ & & & \begin{tabular}{l|l}
540 & $55 \%$
\end{tabular} \\
\hline T35 & & & 3 & $2 \%$ & & & $2100 \%$ & & $2 \%$ \\
\hline Total & 107 & $100 \%$ & 133 & $100 \%$ & $100 \%$ & $100 \%$ & $2100 \%$ & $100 \%$ & $100 \%$ \\
\hline
\end{tabular}

Legend: $\square \varnothing \square \mathrm{D}_{0} \square \mathrm{D}_{1} \square \mathrm{D}_{2}$

Table 31. Degrees of deviation of the exponents for 1PL.INCL

Identifying a tone value as the default exponent for 1PL.INCL is less straightforward than it was with 1SG and 2SG. As for frequency, I have taken T34 to be a general default, but the vast majority of verbs with a PL stem in T1 (93\%), which represent no less than $40 \%$ of the verbs requiring 1 PL.INCL, take T12 instead. I have treated such verbs as showing a $\mathrm{D}_{0}$ deviation, however, given its distribution, it almost counts as a regular rule of exponence. This reinforces the idea that verbs that just exhibit deviations of the $\mathrm{D}_{0}$ type should be taken as part of the core (as will be seen in the next section). Further note that in Sections 6.1 and 6.2 we have also seen that having a lexical tone in T1 has an impact on the realization of $1 \mathrm{SG}$ and $2 \mathrm{SG}$, because the verbs select default overrides such as T12 for 1SG and T3 for 2sG. All other options I have analyzed as strong deviations. The overall inflectional behavior of 1PL.INCL forms for the verbs in the sample is given in Table 32. Under the view in column (iii), we see that taking only the default exponent (T34) and the lowest level of deviation (T12 where $\mathrm{T}_{\mathrm{LEX}}$ is T1), we can account for $94 \%$ of the inflectional exponence for 1PL.INCL.

\begin{tabular}{|llr|r|r|r|}
\hline Exponents of 1PL.INCL & Deviation & & \multicolumn{1}{c}{ i } & ii & iii \\
\hline T34 & $\varnothing$ & 140 & $55 \%$ & $55 \%$ & $95 \%$ \\
\cline { 4 - 5 } T12 if $\mathrm{T}_{\text {LEX }} \mathrm{T} 1$ & $\mathrm{D}_{0}$ & 101 & $40 \%$ & $45 \%$ & \\
\cline { 2 - 4 } \cline { 4 - 5 } Any other T & $\mathrm{D}_{2}$ & 12 & $5 \%$ & & $5 \%$ \\
\hline Total & Total & 253 & $100 \%$ & $100 \%$ & $100 \%$ \\
\hline
\end{tabular}

Table 32. Overall deviation of the exponence for 1PL.INCL 


\section{Calculating the core of tonal inflection in SP-Amuzgo}

In the previous section, with the goal of discerning the core of the tonal inflection of SPAmuzgo, I have proposed a possible way to rank the choice of tonal exponents for 1SG, 2SG and 1PL.INCL along a continuum of morphological complexity. We can now rank verbs according to the exponents they require. For this, we need to revisit all verbs in the sample (grouped conveniently in tonal classes) in the light of the ranking that obtains for each inflectional exponent. Verbs with no inflectional deviations will be considered to form the core of the system. The more deviations a verb presents and the less motivated the deviation in question is, the further away the verb will be from that core.

Depending on paradigmatic class, a verb can be more or less complex depending on the number of cells that require an inflectional tone. This creates a continuum, where verbs of Class I are necessarily the simplest and verbs of Class VIII are necessarily the most complex. Leaving aside both lexical tone and the tone for 1PL.EXCL, we can represent this continuum as in Figure 4, where '-' stands for lexical.

\begin{tabular}{|c|c|c|c|c|c|c|c|}
\hline & & & & $1 \mathrm{SG}$ & $2 \mathrm{G}$ & 1PL.INCL & \\
\hline Less complex & • no INFL & Class I: & \{ & - & - & - & \} \\
\hline \multirow[t]{6}{*}{$\uparrow$} & - one INFL exponent & Class II: & \{ & - & - & INFL & \} \\
\hline & & Class III: & \{ & INFL & - & - & \} \\
\hline & & Class IV: & \{ & - & INFL & - & \} \\
\hline & - two INFL exponents & Class V: & \{ & INFL & - & INFL & \} \\
\hline & & Class VI: & \{ & - & INFL & INFL & \\
\hline & & Class VII: & \{ & INFL & INFL & - & \} \\
\hline More complex & - three INFL exponents & Class VIII: & \{ & INFL & INFL & INFL & \\
\hline
\end{tabular}

Figure 4. Complexity of paradigmatic classes

The continuum in Figure 4 suggests that a verb of Class VIII has more chances of behaving like a deviating verb than a Class II verb, purely on the basis of it having more inflectional exponents to realize. However, as a methodological principle, to produce the core of the system, I neutralize this difference by considering that a cell with lexical tone for 1SG, 2sG or 1PL.EXCL is as morphologically complex as a cell that has inflectional tone realized by a default. In this way, for example, a verb of Class II $\{-/-/$ INFL $\}$ that abides by the default for 1PL.INCL as $\{-\mid-/ \varnothing\}$ is categorized as being as complex as a Class I verb $\{-|-|-\}$; or a verb of Class VII $\{$ INFL/INFL/- $\}$ which has a deviation $\mathrm{D}_{1}$ for $1 \mathrm{SG}$, but abides by the default for $2 \mathrm{SG}$ $\left\{D_{1} / \varnothing /-\right\}$ would be seen as equally complex as a verb of Class VIII $\{$ INFL/INFL/INFL $\}$ that may have $\left\{D_{1} / \varnothing / \varnothing\right\}$; etc. ${ }^{28}$ This view allows us to take all verbs in the sample into consideration to calculate which verbs form part of the core of the system and which verbs deviate, and by how much, from that core.

Taking realization of exponence into account, we can now devise the complexity continuum in Table 33, which is based on the number of deviations and their type. The continuum is defined by two extremes: at one end, we have the most regular verb type, which abides by defaults in all three cells (following one of eight possibilities: $\{-I-I-\},\{-/-/ \varnothing\}$, $\{\varnothing /-/-\},\{-/ \varnothing /-\},\{\varnothing /-/ \varnothing\},\{-/ \varnothing / \varnothing\},\{\varnothing / \varnothing /-\},\{\varnothing / \varnothing / \varnothing\})$; and at the other end, we have the most irregular verb type, which is a Class VIII verb that selects exponents ranked as $\mathrm{D}_{2}$ for all three cells $\left\{\mathrm{D}_{2} / \mathrm{D}_{2} / \mathrm{D}_{2}\right\}$. All possible combinations forming this continuum that involve a

\footnotetext{
${ }^{28}$ In a way, the different paradigmatic classes could be seen as having different degrees of morphological complexity specific to their types, but this is not an issue I deal with here. I consider that membership to a paradigmatic class is lexically specified (although causative verbs, for example, are more prone to belong to Class VII). This means that when it comes to inflecting a verb, speakers need to first know whether a verb is, for example, Class I or Class VIII. Once that information is dealt with, each verb should be judged as equal, each with its own idiosyncratic inflectional properties, so that for inflectional purposes using a default exponent to realize a given value for the types that require it would place such verbs at the same level as verbs with no inflectional tone.
} 
deviation (especially of type $\mathrm{D}_{1}$ and $\mathrm{D}_{2}$ ) are ways for a verb in SP-Amuzgo to be tonally irregular. There are many logical permutations, but in reality, at least where Class VIII is concerned, only 22 of them are attested in the sample. ${ }^{29}$

\begin{tabular}{|c|c|c|c|c|c|c|c|c|c|c|c|}
\hline \multirow{2}{*}{$\begin{array}{c}+ \text { Reg. } \\
\uparrow\end{array}$} & \multicolumn{2}{|l|}{ Deviation } & $\mathrm{i}$ & \multicolumn{2}{|c|}{ ii } & \multicolumn{2}{|c|}{ iii } & \multicolumn{4}{|c|}{ iv } \\
\hline & \multirow{4}{*}{$\begin{array}{l}\text { No D } \\
\mathrm{D}_{0} \\
\mathrm{D}_{0}+\mathrm{D}_{0} \\
\mathrm{D}_{0}+\mathrm{D}_{0}+\mathrm{D}_{0}\end{array}$} & 377 & $67.6 \%$ & 377 & $67 \%$ & \multirow[t]{4}{*}{473} & \multirow[t]{4}{*}{$85 \%$} & \multirow[t]{4}{*}{473} & \multirow[t]{4}{*}{$85 \%$} & Core & \multirow[t]{2}{*}{ Inner } \\
\hline & & 45 & $8.1 \%$ & 181 & $34 \%$ & & & & & & \\
\hline & & 39 & $7.0 \%$ & & & & & & & & \multirow[t]{2}{*}{ Outer } \\
\hline & & 12 & $2.2 \%$ & & & & & & & & \\
\hline & $\mathrm{D}_{1}$ & 32 & $5.7 \%$ & & & & \multirow[t]{10}{*}{$15 \%$} & 55 & $10 \%$ & \multirow{4}{*}{\multicolumn{2}{|c|}{ Medium irreg. }} \\
\hline & $\mathrm{D}_{1}+\mathrm{D}_{0}$ & 6 & $1.1 \%$ & & & & & & & & \\
\hline & $D_{1}+D_{1}$ & 0 & & & & & & & & & \\
\hline & $\mathrm{D}_{2}$ & 17 & $3.0 \%$ & & & & & & & & \\
\hline & $\mathrm{D}_{2}+\mathrm{D}_{0}$ & 9 & $1.6 \%$ & & & & & \multirow[t]{3}{*}{26} & $5 \%$ & \multirow{3}{*}{\multicolumn{2}{|c|}{ High irreg. }} \\
\hline & $\mathrm{D}_{2}+\mathrm{D}_{1}$ & 4 & $0.7 \%$ & & & & & & & & \\
\hline & $\mathrm{D}_{2}+\mathrm{D}_{2}$ & 13 & $2.3 \%$ & & & & & & & & \\
\hline & $\mathrm{D}_{2}+\mathrm{D}_{2}+\mathrm{D}_{0}$ & 2 & $0.4 \%$ & & & & & \multirow[t]{3}{*}{4} & $1 \%$ & \multirow{3}{*}{\multicolumn{2}{|c|}{ Very high irreg. }} \\
\hline & $\mathrm{D}_{2}+\mathrm{D}_{2}+\mathrm{D}_{1}$ & 1 & $0.2 \%$ & & & & & & & & \\
\hline$\downarrow$ & $D_{2}+D_{2}+D_{2}$ & 1 & $0.2 \%$ & & & & & & & & \\
\hline +Irreg. & & 558 & $100 \%$ & 558 & $100 \%$ & 558 & $100 \%$ & 558 & $100 \%$ & & \\
\hline
\end{tabular}

Table 33. Complexity continuum of the tonal inflection of SP-Amuzgo verbs

The situation in Table 33 can be interpreted again from different angles. The view in column (i) just shows the distribution of each gradient. Note that the three most irregular combinations, involving deviations in three cells, together account for less than $1 \%(0.8 \%)$ of all the verbs in the sample. The view in (ii) sees the data by taking an all-or-nothing type of dichotomy that separates verbs abiding by the default from those that show some type of deviation, regardless of type. This view is already promising, because it shows that the tonal inflection of almost $70 \%$ of the verbs of the sample can be accounted for by the defaults I have established in Section 6. The view in (iii) further reinforces this conclusion, because if light deviations are treated as part of the core of the system, the number of verbs that can be accounted for increases to $85 \%$. Finally, the view in (iv) is like (iii), but it gives gradience to the irregularity in the tonal inflection by separating those verbs that are somehow irregular (those showing one or two deviations of type $\mathrm{D}_{1}$ but at most one of type $\mathrm{D}_{2}$ ) from those that are strongly irregular having at least one $\mathrm{D}_{2}$ in addition to at least one other deviation. The most irregular verbs in the sample are those with three deviations.

Under the rule-based approach, the tonal classes we observe in Table 6 can now be conceived of as epiphenomenal arrangements that are the outcomes of the application of rules of exponence; that is, tonal classes can be viewed as attested 'tonal arrangements' rather than as fixed sets of exponents (i.e. tonal classes). As shown in Table 34, the approach I take here accounts for 50 of the 92 tonal arrangements as the outcome of 'core' operations (the abbreviation TA in Table 34 stands for 'tonal arrangement'). While it remains a fact that 42 arrangements reflect irregular outcomes, revealing a system that is unavoidably complex, the model provides us with the possibility of measuring the degree of irregularity of non-core arrangements, showing, for example, that only four verbs (1\% of the sample) are very irregular. A classification of the verbs into attested tonal arrangements (still called 'tonal classes'), as well as paradigmatic classes, attending to which are core and non-core, is given in Appendix B.

29 The ones attested are: $\{\varnothing / \varnothing / \varnothing\} ;\left\{\varnothing / \varnothing / \mathrm{D}_{0}\right\} ;\left\{\varnothing / \varnothing / \mathrm{D}_{2}\right\} ;\left\{\varnothing / \mathrm{D}_{0} / \varnothing\right\} ;\left\{\varnothing / \mathrm{D}_{0} / \mathrm{D}_{0}\right\} ;\left\{\varnothing / \mathrm{D}_{1} / \varnothing\right\} ;\left\{\varnothing / \mathrm{D}_{1} / \mathrm{D}_{0}\right\} ;$ $\left\{\varnothing / \mathrm{D}_{2} / \varnothing\right\} ;\left\{\varnothing / \mathrm{D}_{2} / \mathrm{D}_{0}\right\} ;\left\{\varnothing / \mathrm{D}_{2} / \mathrm{D}_{2}\right\} ;\left\{\mathrm{D}_{0} / \mathrm{D}_{0} / \varnothing\right\} ;\left\{\mathrm{D}_{0} / \mathrm{D}_{0} / \mathrm{D}_{0}\right\} ;\left\{\mathrm{D}_{1} / \varnothing / \varnothing\right\} ;\left\{\mathrm{D}_{1} / \varnothing / \mathrm{D}_{2}\right\} ; \quad\left\{\mathrm{D}_{1} / \mathrm{D}_{0} / \varnothing\right\} ; \quad\left\{\mathrm{D}_{2} / \varnothing / \varnothing\right\} ;$ $\left\{\mathrm{D}_{2} / \varnothing / \mathrm{D}_{0}\right\} ;\left\{\mathrm{D}_{2} / \varnothing / \mathrm{D}_{2}\right\} ;\left\{\mathrm{D}_{2} / \mathrm{D}_{1} / \mathrm{D}_{2}\right\} ;\left\{\mathrm{D}_{2} / \mathrm{D}_{2} / \varnothing\right\} ;\left\{\mathrm{D}_{2} / \mathrm{D}_{2} / \mathrm{D}_{0}\right\} ;$ and $\left\{\mathrm{D}_{2} / \mathrm{D}_{2} / \mathrm{D}_{2}\right\}$. 


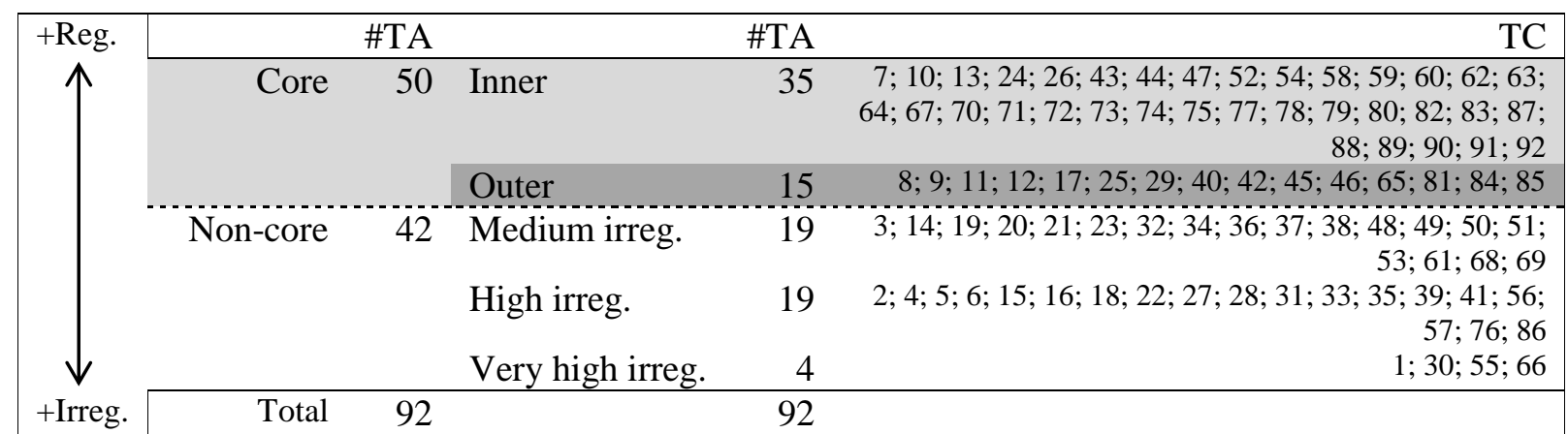

Table 34. Distribution of attested tonal arrangements in the complexity continuum

We can further correlate types of deviation with paradigmatic class. This allows us to evaluate the degree of regularity for each paradigmatic class. This is shown in Table 35, where we can observe that Class VIII is the class with most types of deviating verbs. As already pointed out in Figure 4, this is somewhat expected, because Class VIII is also the class with the greatest number of inflectional distinctions. ${ }^{30}$

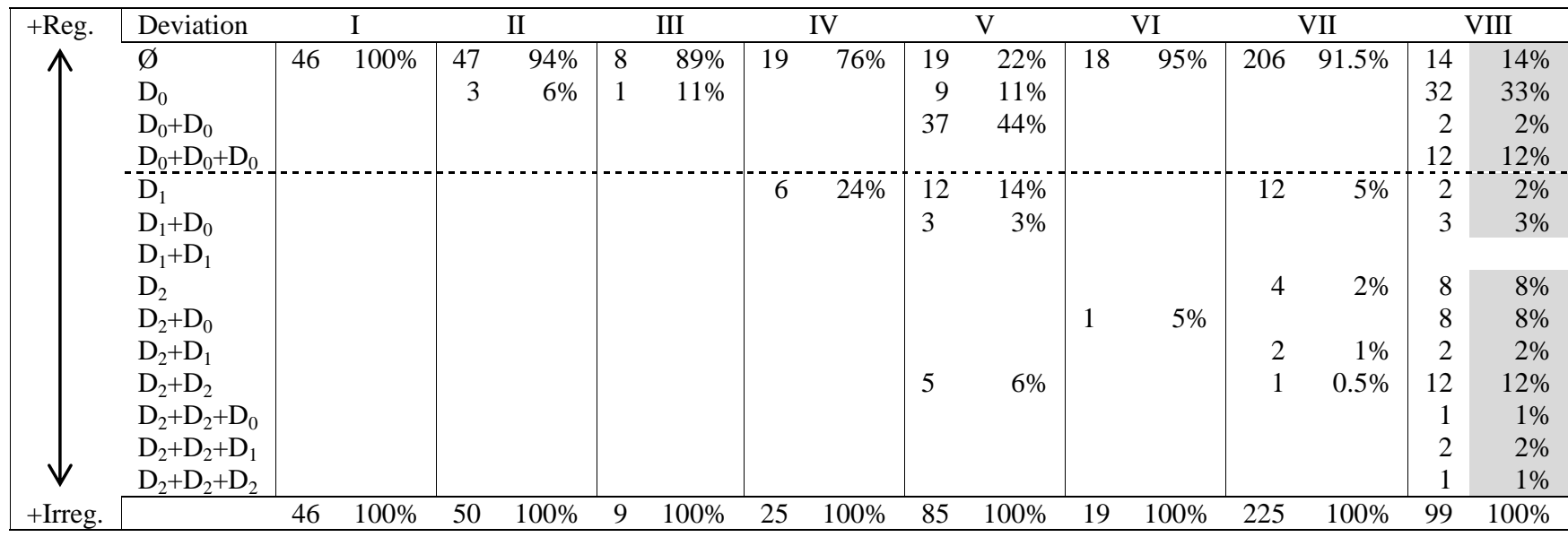

Table 35. Degree of regularity of each paradigmatic class

The overall distribution of the verbs that I take to be 'core verbs' vs 'non-core verbs' by paradigmatic class is given in Table 36, which shows that the most irregular classes are IV, V and VIII.

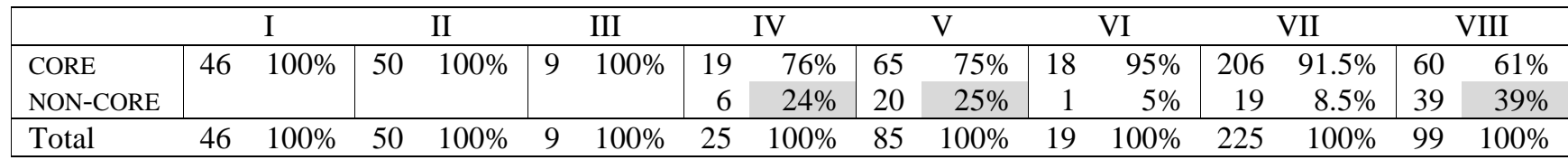

Table 36. Distribution of core vs non-core verbs by paradigmatic class

Finally Table 37 provides a different view of the same data, now showing the distribution of each type of deviation across the different paradigmatic classes. Again, the more complex the deviation gets, the likelier it is that such deviations are exhibited by a Class VIII verb (although $\mathrm{D}_{0}+\mathrm{D}_{0}$ is typically found in verbs of Class $\mathrm{V}$, the second most irregular paradigmatic class). Table 37 makes it possible to see that verbs without deviations occur across all paradigmatic classes, but it further reveals that only $4 \%$ of such verbs belong to Class VIII.

\footnotetext{
${ }^{30}$ It could be argued that this needn't be the case, because verbs of Class VIII could just as well have abided by defaults. However, it remains a descriptive fact about SP-Amuzgo's tonal inflection that verbs of this paradigmatic class are the ones that display the greatest number of idiosyncrasies.
} 


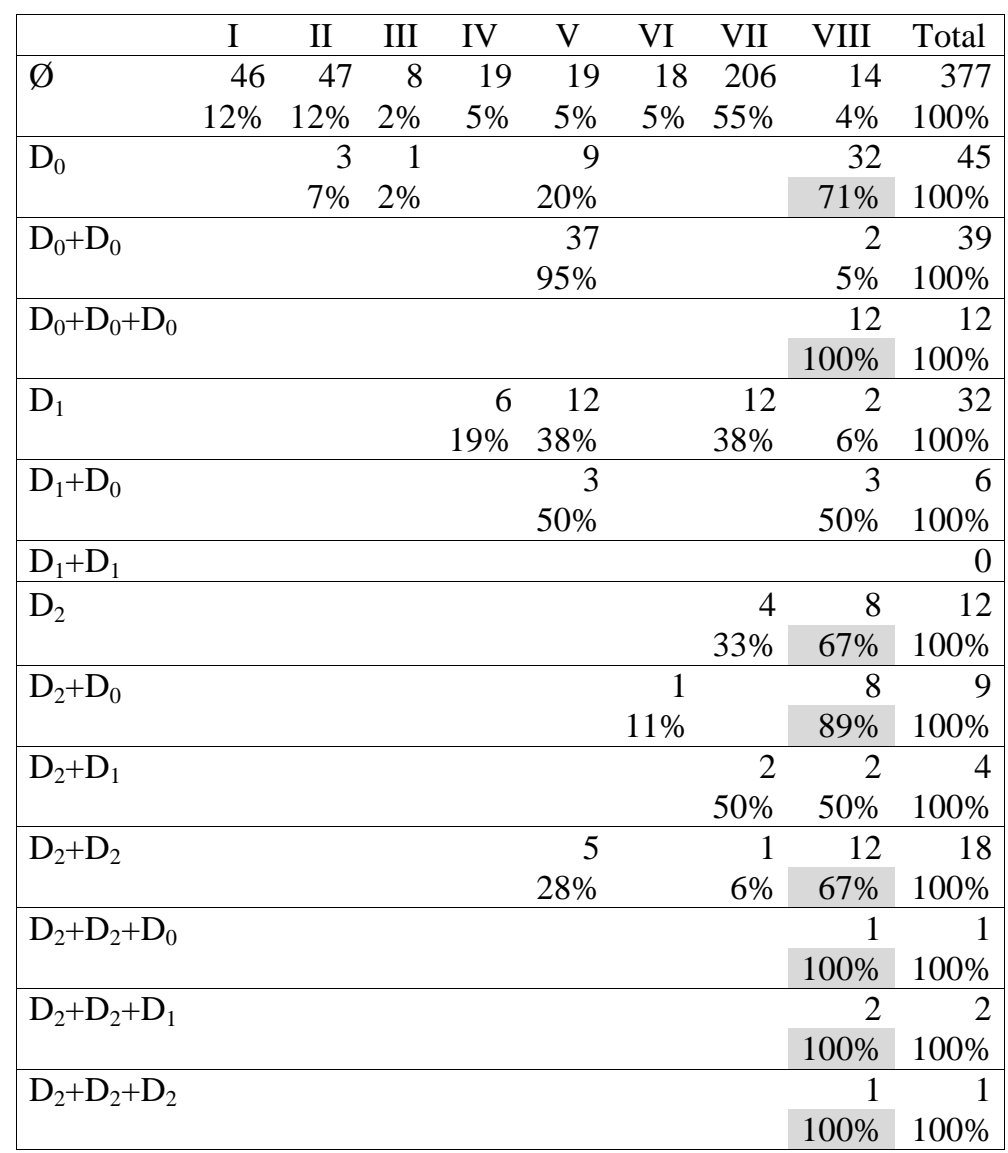

Table 37. Distribution of deviation type by paradigmatic class

\section{Conclusion}

In this paper, I have shown that the description of the tonal inflection of SP-Amuzgo verbs presents a real challenge because if the system is viewed from the perspective of a model based on tonal classes, the result we obtain is of a chaotic system. In an attempt to make sense of the system, I have advocated an alternative approach, which involves classifying verbs according to their paradigmatic signature and then dealing with the remaining tonal allomorphy by way of realizational rules. In order to capture the tonal inflection of an active verb in SP-Amuzgo, it is necessary to answer the six questions in (3):

(3) a. What is the tone for $3 \mathrm{SG}$ and PL?

b. Is there tonal syncretism between the SG stem and the tone for $1 \mathrm{SG}$ or $2 \mathrm{SG}$ ?

c. If the answer to (b) is 'no' and either $1 \mathrm{SG}$ or $2 \mathrm{SG}$ is encoded by T53, what is the tone for $1 \mathrm{SG}$ or $2 \mathrm{SG}$ ?

d. Is there tonal syncretism between the PL stem and the tone for 1PL.INCL?

e. If the answer to (d) is 'no' and 1PL.INCL is not marked by T34 (or T12, when the PL stem has T1), what is the tone for 1PL.INCL?

The answer to question (a) indicates that to master an active verb's paradigm, as already suggested in Kim (2016), speakers need to learn two stems (SG and PL) along with their lexical tones. The answers to questions (b) and (d) are sufficient to indicate which paradigmatic class a verb belongs to, as illustrated in Table 38.

\begin{tabular}{|c|c|c|c|c|c|c|c|c|c|}
\hline Question (b) & $\begin{array}{l}1 \mathrm{SG}=\mathrm{SG} \\
2 \mathrm{SG}=\mathrm{SG} \\
1 \mathrm{PL} . \mathrm{INCL}=\mathrm{PL}\end{array}$ & $\begin{array}{l}\text { yes } \\
\text { yes } \\
\text { yes }\end{array}$ & $\begin{array}{c}\text { yes } \\
\text { yes } \\
\text { no }\end{array}$ & $\begin{array}{l}\text { no } \\
\text { yes } \\
\text { yes }\end{array}$ & $\begin{array}{c}\text { yes } \\
\text { no } \\
\text { yes }\end{array}$ & $\begin{array}{l}\text { no } \\
\text { yes } \\
\text { no }\end{array}$ & $\begin{array}{l}\text { yes } \\
\text { no } \\
\text { no }\end{array}$ & $\begin{array}{l}\text { no } \\
\text { no } \\
\text { yes }\end{array}$ & $\begin{array}{l}\text { no } \\
\text { no } \\
\text { no }\end{array}$ \\
\hline & & I & II & III & IV & V & VI & VII & VIII \\
\hline
\end{tabular}

Table 38. Conditions for membership of paradigmatic classes 
Questions (c) and (e) would be pertinent if the verb has an inflectional deviation from default exponents. I have introduced a way of evaluating the degree of deviation of a rule that requires exponents other than default ones. This was intended as a way to produce a gradience of irregularity in the system, so that verbs that are located further away from the core are seen as morphologically more complex. The rationale for this lies in the fact that to inflect such verbs speakers need to be in a position to have an answer to questions (c) and (e), which entails having to handle more morphological information about the respective lexemes.

This gradience further allows us to produce a better description of the verbal inflection of SP-Amuzgo, because it put us in a descriptive position to say something about how the tonal inflection of verbs A and B relate to each other, and to other verbs. Being able to discern patterns when confronted with the complexities of SP-Amuzgo tonal inflection may have further pedagogical advantages for learners of Amuzgo grammar. A model that allows one to identify core verbs provides a reference point from which to judge other verbs' standing with respect to the core. The taxonomic exercise that I have proposed for SP-Amuzgo has shown that, for a corpus of 558 verbs, we can account for $85 \%$ of them by rules. The exercise further shows that there are thirty verbs that can now be descriptively categorized as being very irregular, four of which are especially irregular. For example, the four verbs in Table 39, which all belong to paradigmatic class VIII, can now be seen as exemplifying two very regular verbs, the verbs 'put over' and 'clean', which abide by defaults, and two of the four most irregular verbs, the verbs 'change domicile' and 'search', which both display very strong deviations ( $\{\mathrm{D} 2 / \mathrm{D} 2 / \mathrm{D} 2\}$ and $\{\mathrm{D} 2 / \mathrm{D} 1 / \mathrm{D} 2\}$, respectively).

\begin{tabular}{|c|c|c|c|c|}
\hline \multirow{3}{*}{ IMPF } & \multicolumn{4}{|c|}{ (PCVIII) } \\
\hline & $(\mathrm{NCa})$ & & $(\mathrm{NCb})$ & \\
\hline & 'put over' & (TC67) & 'clean' & (TC7) \\
\hline \multirow{6}{*}{$\begin{array}{l}\text { 1SG } \\
\text { 2SG } \\
\text { 3SG } \\
\text { 1PL.INCL } \\
\text { 1PL.EXCL } \\
\text { 2PL } \\
\text { 3PL }\end{array}$} & to $^{3}$-tyis ${ }^{53}$ & 53 & \multirow{6}{*}{ 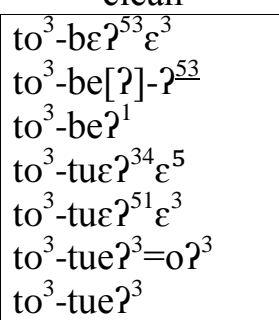 } & 53 \\
\hline & to $^{3}$-tyio? $?^{53}$ & 53 & & 53 \\
\hline & to $^{3}-$ tyio $^{3}$ & 3 & & 1 \\
\hline & to ${ }^{3}$ tyis $0^{34} \rho^{5}$ & 34 & & 34 \\
\hline & to $^{3}$-tyis ${ }^{51}$ & 51 & & 51 \\
\hline & $\begin{array}{l}\text { to }^{3}-\text { tyio }^{3}=o P^{3} \\
\text { to }^{3}-\text { tyio }^{3}\end{array}$ & 3 & & 3 \\
\hline & 'change domicile' & (TC66) & 'search' & (TC1) \\
\hline $1 \mathrm{SG}$ & to $^{3}-\mathrm{ba}^{1}+$ ntha $^{1}$ & 1 & \multirow{6}{*}{ 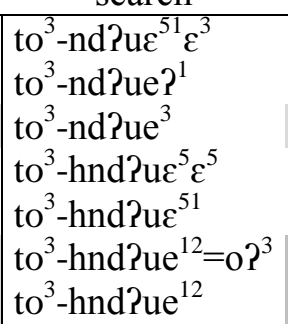 } & 51 \\
\hline $2 \mathrm{SG}$ & to $^{3}-\mathrm{ba}^{3}+$ tha? $^{1}$ & 1 & & 1 \\
\hline $3 \mathrm{SG}$ & to $^{3}-\mathrm{ba}^{5}+\mathrm{ntha}^{35}$ & 35 & & 3 \\
\hline 1PL.INCL & to $^{3}-\operatorname{tza}^{5}+n \operatorname{tha}^{5} a^{5}$ & 5 & & 5 \\
\hline 1PL.EXCL & to $^{3}-$ tza $^{5}+$ ntha $^{51}$ & 51 & & 51 \\
\hline $\begin{array}{l}2 \mathrm{PL} \\
3 \mathrm{PL}\end{array}$ & $\begin{array}{l}\text { to }^{3}-\text { tza }^{5}+\text { ntha }^{35}=o ?^{3} \\
\text { to }^{3}-\text { tza }^{5}+\text { ntha }^{35}\end{array}$ & 35 & & 12 \\
\hline
\end{tabular}

Table 39. Examples of two very regular and two very irregular verbs

Generating new data from the complex tonal paradigms of the Oto-Manguean languages from Mexico is an enterprise that is not short of challenges. It requires great expertise in the phonetic-phonology interface on the part of the field linguist, the systematicity and keen eye of the inflectional morphologist, vast amounts of time to complete full paradigms and annotate the data, and the willing long-term cooperation of speakers. This study would not have been possible without the great linguistic expertise and professional commitment of native Amuzgo linguist L. Fermín Tapia García. ${ }^{31}$ May the area of morphology become of interest to other native linguists of other equally complex languages, because with their help

\footnotetext{
${ }^{31}$ Together with the efforts of linguists like Yuni Kim, who make the data accessible to the larger community of linguists and language users.
} 
we may one day be in a better position to understand the ways of paradigmatic irregularity in non-Indo-European languages with complex morphology.

Acknowledgements: This work has been evolving thanks in part to the comments I received from numerous colleagues at different events where I presented my progress and I am grateful to all of them. My special thanks go to Olivier Bonami, Gilles Boyé and Géraldine Walther, who helped me to better understand the implications of my metrics, and to Yuni Kim, who helped me to understand the intricacies of the morphophonology of Amuzgo. I am immensely grateful to the two anonymous reviewers and to the editor in charge of my article in Morphology for all their invaluable comments that allowed me to improve this proposal, to Fermín Tapia García for sharing his precious Amuzgo data with all of us, and to Tim Feist for proof-reading my English on several occasions and for reading the final manuscript with an unparalleled degree of attention. All errors remain my own responsibility.

\section{References}

Ackerman, Farrell \& Robert Malouf. 2013. Morphological organization: The low conditional entropy conjecture. Language 89(3): 429-464

Ackerman, Farrell; James Blevins \& Robert Malouf. 2009. Parts and wholes: Implicative patterns in inflectional paradigms. In James Blevins \& Juliette Blevins (eds.), Analogy in grammar: Form and acquisition, pp. 54-82. Cambridge: Cambridge University Press.

Ackerman, Farrell; Gregory T. Stump \& Gert Webelhuth. 2011. Lexicalism, Periphrasis, and Implicative Morphology. In Robert D. Borsley \& Kersti Börjars (eds.), Non- Transformational Syntax: Formal and Explicit Models of Grammar, pp. 325-358. Oxford: Blackwell

Albright, Adam \& Erik Fuss. 2012. Syncretism. In Jochen Trommer (ed.), The morphology and phonology of exponence, pp. 236-288. Oxford: Oxford University Press.

Anderson, Stephen. 1992. A-morphous morpohology. Cambridge: Cambridge University Press.

Andrews, A. D. 1990. Unification and morphological blocking. Natural Language and Linguistic Theory 8: 507-58.

Apostol Polanco, Jair. 2014. Clases flexivas verbales en el amuzgo de Xochistlahuaca, Guerrero. Unpublished MA thesis at CIESAS, Mexico.

Aronoff, Mark. 1994. Morphology by itself: Stems and inflectional classes. Cambridge, MA: MIT Press.

Baerman, Matthew. 2005. Directionality and (un)natural classes in syncretism. Language 80: 807-824.

Baerman, Matthew, Dunstan Brown \& Greville G. Corbett. 2005. The syntax-morphology interface: A study of syncretism. Cambridge: Cambridge University Press.

2009. Morphological Complexity: a typological perspective. Paper read at the Conference 'How do we cite words in action: Interdisciplinary approaches to understanding word processing and storage', Pisa, 11-14 October.

2015. Understanding and measuring morphological complexity: An introduction. In Matthew Baerman, Dunstan Brown \& Greville G. Corbett (eds.), Understanding and measuring morphological complexity, pp. 3-11. Oxford : Oxford University Press.

Beniamine, Sacha. 2018. Classifications flexionnelles: Étude quantitative des structures de paradigmes. Unpublished PhD Thesis at Paris-Sorbonne University \& Paris-Diderot University.

Beniamine, Sacha, Olivier Bonami, \& Benoît Sagot. 2017. Inferring inflection classes with description length. Journal of Language Modelling 5(3): 465-525.

Blevins, James P. 1995. Syncretism and paradigmatic opposition. Linguistics and philosophy 18, 11352.

2006. Word-based morphology. Journal of Linguistics 42: 531-573.

Blevins, James; Ackerman, Farrell \& Robert Malouf. In press. Word and Paradigm Morphology. In Jenny Audring \& Francesca Masini (eds.), The Oxford Handbook of Morphological Theory. Oxford: Oxford University Press.

Bonami, Olivier. 2012. Discovering implicative morphology. Paper read at Les Décembrettes 8: Colloque international de morphologie. 6-7 December. University of Bourdeaux

2014. La structure fine des paradigmes de flexion Études de morphologie descriptive, théorique et formelle. Mémoire d'habilitation à diriger des recherches, Tome I : document de synthèse. Paris Diderot University. 
Bonami, Olivier, and Sarah Beniamine. 2015. Implicative structure and joint predictiveness. In Vito Pirelli, Claudia Marzi and Marcello Ferro (eds.), Word Structure and Word Usage. Proceedings of the NetWordS Final Conference.

Bonami, Olivier and Sacha Beniamine. 2016. Joint predictiveness in inflectional paradigms. Word Structure 9(2): 156-192.

Boyé, Gilles \& Gauvain Schalchli. 2016. The status of paradigms. In Andrew Hippisley \& Gregory Stump (eds.), The Cambridge handbook of morphology, pp. 206-234. Cambridge: Cambridge University Press.

Brown, Dunstan. 2016. Defaults and Overrides in Morphological Description. In Andrew Hippisley \& Gregory Stump (eds.), The Cambridge handbook of morphology, pp. 272-296. Cambridge: Cambridge University Press.

Brown, Dunstan \& Andrew Hippisley. 2012. Network Morphology: A defaults based theory of word structure. Cambridge: Cambridge University Press.

Buck, Marjorie. J. 2000. Gramática amuzga de San Pedro Amuzgos, Oaxaca. In C. Stewart and R. Stewart (eds.), Diccionario amuzgo de San Pedro Amuzgos, Oaxaca , pp. 361-480. Mexico City: SIL Mexico.

2018. Gramática del amuzgo de Xochistlahuaca, [Gramáticas de lenguas indígenas de México, 16]. Mexico City: Instituto Lingüístico de Verano.

Carstairs, Andrew. 1983. Paradigm economy. Journal of Linguistics 19: 115-28.

Corbett, Greville G. \& Norman Fraser. 1993. Network Morphology: a DATR account of Russian nominal inflection. Journal of Linguistics 29. 113-142.

Corbett, Greville G. 2015. Morphosyntactic complexity: A typology of lexical splits. Language 91(1): 145-193.

De Jesús García, Iván. 2019. Fonología del amuzgo de Cochoapan, Guerrero. Unpublished MA dissertation in Indoamerican Linguistics, CIESAS, Mexico City.

DoBui, Bien. 2018. Grammaire de l'amuzgo de Xochistlahuaca, une langue otomangue orientale : Documentation d'une variété amuzgoane de langue en danger. Unpublished $\mathrm{PhD}$ Thesis at Paris-Sorbonne University.

Feist, Timothy, Enrique L. Palancar \& Fermín Tapia. 2015. Oto-Manguean Inflectional Class Database: San Pedro Amuzgos Amuzgo. University of Surrey. doi.org/ 10.15126/SMG.28/1.04

Finkel, Raphael \& Gregory T. Stump. 2007. Principal parts and morphological typology. Morphology 17: 39-75.

Finkel, Raphael \& Gregory T. Stump. 2009. Principal parts and degrees of paradigmatic transparency. In James Blevins \& Juliette Blevins (eds.), Analogy in grammar: Form and acquisition, pp. 1354. Cambridge: Cambridge University Press.

Hernández Hernández, Natalia. 2019. El sistema tonal en el amuzgo de San Pedro Amuzgos: interacción entre el tono de la base nominal y los clíticos. Unpublished MA dissertation in Indoamerican Linguistics, CIESAS, Mexico City.

Herrera Zendejas, Esther. 2014. Mapa fónico de las lenguas mexicanas: Formas sonoras 1 y 2 (Chapter 5). Mexico City: El Colegio de México.

INEGI. 2010. Censo de población y vivienda. Instituto Nacional de Estadística y Geografía, Mexico. <https://www.inegi.org.mx/app/indicadores/?ag=20300\#divFV6207019034>

Kim, Yuni. 2016. Tonal overwriting and inflectional exponence in Amuzgo, in Enrique L. Palancar \& Jean-Léo Léonard (eds.), Tone and inflection: New facts and new perspectives, pp. 199224.Berlin: Mouton de Gruyter.

2019. A morphophonological parameter hierarchy for Amuzgo glottalization classes, in Enrique L. Palancar; Timothy Feist \& Matthew Baerman (eds.), Inflectional class complexity in the OtoManguean languages, pp. 247-278, Amerindia 41.

Matthews, Peter H. 1972. Morphology. Cambridge University Press, Cambridge

Merrifield, William. R. \& Alfred E. Anderson. 2007. Diccionario chinanteco de la diáspora del pueblo antiguo de San Pedro Tlatepuzco Oaxaca [Vocabularios indígenas 39]. Mexico City: Instituto Lingüístico de Verano.

Merrifield, William. R. 1968. Palantla Chinantec grammar [Papeles de la Chinantla: Vol. 5]. Mexico City: Museo Nacional de Antropología.

Müller, Gereon. 2007. Notes on paradigm economy. Morphology 17(1): 1-38.

Palancar, Enrique L. \& Timothy Feist. 2015. Agreeing with subjects in number: the rare split of Amuzgo inflection. Linguistic Typology 19(3): 337-383. 
Palancar, Enrique L. 2016. A typology of tone and inflection: A view from the Oto-Manguean languages from Mexico. In Enrique L. Palancar \& Jean-Léo Léonard (eds.), Tone and inflection: New facts and new perspectives, pp. 109-140. Berlin: Mouton de Gruyter.

Sagot, Benoît \& Géraldine Walther. 2011. Non-canonical inflection: Data, formalisation and complexity measures. In Cerstin Mahlow \& Michael Piotrowski (eds.), Systems and frameworks in computational morphology, pp. 23-45. Zurich: Springer-Verlag.

Sagot, Benoît. 2013. Comparing Complexity Measures. Paper read at Computational approaches to morphological complexity. Paris, France.

Sims, Andrea \& Jeff Parker. 2016. How inflection classes work: On the informativity of implicative structure. Word Structure 9(2): 215-239.

Smith-Stark, Thomas C. \& Fermín Tapia García. 2002. El amuzgo como lengua activa. In Paulette Levy (ed.), Del cora al maya yucateco: Estudios lingüísticos sobre algunas lenguas mexicanas, pp. 81-129. Mexico City: Universidad Nacional Autónoma de

Stump, Gregory T. 2016. Inflectional paradigms: Content and form at the syntax-morphology interface, [Cambridge Studies in Linguistics, 149]. Cambridge: Cambridge University Press.

Stump, Gregory T. and Raphael Finkel. 2015. Contrasting modes of representation for inflectional systems: Some implications for computing morphological complexity. In Matthew Baerman, Dunstan Brown \& Greville G. Corbett (eds.), Understanding and measuring morphological complexity, pp. 119-140. Oxford : Oxford University Press.

------2016. Morphological Typology: From Word to Paradigm. Cambridge: Cambridge University Press.

Stewart, C. \& R. Stewart, (eds.). 2000. Diccionario amuzgo de San Pedro Amuzgos, Oaxaca. Mexico City: SIL Mexico.

Tapia García, L. Fermín. 1999. Tzon 'tzíkindyi jñò ndá: Tzjón Noà yo jñò tzko. Diccionario amuzgoespañol, el amuzgo de San Pedro Amuzgos, Oaxaca. Mexico City: CIESAS \& Plaza y Valdés.

Walther, Géraldine. 2013. Sur la canonicité en morphologie: perspective empirique, formelle et computationnelle. Unpublished $\mathrm{PhD}$ Thesis at Paris-Diderot University.

Wichmann, Søren. 2019. Power-laws and preferential attachment in linguistic morphology: Evidence from Me?pá verb classes in Enrique L. Palancar; Timothy Feist \& Matthew Baerman (eds.), Inflectional class complexity in the Oto-Manguean languages, pp. 19-38, Amerindia 41. 
Appendix A

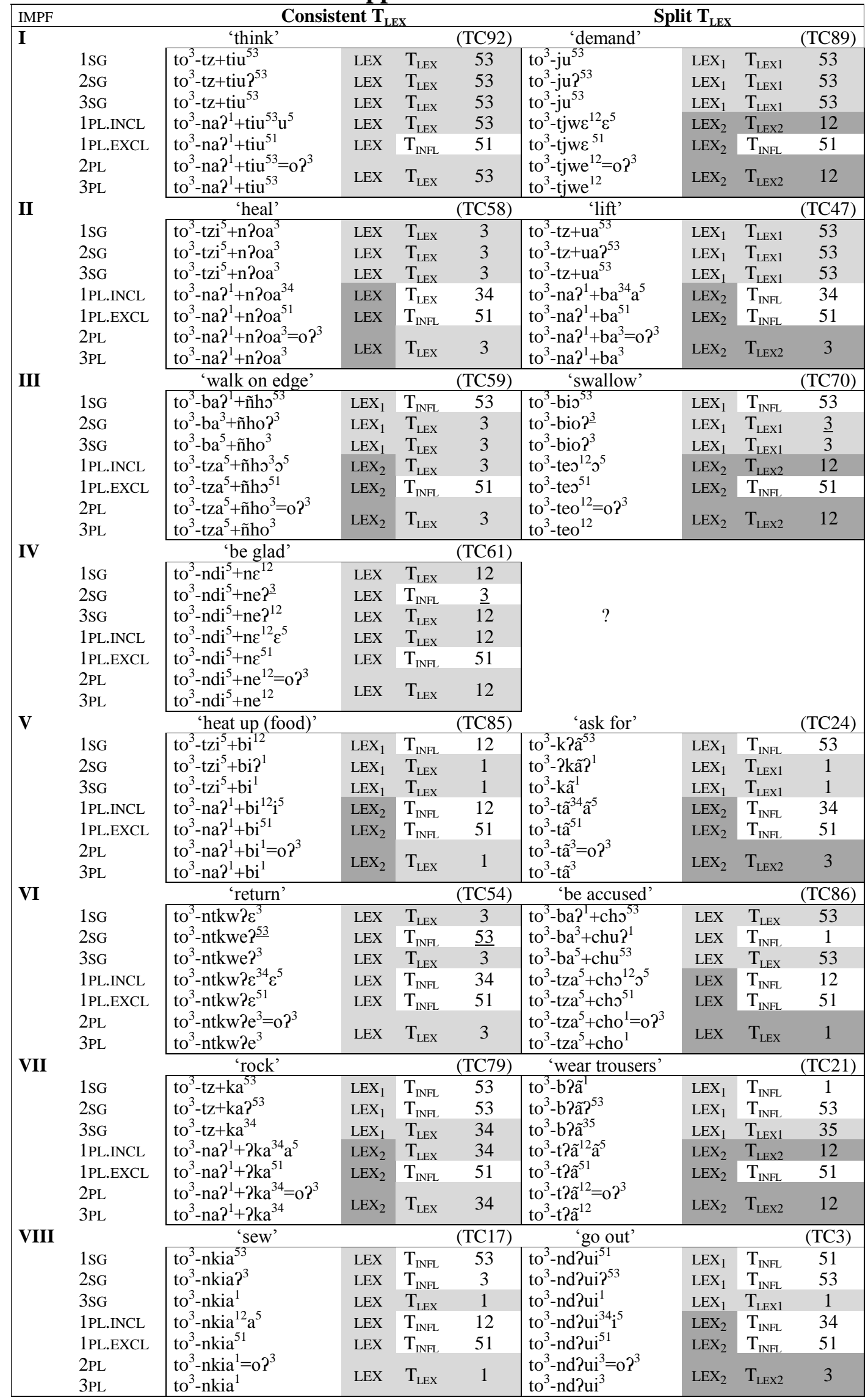


Appendix B

\begin{tabular}{|c|c|c|c|c|c|c|c|c|c|c|c|c|c|c|c|c|c|}
\hline \multirow[b]{2}{*}{ PC } & \multicolumn{9}{|c|}{ CORE VERBS } & \multicolumn{8}{|c|}{ NON-CORE VERBS } \\
\hline & $\mathrm{NC}$ & TC & Deviation & 1SG & $2 \mathrm{SG}$ & SG & PL & 1PL & \# & TC & Deviation & 1SG & & SG & PL & 1PI & \# \\
\hline \multirow[t]{6}{*}{ I } & $\mathrm{a}$ & 90 & $\{-I-I-\}$ & 12 & 12 & 12 & 12 & 12 & 15 & & & & & & & & \\
\hline & & 91 & $\{-1-1-\}$ & 51 & 51 & 51 & 51 & 51 & 2 & & & & & & & & \\
\hline & & 92. & $\{-1-1-\}$ & 53 & 53 & 53. & 53. & 53 & 25 & & & & & & & & \\
\hline & $\mathrm{b}^{-}$ & 87 & $\{-l-l-\}$ & 3 & 3 & 3 & 1 & 1 & 1 & & & & & & & & \\
\hline & & 88 & $\{-|-|-\}$ & 3 & 3 & 3 & 12 & 12 & 1 & & & & & & & & \\
\hline & & 89 & $\{-|-|-\}$ & 53 & 53 & 53 & 12 & 12 & 2 & & & & & & & & \\
\hline \multirow[t]{7}{*}{ II } & a & 58 & $\{-1-/ \varnothing\}$ & 3 & 3 & 3 & 3. & 34 & 43 & & & & & & & & \\
\hline & $\mathrm{b}$ & 43 & $\{-1-\not \varnothing\}$ & 3 & 3 & 3 & 1 & $34^{-}$ & 1 & & & & & & & & \\
\hline & & 44 & $\{-1-/ \varnothing\}$ & 51 & 51 & 51 & 3 & 34 & 1 & & & & & & & & \\
\hline & & 47 & $\{-I-/ \varnothing\}$ & 53 & 53 & 53 & 3 & 34 & 2 & & & & & & & & \\
\hline & & 42 & $\{-l-/ \mathrm{D} 0\}$ & 3 & 3 & 3 & 1 & 12 & 1 & & & & & & & & \\
\hline & & 45 & $\{-1-/ \mathrm{D} 0\}$ & 51 & 51 & 51 & 1 & 12 & 1 & & & & & & & & \\
\hline & & 46 & $\{-/-/ \mathrm{D} 0\}$ & 53 & 53 & 53 & 1 & 12 & 1 & & & & & & & & \\
\hline III & a & 59 & $\{\varnothing /-I-\}$ & 53 & 3 & 3 & 3. & 3 & 1. & & & & & & & & \\
\hline & b & 82 & $\{\varnothing \bar{l}-\bar{l}-\}$ & $53^{-}$ & 3 & 3 & 12 & 12 & 6 & & & & & & & & \\
\hline & & 83 & $\{\varnothing /-I-\}$ & 53 & 3 & 3 & 35 & 35 & 1 & & & & & & & & \\
\hline & & 84 & $\{\mathrm{D} 0 /-/-\}$ & 12 & 1 & 1 & 12 & 12 & 1 & & & & & & & & \\
\hline IV & $\mathrm{a}$ & 60 & $\{-/ \varnothing /-\}$ & 3 & 53 & 3 & 3 & 3 & 1 & 61 & $\{-/ \mathrm{D} 1 /-\}$ & 12 & 3 & 12 & 12 & 12 & 6 \\
\hline & & 62 & $\{-\mid \varnothing /-\}$ & 12 & 53 & 12 & 12 & 12 & 17 & & & & & & & & \\
\hline & & 63 & $\{-/ \varnothing /-\}$ & 51 & 53 & 51 & 51 & 51 & 1 & & & & & & & & \\
\hline $\mathrm{V}$ & $\mathrm{a}$ & 52 & $\{\varnothing /-/ \varnothing\}$ & 53 & 3 & 3 & 3 & 34 & 14 & 51 & $\{\mathrm{D} 1 /-/ \mathrm{D} 0\}$ & 51 & 1 & 1 & 1 & 12 & 3 \\
\hline & & 85 & $\{\mathrm{D} 0 /-/ \mathrm{D} 0\}$ & 12 & 1 & 1 & 1 & 12 & 37 & 50 & $\{\mathrm{D} 2 /-/ \varnothing\}$ & 1 & 3 & 3 & 3 & 34 & 3 \\
\hline & & & & & & & & & & 53 & $\{\varnothing /-/ \mathrm{D} 2\}$ & 53 & 3 & 3 & 3 & 35 & 2. \\
\hline & b & 24 & $\{\varnothing /-/ \varnothing\}$ & 53 & 1 & 1 & 3 & 34 & 4 & 23 & $\{\mathrm{D} 1 /-/ \varnothing\}$ & 51 & 1 & 1 & 3 & 34 & 12 \\
\hline & & 26 & $\{\varnothing /-/ \varnothing\}$ & 53 & 3 & 3 & 1 & 34 & 1 & & & & & & & & \\
\hline & & 25 & $\{\varnothing /-/ \mathrm{D} 0\}$ & 53 & 3 & 3 & 1 & 12 & 9 & & & & & & & & \\
\hline VI & a & 54 & $\{-/ \varnothing / \varnothing\}$ & 3 & 53 & 3 & 3 & 34 & 18 & & & & & & & & \\
\hline & $\mathrm{b}$ & & & & & & & & & 86 & $\{-/ \mathrm{D} 2 / \mathrm{D} 0\}$ & 53 & 1 & 53 & 1 & 12 & 1 \\
\hline VII & $\mathrm{a}$ & 77 & $\{\varnothing / \varnothing /-\}$ & 53 & 53 & 5 & 5 & 5 & 85 & 49 & $\{\mathrm{D} 1 / \varnothing /-\}$ & 3 & 53 & 34 & 34 & 34 & 12 \\
\hline & & 78 & $\{\varnothing / \varnothing /-\}$ & 53 & 53 & 12 & 12 & 12 & 9 & 48 & $\{\mathrm{D} 2 / \varnothing /-\}$ & 1 & 53 & 5 & 5 & 5 & 2 \\
\hline & & 79 & $\{\varnothing / \varnothing /-\}$ & 53 & 53 & 34 & 34 & 34 & 38 & 76 & $\{\mathrm{D} 2 / \mathrm{D} 2 /-\}$ & 3 & 3 & 5 & 5 & 5 & 1 \\
\hline & & 80 & $\{\varnothing / \varnothing /-\}$ & 53 & 53 & 35 & 35 & 35 & 52 & & & & & & & & \\
\hline & b & $70^{-1}$ & $\{\varnothing / \varnothing /=\}$ & 53 & 53 & 3 & 12 & 12 & 3 & 20 & $\{\mathrm{D} 2 / \varnothing /-\}$ & 1 & 53 & 5 & 12 & 12 & 1 \\
\hline & & 71 & $\{\varnothing / \varnothing /-\}$ & 53 & 53 & 5 & 12 & 12 & 3 & 21 & $\{\mathrm{D} 2 / \varnothing /-\}$ & 1 & 53 & 35 & 12 & 12 & 1 \\
\hline & & 72 & $\{\varnothing / \varnothing /-\}$ & 53 & 53 & 34 & 12 & 12 & 10 & 22 & $\{\mathrm{D} 2 / \mathrm{D} 1 /-\}$ & 51 & 1 & 3 & 12 & 12 & 2 \\
\hline & & 73 & $\{\varnothing / \varnothing /-\}$ & 53 & 53 & 35 & 12 & 12 & 4 & & & & & & & & \\
\hline & & 74 & $\{\varnothing / \varnothing /-\}$ & 53 & 53 & 5 & 35 & 35 & 1 & & & & & & & & \\
\hline & & 75 & $\{\varnothing / \varnothing /-\}$ & 53 & 53 & 51 & 5 & 5 & 1 & & & & & & & & \\
\hline VIII & $\mathrm{a}$ & 67 & $\{$ (Ø/Ø/Ø $\}$ & 53 & 53 & 3 & 3 & 34 & 2 & 19 & $\{\varnothing / \mathrm{D} 2 / \varnothing\}$ & 53 & 51 & 3 & 3 & 34 & 1 \\
\hline & & 17 & $\{\varnothing / \mathrm{D} 0 / \mathrm{D} 0\}$ & 53 & 3 & 1 & 1 & 12 & 1 & 69 & $\{\varnothing / \varnothing / \mathrm{D} 2\}$ & 53 & 53 & 35 & 35 & 5 & 1 \\
\hline & & 81 & $\{\mathrm{D} 0 / \mathrm{D} 0 / \mathrm{D} 0\}$ & 12 & 3 & 1 & 1 & 12 & 12 & 68 & $\{\varnothing / \varnothing / \mathrm{D} 2\}$ & 53 & 53 & 5 & 5 & 12 & 2 \\
\hline & & & & & & & & & & 15 & $\{\mathrm{D} 1 / \varnothing / \mathrm{D} 2\}$ & 3 & 53 & 34 & 34 & 35 & 2 \\
\hline & & & & & & & & & & 16 & $\{\mathrm{D} 2 / \varnothing / \mathrm{D} 2\}$ & 3 & 53 & 35 & 35 & 5 & 1 \\
\hline & & & & & & & & & & 18 & $\{\varnothing / \mathrm{D} 2 / \mathrm{D} 2\}$ & 53 & 12 & 3 & 3 & 35 & 1 \\
\hline & & & & & & & & & & 66 & \{D2/D2/D2 $\}$ & 1. & 1 & 35 & 35 & 5 & 1. \\
\hline & $\mathrm{b}$ & 7 & $\{\varnothing / \varnothing / \varnothing\}$ & 53 & 53 & 1 & 3 & 34 & 7 & 3 & $\{\mathrm{D} 1 / \varnothing / \varnothing\}$ & $51^{-}$ & 53 & 1 & 3 & 34 & 1 \\
\hline & & 10 & $\{\varnothing / \varnothing / \varnothing\}$ & 53 & 53 & 51 & 3 & 34 & 2 & 38 & $\{\varnothing / \mathrm{D} 1 / \varnothing\}$ & 53 & 1 & 3 & 1 & 34 & 1 \\
\hline & & 13 & $\{\varnothing / \varnothing / \varnothing\}$ & 53 & 53 & 35 & 12 & 34 & 1 & 36 & $\{\mathrm{D} 1 / \mathrm{D} 0 / \varnothing\}$ & 51 & 3 & 1 & 3 & 34 & 1 \\
\hline & & 64 & $\{\varnothing / \varnothing / \varnothing\}$ & 53 & 53 & 34 & 3 & 34 & 1 & 32 & $\{\mathrm{D} 2 / \varnothing / \varnothing\}$ & 1 & 53 & 5 & 1 & 34 & 1 \\
\hline & & 65 & $\{\varnothing / \varnothing / \varnothing\}$ & 53 & 53 & 34 & 12 & 34 & 1 & 34 & $\{\mathrm{D} 2 / \varnothing / \varnothing\}$ & 1 & 53 & 35 & 1 & 34 & 2 \\
\hline & & 40 & $\{\varnothing / \mathrm{D} 0 / \varnothing\}$ & 53 & 3 & 1 & 3 & 34 & 11 & 37 & $\{\varnothing / \mathrm{D} 1 / \mathrm{D} 0\}$ & 53 & 1 & 3 & 1 & 12 & 2 \\
\hline & & 8 & $\{\varnothing / \varnothing / \mathrm{D} 0\}$ & 53 & 53 & 3 & 1 & 12 & 3 & 14 & $\{\varnothing / \varnothing / \mathrm{D} 2\}$ & 53 & 53 & 35 & 1 & 5 & 1 \\
\hline & & 9 & $\{\varnothing / \varnothing / \mathrm{D} 0\}$ & 53 & 53 & 5 & 1 & 12 & 2 & 4 & $\{\mathrm{D} 2 / \varnothing / \mathrm{D} 0\}$ & 51 & 53 & 5 & 1 & 12 & 1 \\
\hline & & 11 & $\{\varnothing / \varnothing / \mathrm{D} 0\}$ & 53 & 53 & 34 & 1 & 12 & 1 & 33 & $\{\mathrm{D} 2 / \varnothing / \mathrm{D} 0\}$ & 1 & 53 & 35 & 1 & 12 & 1 \\
\hline & & 12 & $\{\varnothing / \varnothing / \mathrm{D} 0\}$ & 53 & 53 & 35 & 1 & 12 & 15 & 31 & $\{\mathrm{D} 2 / \varnothing / \mathrm{D} 0\}$ & 1 & 53 & 5 & 1 & 12 & 3 \\
\hline & & 29 & $\{\mathrm{D} 0 / \mathrm{D} 0 / \varnothing\}$ & 12 & 3 & 1 & 3 & 34 & 1 & 39 & $\{\varnothing / \mathrm{D} 2 / \mathrm{D} 0\}$ & 53 & 1 & 5 & 1 & 12 & 1 \\
\hline & & & & & & & & & & 41 & $\{\varnothing / \mathrm{D} 2 / \mathrm{D} 0\}$ & 53 & 12 & 3 & 1 & 12 & 2 \\
\hline & & & & & & & & & & 2 & $\{\mathrm{D} 2 / \mathrm{D} 2 / \varnothing\}$ & 51 & 12 & 53 & 3 & 34 & 1 \\
\hline & & & & & & & & & & 6 & $\{\mathrm{D} 2 / \mathrm{D} 2 / \varnothing\}$ & 1 & 1 & 5 & 3 & 34 & 1 \\
\hline & & & & & & & & & & 27 & $\{\mathrm{D} 2 / \mathrm{D} 2 / \varnothing\}$ & 1 & 3 & 5 & 3 & 34 & 1 \\
\hline & & & & & & & & & & 28 & $\{\mathrm{D} 2 / \mathrm{D} 2 / \varnothing\}$ & 1 & 3 & 35 & 3 & 34 & 1 \\
\hline & & & & & & & & & & 35 & $\{\mathrm{D} 2 / \mathrm{D} 2 / \varnothing\}$ & 12 & 3 & 35 & 12 & 34 & 1 \\
\hline & & & & & & & & & & 56 & $\{\mathrm{D} 2 / \mathrm{D} 2 / \varnothing\}$ & 1 & 1 & 35 & 1 & 34 & 1 \\
\hline & & & & & & & & & & 57 & $\{\mathrm{D} 2 / \mathrm{D} 2 / \varnothing\}$ & 3 & 3 & 5 & 3 & 34 & 2 \\
\hline & & & & & & & & & & 5 & $\{\varnothing / \mathrm{D} 2 / \mathrm{D} 2\}$ & 53 & 3 & 35 & 12 & 5 & 2 \\
\hline & & & & & & & & & & 30 & $\{\mathrm{D} 2 / \mathrm{D} 2 / \mathrm{D} 0\}$ & 1 & 3 & 35 & 1 & 12 & 1 \\
\hline & & & & & & & & & & 55 & $\{\mathrm{D} 2 / \mathrm{D} 2 / \mathrm{D} 0\}$ & 1 & 1 & 5 & 1 & 12 & 1 \\
\hline & & & & & & & & & & 1 & $\{\mathrm{D} 2 / \mathrm{D} 1 / \mathrm{D} 2\}$ & 51 & 1 & 3 & 12 & 5 & 1 \\
\hline Total & & & & & & & & & 473 & & & & & & & & 85 \\
\hline
\end{tabular}

